Key Words:

XAFS, MST

Strontium

Retention:

Permanent

\title{
Characterization of Sorbed Strontium on Monosodium Titanate
}

Martine C. Duff, Douglas B. Hunter, David T. Hobbs and Samuel D. Fink

REPORT DATE: JUNE 25, 2001
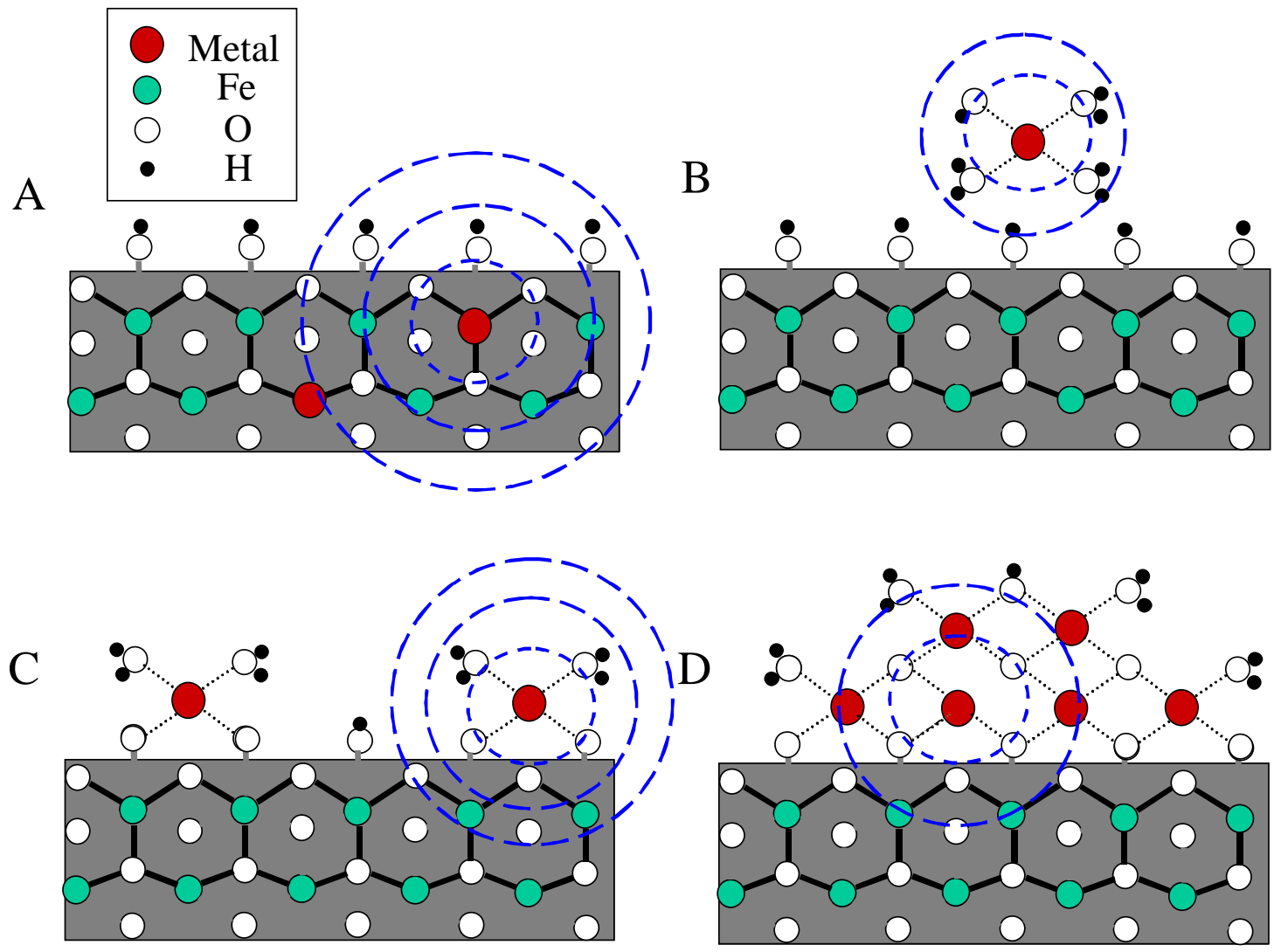

Westinghouse

Savannah River Company

Aiken, SC 29808

(w) 戛亚 $\mathrm{BNFL}_{\mathrm{BNF}}$

Prepared for the U.S. Department of Energy

under Contract Number DE-AC09-96SR18500 
This document was prepared in conjunction with work accomplished under Contract No.

DE-AC09-96SR18500 with the U.S. Department of Energy.

\section{DISCLAIMER}

This report was prepared as an account of work sponsored by an agency of the United States Government. Neither the United States Government nor any agency thereof, nor any of their employees, makes any warranty, express or implied, or assumes any legal liability or responsibility for the accuracy, completeness, or usefulness of any information, apparatus, product or process disclosed, or represents that its use would not infringe privately owned rights. Reference herein to any specific commercial product, process or service by trade name, trademark, manufacturer, or otherwise does not necessarily constitute or imply its endorsement, recommendation, or favoring by the United States Government or any agency

thereof. The views and opinions of authors expressed herein do not necessarily state or reflect those of the United States Government or any agency thereof.

This report has been reproduced directly from the best available copy.

Available for sale to the public, in paper, from: U.S. Department of Commerce, National Technical Information Service, 5285 Port Royal Road, Springfield, VA 22161, phone: (800)

553-6847, fax: (703) 605-6900, email: orders@ntis.fedworld.gov online ordering: http://www.ntis.gov/ordering.htm

Available electronically at http://www.doe.gov/bridge

Available for a processing fee to U.S. Department of Energy and its contractors, in paper, from: U.S. Department of Energy, Office of Scientific and Technical Information, P.O. Box 62, Oak Ridge, TN 37831-0062, phone: (865 ) 576-8401, fax: (865) 576-5728, email: reports@ adonis.osti.gov 
Key Words:

XAFS, MST

Strontium

Retention:

Permanent

\section{Characterization of Sorbed Strontium on Monosodium Titanate}

Martine C. Duff, Douglas B. Hunter, David T. Hobbs and Samuel D. Fink

REPORT DATE: JULY 25, 2001
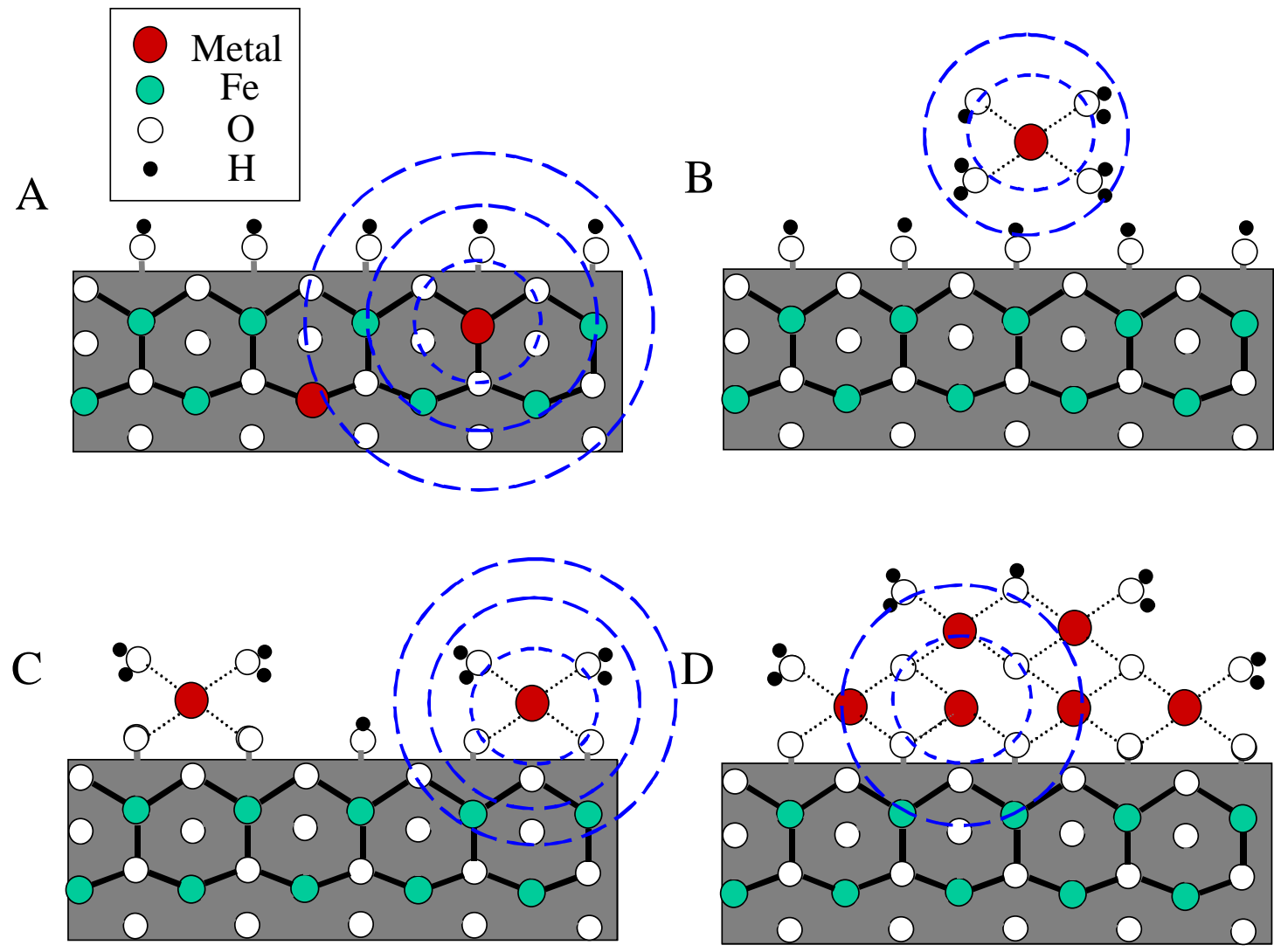

\section{Westinghouse}

Savannah River Company

Aiken, SC 29808

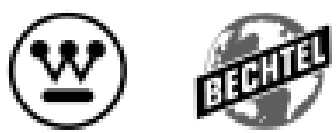




\section{REVIEWS AND APPROVALS}

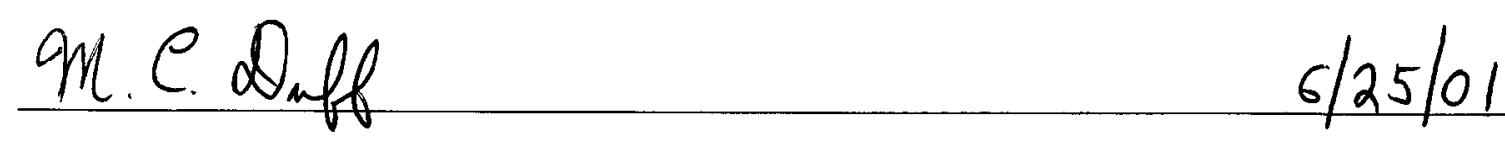

M. C. Duff, Author, Waste Processing Technology

Date

Nouglas B. afunter 6/25/01

D. B. Hunter, Author, Nonproliferation Technology Date

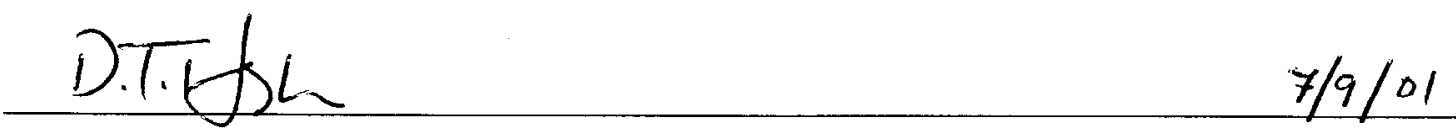

D. T. Hobbs, Author, Waste Processing Technology

Date

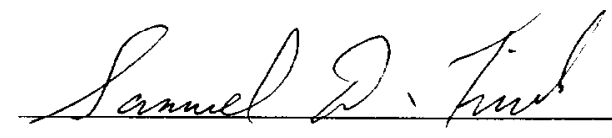

S. D. Fink, Level 4 Manager and TFA Lead Waste Processing Technology

Date

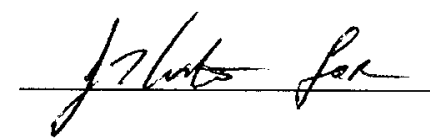

R. E. Edwards, Manager, Process Engineering

Date

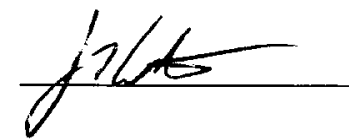

J. T. Carter, Director of Engineering, SWPF

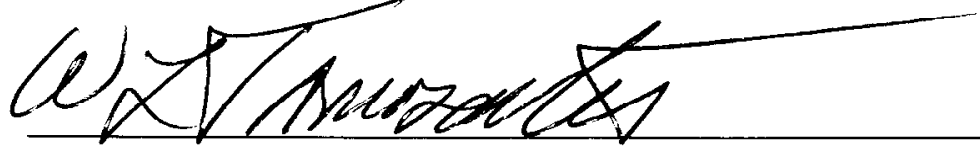

W. L. Tamosaitis, Manager, Waste Processing Technology $6 / 2961$

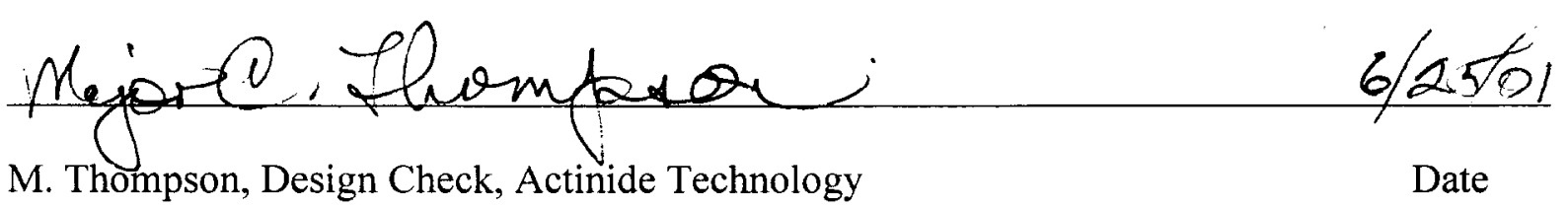




\section{TABLE OF CONTENTS}

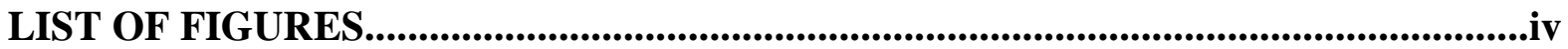

LIST OF TABLES .................................................................................................................

ACRONYMS AND ABBREVIATIONS.................................................................... vii

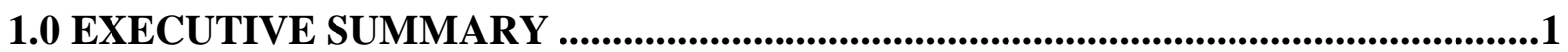

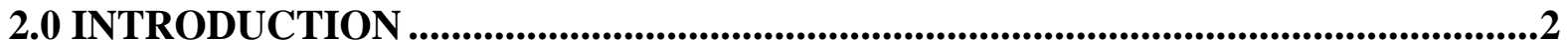

2.1 Uptake Mechanisms of Metals by Surfaces......................................................................2

2.2 Use of XAFS Techniques to Characterize Metal Uptake by Surfaces........................4

2.3 Experimental Objectives.........................................................................................................4

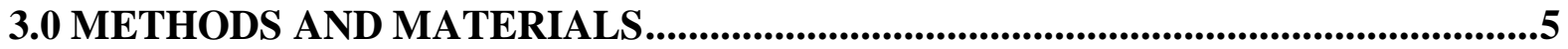

3.1 Sample Preparation....................................................................................................................5

3.1.1 XANES and EXAFS Data Collection and Analyses.................................................6

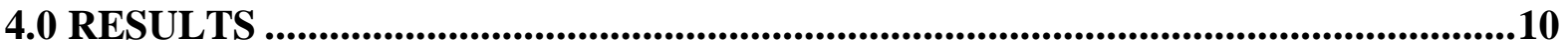

4.1.1 Background on Sr-XAFS Studies with Sr-containing Materials........................10

4.1.2 Sr-XANES Studies with Sr-loaded MST Samples. .................................................13

4.2 EXAFS Analyses.................................................................................................................15

4.2.1 The $k^{3-}$ weighted Chi Data for the Sr Standards and Sr-Loaded MST.............16

4.2.2 Fourier-Transformed Data for the Dilute $\mathrm{SrCl}_{2}$ Solution and $\mathrm{Sr}^{2+}$-loaded

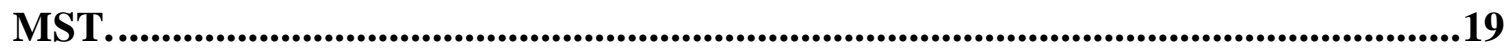

4.2.2.1 Higher Shell Fits for Sr-Ti and Sr-O Interactions........................................28

4.3 Modeling of $\mathrm{Sr}^{2+}$ Sorption on MST..............................................................29

4.4 Comparison of First Shell Coordination Data with Literature Findings.................30

4.5 Comparison of Second and Third Shell Coordination Data with Literature

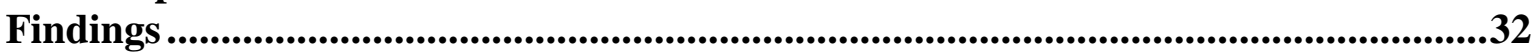

5.0 DISCUSSION AND CONCLUSIONS .............................................................................34

5.1 Determination of the Uptake Mechanism......................................................................34

5.2 Influence of Sorption Mechanism on Process.................................................................34

5.3 The Structure of MST is Unknown ................................................................................35

5.4 Suggestions for Further Study .................................................................................................35

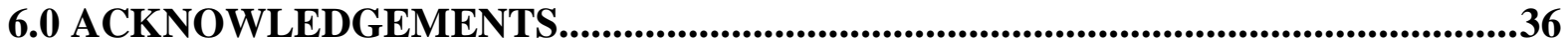

7.0 APPENDIX ..........................................................................................................................37

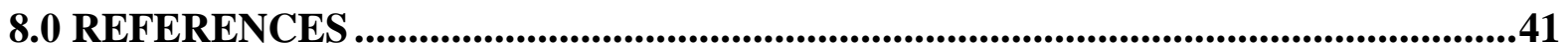


WSRC-TR-2001-00245, REVISION 0

\section{LIST OF FIGURES}

Figure 2-1 Simplified diagram of the types of associations a metal could have with a surface. A) Structural incorporation, B) Outer-sphere (electrostatic) sorption, C) Specific or inner-sphere sorption and D) Surface precipitation. Blue rings denote first, second and third environments that can be probed with XAFS techniques.

Figure 3-1 Photograph of the moist $\mathrm{Sr}^{2+}$-loaded MST samples analyzed using XAFS techniques. Sample 1a (left), which had the highest $\mathrm{Sr}^{2+}$ loading, is more yellow in color than that of the samples with lower levels of sorbed $\mathrm{Sr}^{2+}$....

Figure 3-2 Diagram of the downstream portion of the hutch table at NIST beamline X23a2 (not drawn to scale).

Figure 3-3 Side view of the downstream portion of the hutch table at beamline X26a. The SiLi detector (light blue item on right of table) was not used in this study (picture kindly provided by A. Lanzirotti, Univ. of Chicago).

Figure 3-4 Overhead view of the downstream portion of the hutch table at beamline X26a showing a) the incoming beam with (closed) shutter, b) ion chamber, and c) the sample holder. The pin diode detector used in this study is not shown. (Photo provided by A. Lanzirotti, Univ. of Chicago.)....

Figure 4-1 Plot of the Sr-XANES data for the $\mathrm{Sr}^{2+}$-loaded MST samples. We obtained the SrMST4 data at beamline X23a2; and acquired the remaining data at beamline X26a...14 Figure 4-2 Plot of the Sr-XANES data for two of the $\mathrm{Sr}^{2+}$-loaded MST samples and the two $\mathrm{Sr}^{2+}$-containing solutions. We acquired the SrMST4 data at beamline X23a2 and acquired the remaining data at beamline X26a.

Figure 4-3 Plot of the Sr-XANES data for a $\mathrm{Sr}^{2+}$-loaded MST sample and the $\mathrm{Sr}^{2+}$-containing solids. We acquired the data for Sr standards at beamline X26a and acquired data for SrMST4 at beamline X23a2.

Figure 4-4 The $k^{3}$-weighted chi data (the plot of the wavevector in reciprocal space) for the $\mathrm{Sr}^{2+}$-loaded MST samples. We collected the data at beamline X26A-with the exception of that for SrMST4, which we collected at X23a2.

Figure 4-5 The $k^{3}$-weighted chi data for $\mathrm{Sr}^{2+}$ in $\mathrm{SrCO}_{3(\mathrm{~s})}$ and $\mathrm{SrHLW}_{(\mathrm{aq})}$. We collected the data at beamline X26A.

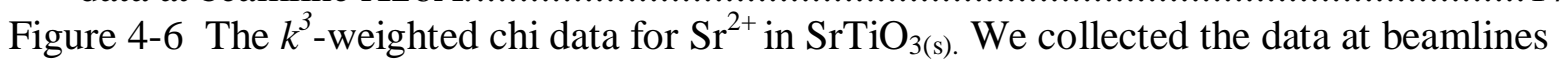
$\mathrm{X} 26 \mathrm{a}$ and X23a2. .18

Figure 4-7 The $k^{3}$-weighted chi data $\mathrm{Sr}^{2+}$ in $\mathrm{Sr}\left(\mathrm{NO}_{3}\right)_{2(\mathrm{~s})}$ We collected the data at beamline

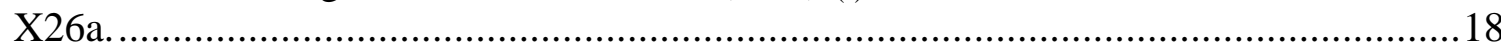

Figure 4-8 FT RDF data for $\mathrm{Sr}^{2+}$-loaded MST samples and the $\mathrm{SrCl}_{2(\mathrm{aq})}$ standard. .............20

Figure 4-9 FT RDF data and first shell Sr-O model fit data for SrMST1 without the third cumulant term-uncorrected for phase shift....................................................21

Figure 4-10 FT RDF data and first shell Sr-O model fit data for SrMST1. The third cumulant term was included in the fit-uncorrected for phase shift...........................22

Figure 4-11 FT RDF data and first shell Sr-O model fit data for SrMST3 without the third

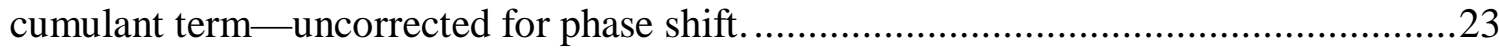

Figure 4-12 FT RDF data and first shell Sr-O model fit data for SrMST3. The third cumulant term was included in the fit - uncorrected for phase shift...........................24

Figure 4-13 FT RDF data and first shell Sr-O model fit data for SrMST4 without the third

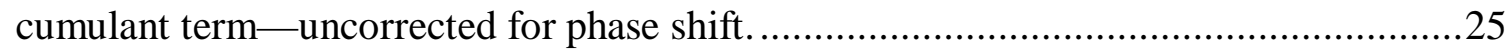

Page iv of 14 
Figure 4-14 FT RDF data and first shell Sr-O model fit data for SrMST4. The third cumulant term was included in the fit-uncorrected for phase shift. .26

Figure 4-15 FT RDF data and first shell $\mathrm{Sr}-\mathrm{O}$ model fit data for the dilute $\mathrm{SrCl}_{2}$ solution without the third cumulant term-uncorrected for phase shift.

Figure 4-16 Back-transformed chi data and model second and third shell fit data for interactions of $\mathrm{Sr}_{-} \mathrm{Ti}_{1}, \mathrm{Sr}_{-} \mathrm{O}_{1}$ and $\mathrm{Sr}-\mathrm{Ti}_{2}$ for $\mathrm{Sr}^{2+}$-loaded SrMST1.

Figure 4-17 Back-transformed chi data and model second and third shell fit data for interactions of $\mathrm{Sr}_{-} \mathrm{Ti}_{1}, \mathrm{Sr}_{-} \mathrm{O}_{1}$ and $\mathrm{Sr}_{-} \mathrm{Ti}_{2}$ for $\mathrm{Sr}^{2+}$-loaded SrMST3.

Figure 4-18 Back-transformed chi data and model second and third shell fit data for interactions of $\mathrm{Sr}_{-} \mathrm{Ti}_{1}, \mathrm{Sr}_{-} \mathrm{O}_{1}$ and $\mathrm{Sr}-\mathrm{Ti}_{2}$ for $\mathrm{Sr}^{2+}$-loaded SrMST4.

Figure 4-19 EXAFS-based molecular model of association of $\mathrm{Sr}^{2+}$ with $\mathrm{TiO}_{6}$ groups. ..........33

Figure 4-20 EXAFS-based molecular model of association of $\mathrm{Sr}^{2+}$ with corner-shared $\mathrm{TiO}_{6}$ groups.

Figure 7-1 Back-transformed chi data and model fit second shell data for interactions of Sr-O without the $\mathrm{C} 3$ term for $\mathrm{Sr}^{2+}$-loaded SrMST1.

Figure 7-2 Back-transformed chi data and model fit second shell data for interactions of Sr$\mathrm{O}$ with the $\mathrm{C} 3$ term for $\mathrm{Sr}^{2+}$-loaded SrMST1.

Figure 7-3 Back-transformed chi data chi data and model fit data for second shell interaction of $\mathrm{Sr}$-Ti without the $\mathrm{C} 3$ term for $\mathrm{Sr}^{2+}$-loaded SrMST1 .38

Figure 7-4 Back-transformed chi data and model fit data for second shell interactions of Sr-

Ti with the C3 term for $\mathrm{Sr}^{2+}$-loaded SrMST1. .38

Figure 7-5 Back-transformed chi data and model fit data for third shell $\mathrm{Sr}-\mathrm{O}$ interactions without the C3 term for $\mathrm{Sr}^{2+}$-loaded SrMST1.

Figure 7-6 Back-transformed chi data and model fit data for third shell Sr-O interactions with the $\mathrm{C} 3$ term for $\mathrm{Sr}^{2+}$-loaded SrMST1.

Figure 7-7 Back-transformed chi data and model fit data for interactions of second shell Sr-

$\mathrm{Ti}$ and third shell $\mathrm{Sr}-\mathrm{O}$ interactions for $\mathrm{Sr}^{2+}$-loaded SrMST1 - without the $\mathrm{C} 3$ term. .....40 
WSRC-TR-2001-00245, REVISION 0

\section{LIST OF TABLES}

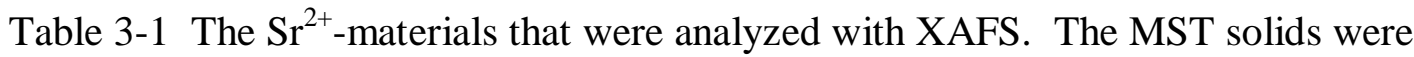
equilibrated for 1 week with the target metal.................................................................5

Table 3-2 Reference $\mathrm{Sr}^{2+}$ materials used as standards for the XAFS analyses.......................6

Table 4-1 Literature XAFS fit data for solid phase of $\mathrm{Sr}^{2+}$. The magnitude of the DebyeWaller Factor $\left[\sigma^{2}[\AA]^{2}\right]$ indicates the variation in the bond length determination.

Table 4-2 First coordination shell $\mathrm{Sr}-\mathrm{O}$ fit literature data for dissolved $\mathrm{Sr}^{2+}$. The magnitude of the Debye-Waller Factor [represented in as $\left.\sigma^{2}[\AA]^{2}\right]$ indicates the variation of the bond length determination.

Table 4-3 Fit results for a first shell Sr-O interaction with and without the third cumulant (C3) term for the $\mathrm{Sr}^{2+}$ sorbed MST samples. Use of the third cumulant term in the fits for $\mathrm{Sr}$ in the dilute $\mathrm{SrCl}_{2(\mathrm{aq})}$ solution yielded no differences (in CN or R). Fits for SrMST2 were not performed due to insufficient data quality. DeltaR and deltaCN represent the change in $\mathrm{R}$ and $\mathrm{CN}$ values (respectively) with the inclusion of the $\mathrm{C} 3 \mathrm{term}$. The magnitude of the Debye-Waller Factor [represented in as $\left.\sigma^{2}[\AA]^{2}\right]$ indicates the variation of the bond length determination (or spread but not error). It also provides information on goodness of fit - for example, a negative value would indicate a poor fit. A decrease in the $\mathrm{D}-\mathrm{W}$ factor with inclusion of the $\mathrm{C} 3$ term signifies that there is less variance and hence better fit. Addition of the third cumulant (C3) term in the fit accounts for the anharmonicity arising from weak back-scatterers. The addition of this $\mathrm{C} 3$ variable in the fitting process should result in a smaller $\mathrm{D}-\mathrm{W}$ factor. Without the $\mathrm{C} 3$ term, the $\mathrm{D}-\mathrm{W}$ factor is overestimated.

Table 4-4 Fit results for a second and third shell $\mathrm{Sr}$ interactions with and without the third cumulant (C3) term for the $\mathrm{Sr}^{2+}$ sorbed MST samples. Use of the third cumulant term in the fits for $\mathrm{Sr}$ in the dilute $\mathrm{SrCl}_{2(\mathrm{aq})}$ solution yielded no differences (in $\mathrm{CN}$ or $\mathrm{R}$ ). The third cumulant term was not included in fits for second and third shell interactions due to a limited number of degree of freedom, which did not allow addition of another floating variable. Fits for SrMST2 were not performed due to insufficient data quality. 
WSRC-TR-2001-00245, REVISION 0

\section{ACRONYMS AND ABBREVIATIONS}

\begin{tabular}{|c|c|}
\hline $\mathrm{CN}$ & Coordination number \\
\hline$\delta(\mathrm{K})$ & Electronic phase shifts due to atomic potentials \\
\hline EXAFS & Extended X-ray Absorption Fine-Structure \\
\hline $\mathrm{E}$ & $E$ is the kinetic energy of the photoelectron \\
\hline $\mathrm{E}_{0}$ & $\begin{array}{l}\text { EXAFS defined edge energy in electron volts or } \mathrm{eV} \text { (not equal to edge } \\
\text { energy as defined by XANES but is equal to the energy of the } \\
\text { photoelectron at } k=0 \text {. }\end{array}$ \\
\hline $\mathrm{E}_{0}$ Shift & A relative value of $E_{0}$ (a variable in the EXAFS Equation) \\
\hline $\mathrm{F}$ & Backscattering amplitude of the atom \\
\hline FEFF & $\begin{array}{l}\text { An automated computer program for making ab initio multiple } \\
\text { scattering calculations of XAFS and XANES spectra for atoms. }\end{array}$ \\
\hline $\mathrm{FeOOH}$ & The Fe(III)-oxide mineral goethite. \\
\hline FFIT & $\begin{array}{l}\text { A Levenberg-Marquardt fitting program created by researchers at the } \\
\text { University of Washington }\end{array}$ \\
\hline FT & Fourier-transform \\
\hline$\hbar$ & Plank's constant \\
\hline HLW & High Level Waste \\
\hline $\mathrm{HFO}$ & Hydrous ferric oxide. \\
\hline HMO & Hydrous manganese oxide. \\
\hline$k$ & Chi where $k$ is the square root of $\left[\left(2 \mathrm{~m} / \hbar^{2}\right) *\left(\mathrm{E}-\mathrm{E}_{0}\right)\right]$ \\
\hline $\mathrm{m}$ & Mass of the photoelectron \\
\hline MST & Monosodium titanate \\
\hline NSLS & National Synchrotron Light Source \\
\hline $\mathrm{O}$ & Oxygen \\
\hline $\mathrm{R}$-space & $\begin{array}{l}\text { R-space pertains to mean atom position or bond distance (radial } \\
\text { distance in } \AA \text { ) }\end{array}$ \\
\hline RDF & Radial Distribution Function \\
\hline RT & Room Temperature. \\
\hline $\mathrm{S} / \mathrm{N}$ & Signal to Noise \\
\hline $\mathrm{S}^{\wedge} 2$ or $\mathrm{S}_{0}^{2}$ & $\begin{array}{l}\text { Amplitude reduction factor (EXAFS Equation variable associated with } \\
\text { central atom shake-up and shake-off effects) }\end{array}$ \\
\hline$\sigma^{2}$ or SIGMA $^{2}$ & $\begin{array}{l}\text { Debye-Waller Factor or Relative Mean Square Disorder in bond length } \\
\text { (a variable in the EXAFS Equation) }\end{array}$ \\
\hline $\mathrm{Si}(\mathrm{Li})$ & An energy dispersive Li-doped silicon detector \\
\hline $\mathrm{Sr}$ & Strontium \\
\hline SRTC & Savannah River Technology Center \\
\hline $\mathrm{Ti}$ & Titanium \\
\hline WSRC & Westinghouse Savannah River Company \\
\hline XAFS & X-ray Absorption Fine-Structure (XANES plus EXAFS) \\
\hline XANES & X-ray Absorption Near-Edge Structure \\
\hline XRD & $\mathrm{X}$-ray Diffraction \\
\hline
\end{tabular}


WSRC-TR-2001-00245, REVISION 0

\subsection{EXECUTIVE SUMMARY}

Approximately 130 million L of High-Level Radioactive Waste (HLW, the waste product associated with the dissolution of spent fuel rods for the recovery of plutonium) material reside in carbon steel subsurface tanks awaiting treatment at the Savannah River Site (SRS). The currently proposed designs for the Salt Processing Facility at the SRS include use of monosodium titanate (MST) to remove the strontium (Sr) and actinides from the HLW. Solid phases such as the titanates have a strong affinity for dissolved $\mathrm{Sr}^{2+}$ and actinides under conditions relevant to processing of highly alkaline HLW salt solutions but the mechanism of Sr uptake by MST is not known. Although the salt solutions contain high levels of $\mathrm{Na}^{+}$(several M) which is a potential competitor with $\mathrm{Sr}^{2+}$ for sorption sites on MST, $\mathrm{Sr}^{2+}$ is preferred over $\mathrm{Na}^{+}$by MST - despite the high levels of (background) $\mathrm{Na}^{+}$. This preference for $\mathrm{Sr}^{2+}$ is not understood and the structure of MST is not known. Uptake processes of dissolved species by solids can occur by several mechanisms: structural incorporation, ion exchange (electrostatic or outer-sphere) sorption, specific adsorption and surface precipitation. Fundamental information about the mechanism of uptake will provide a better understanding about processing with MST, such as washing after $\mathrm{Sr}^{2+}$ and actinide removal. This report discusses the characterization of the nature of $\mathrm{Sr}^{2+}$ sorption on MST in HLW salt solutions. The study used X-ray absorption fine-structure spectroscopy (XAFS) to characterize the chemistry of $\mathrm{Sr}^{2+}$ on MST yielding the following conclusions.

- The speciation of sorbed $\mathrm{Sr}^{2+}$ on MST does not change over the range of surface $\mathrm{Sr}^{2+}$ loadings examined in this study.

- $\mathrm{The}^{2+} \mathrm{r}^{2+}$ undergoes partial dehydration upon sorption to MST.

- Presence of Ti in the second coordination shell of the $\mathrm{Sr}^{2+}$ on the MST suggests that specific adsorption is the predominant mechanism and that electrostatic bonding (also known as ion exchange of hydrated surface-associated species such as dissolved $\mathrm{Na}^{+}$) in the electric double-layer of the HLW salt simulant solution does not occur.

- Some structural incorporation of $\mathrm{Sr}^{2+}$ (as a replacement for structural $\mathrm{Na}^{+}$) may occur but there are not enough Ti atoms in the second shell to suggest that this is the primary mechanism of uptake.

- Interpretations of the EXAFS data and EXAFS-based molecular modeling suggest $\mathrm{Sr}^{2+}$ may associate with more than one $\mathrm{TiO}_{6}$ octahedra (assuming the presence of Ti octahedra because the structure of MST is not known) as a partially aquated ion.

- The speciation of sorbed $\mathrm{Sr}^{2+}$ on MST was not like that of $\mathrm{Sr}^{2+}$ in the HLW salt simulant solution, suggesting that a change in the $\mathrm{Sr}^{2+}$ coordination environment occurs upon sorption to MST.

Page 1 of 43 
WSRC-TR-2001-00245, REVISION 0

\subsection{INTRODUCTION}

Solid phases such as the titanates have a strong affinity for dissolved $\mathrm{Sr}^{2+}$ and actinides under conditions relevant to the processing of highly alkaline HLW salt solutions. These sorptive materials are being considered for use in HLW treatment to concentrate dissolved forms of radiostrontium and actinides. Removal and retention of dissolved species by reactive surface does not always involve "sorption"-even in the most general sense. We will discuss how our study findings relate to process chemistry and engineering in the Discussion and Conclusions section of this report but first we will discuss four mechanisms of metal uptake by surfaces and the use of XAFS spectroscopic methods elucidate the coordination and bonding environment of those metals.

\subsection{Uptake Mechanisms of Metals by Surfaces.}

Uptake processes by solids can occur by several mechanisms: structural incorporation, ion exchange (electrostatic or outer-sphere) sorption, specific adsorption and surface precipitation. A schematic of these processes is shown in Figure 2-1. Many of these terms have been used loosely in the literature and their use varies with scientific discipline. Our presentation focuses on the surface and its interaction with the sorbing solution species. A more thorough review of these processes is presented elsewhere. ${ }^{1,2}$ Expression of these uptake processes can depend on the amount of metal added, solution and solid phase characteristics.

"Ion exchange" can have different meanings, which results in some confusion in the literature. One very general way to express ion exchange is structural incorporation, which is the substitution of a solution species for a structural atom:

$$
\mathrm{CaCO}_{3(\mathrm{~s})}+\mathrm{Sr}^{2+} \longrightarrow \mathrm{SrCO}_{3(\mathrm{~s})}+\mathrm{Ca}^{2+}
$$

This type of sorption typically requires ready access to structural atoms. Another example of this process would be the exchange of the structural $\mathrm{Na}^{+}$in monosodium titanate (MST) with $\mathrm{Sr}^{2+}$. Although little is known about the structure of MST, access (for $\mathrm{Sr}^{2+}$ ) could occur within long sheets of edge linked $\mathrm{TiO}_{6}$ octahedra that contain $\mathrm{Na}^{+}$ions. In this case, the structural incorporation of $\mathrm{Sr}^{2+}$ in MST would result in the presence of several $\mathrm{Ti}$ atoms in the second coordination shell of the $\mathrm{Sr}^{2+}$. Ideally, structural incorporation of the $\mathrm{Sr}^{2+}$ should also result in a similar number of first shell oxygen atoms to that of the replaced ion prior to its release. Therefore, the local environment of the exchanged atom would resemble the environment the newly exchanged atom had prior to its release (Figure 2-1). 

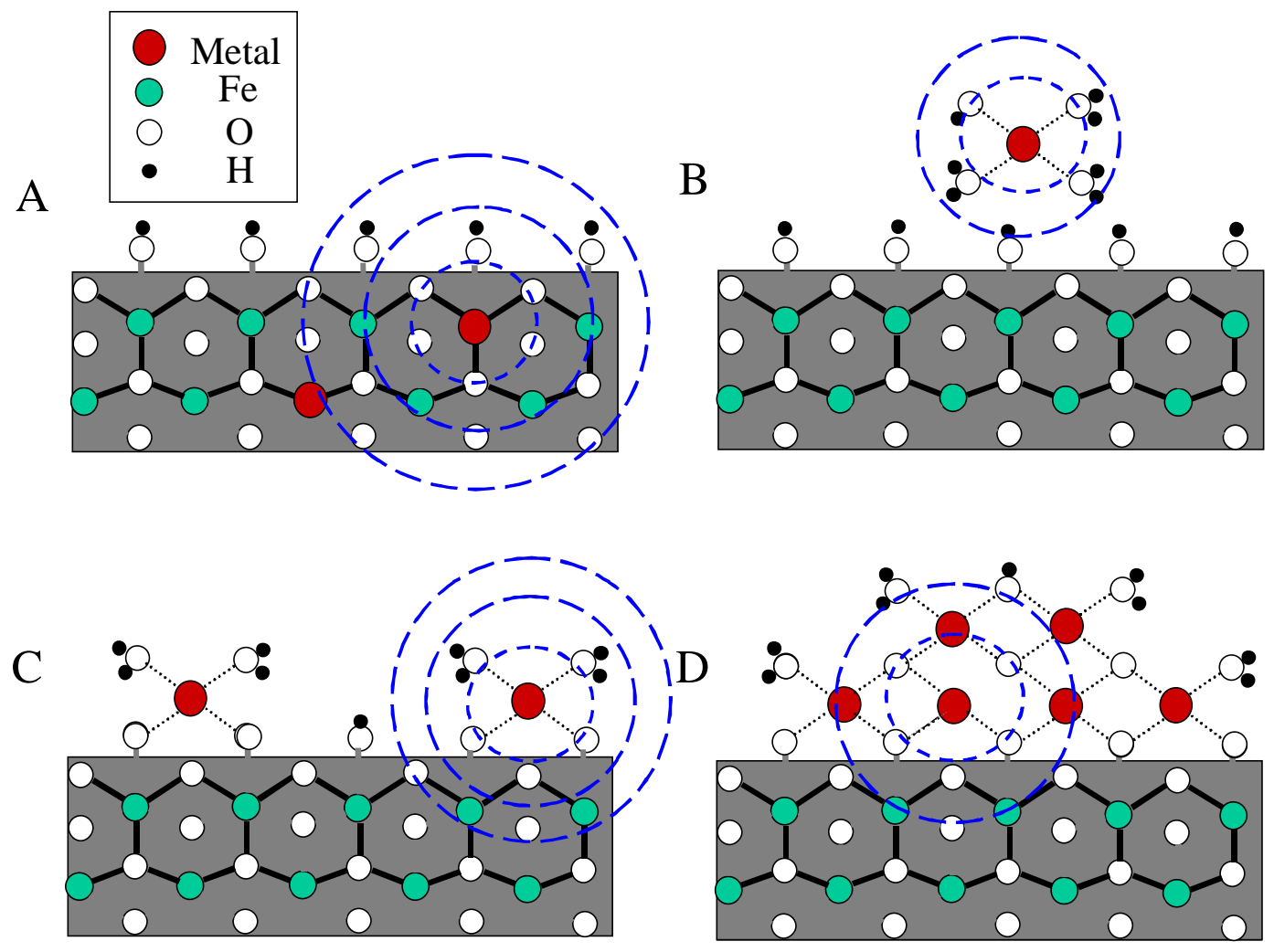

Figure 2-1 Simplified diagram of the types of associations a metal could have with a surface. A) Structural incorporation, B) Outer-sphere (electrostatic) sorption, C) Specific or inner-sphere sorption and D) Surface precipitation. Blue rings denote first, second and third environments that can be probed with XAFS techniques.

Ion exchange in a more restrictive sense is an electrostatic process involving the replacement of a one readily exchangeable hydrated ion by another similarly exchangeable ion (Figure 2-1). This type of sorption is also referred to as outer sphere sorption. Ion exchange does not involve the formation of bonds on the participating surface because the sorbed ion is present in the diffuse double layer (DDL). This type of sorption is normally reversible ${ }^{3}$ and is a function of ionic strength. At high ionic strengths, the DDL collapses and less sorption by ion exchange is observed than at low ionic strengths. Ion exchange sorption is often associated with materials that have constant surface charge and exhibit no change in overall surface charge upon ion exchange sorption. An example of this process would be exchange of hydrated $\mathrm{Na}^{+}$ion for hydrated $\mathrm{Sr}^{2+}$ in the DDL.

Specific adsorption involves the formation of predominantly covalent bond with the surface, but the bond can have some ionic behavior. This type of sorption is often referred to as chemisorption or inner sphere sorption. Specifically adsorbed metals often contain one or more atoms from the participating surface in the second coordination shell (Figure 2-1). This type of sorption involves the release of $\mathrm{H}^{+}$or structural surface ions (such as $\mathrm{Na}^{+}$in MST) upon sorption. For example, specific sorption of $\mathrm{Sr}^{2+}$ to MST could result in the Page 3 of 43 
presence of $\mathrm{Ti}$ atoms in the second coordination shell of the $\mathrm{Sr}^{2+}$. Specific adsorption is usually irreversible. ${ }^{3}$. However, in the literature, specific adsorption is rarely differentiated from structural incorporation or surface precipitation. Specific adsorption may involve mononuclear complexes or polymeric species. Specific adsorption is influenced by other solution- and surface-related variables. ${ }^{4}$

Surface Precipitation occurs by nucleation of new solid phase on a host surface (Figure 2-1). For example, when the concentration of a dissolved metal such as $\mathrm{Sr}^{2+}$ is high enough to result in the super-saturation of one or more $\mathrm{Sr}^{2+}$-containing phase [such as $\left.\mathrm{SrCO}_{3(\mathrm{~s})}\right]$ in the presence of MST, the MST facilitates the nucleation of the new solid $\mathrm{Sr}^{2+}-$ rich phase. Surface precipitation of $\mathrm{Sr}^{2+}$ would result in existence of second shell $\mathrm{Sr}^{2+}$ atoms around each $\mathrm{Sr}^{2+}$.

\subsection{Use of XAFS Techniques to Characterize Metal Uptake by Surfaces.}

The environment of metals associated with surfaces can be investigated with analytical techniques such as X-ray absorption fine-structure (XAFS) spectroscopy. We will use Sr-XAFS to study the environment of the sorbed $\mathrm{Sr}^{2+}$. To determine the nature of metal sorption on MST, the XAFS studies will use with solids that have a range of $\mathrm{Sr}^{2+}$ loadings in a HLW salt simulant solution. The XAFS spectroscopic techniques are among the best for providing detailed chemical speciation information in environmental samples-particularly when information from multiple characterization techniques is available. The term XAFS is applies to X-ray absorption near-edge structure (XANES) and extended X-ray absorption fine-structure (EXAFS) spectroscopic techniques. The XAFS spectra give robust local structural information on coordination number $(\mathrm{CN})$, bonding symmetry, neighbor and nearneighbor atomic distances and bond disorder (as the root mean square deviations of distances about the average values). Additionally, the information gained is atom specific-making it a versatile technique for structural determinations of atom clusters. ${ }^{5,6}$

The XANES techniques involve multiple scatterings of an ejected photoelectron with moderate kinetic energy with neighboring atoms. Unlike EXAFS, for XANES the ejected photoelectron does not enter the continuum. ${ }^{5}$ The XANES spectroscopic techniques can provide information on the local coordination environment and oxidation state of the metal of interest. ${ }^{5}$ The EXAFS spectroscopy in particular has been quite successfully applied to the structural elucidation of metals clusters and sorbed metals on surfaces because the technique does not require long range order (i.e., periodicity) or crystalline samples.

\subsection{Experimental Objectives.}

The primary objective of this research was to obtain information on speciation of $\mathrm{Sr}^{2+}$ after reaction with MST in highly alkaline HLW simulant solutions. Prior to this preliminary study, little information was available on the speciation of sorbed $\mathrm{Sr}^{2+}$ on these materials. Several metal-loaded MST samples were prepared to have a range of metal loadings. We used XAFS techniques to obtain information on the average local structural speciation of the sorbed $\mathrm{Sr}^{2+}$ and actinides such as $\mathrm{CN}$, geometry, near and next-nearest neighbor environment of the target metals. 


\subsection{METHODS AND MATERIALS}

Samples were prepared for XAFS analyses. The details of the sample preparation, XAFS data collection and data analyses are presented below.

\subsection{Sample Preparation.}

A synthetic HLW salt solution was made of $1.33 \mathrm{M} \mathrm{NaOH}, 2.6 \mathrm{M} \mathrm{NaNO}_{3}, 0.43$ $\mathrm{Na}\left(\mathrm{AlO}_{4}\right)_{2} 0.34 \mathrm{M} \mathrm{NaNO}_{2}, 0.52 \mathrm{M} \mathrm{NaSO}_{4}$ and $0.026 \mathrm{M} \mathrm{NaCO}_{3}$. One liter of the HLW salt solution was allowed to equilibrate with MST (amounts listed in Table 3-1) for a one week period. The samples were filtered with a $0.45-\mu \mathrm{m}$ polycarbonate filter. The solids were placed in 3-mL microcentrifuge tubes as shown in Figure 3-1 with a small amount of salt solution. Several reference materials were prepared for XAFS analyses (Table 3-2).

Table 3-1 The $\mathrm{Sr}^{2+}$-materials that were analyzed with XAFS. The MST solids were equilibrated for 1 week with the target metal.

\begin{tabular}{|l|c|c|c|}
\hline $\begin{array}{l}\text { Treatment } \\
\text { Name }\end{array}$ & $\mathrm{Sr}^{2+}$ Concentration Added & Solid Amount $(\mathrm{g})$ & Loading $\left(\mathrm{mg} \mathrm{kg}^{-1}\right)$ \\
\hline SrMST1 & $1 \mathrm{mg} \mathrm{Sr}^{2+} \mathrm{L}^{1}$ & 0.1 & 9000 \\
\hline SrMST2 & $1 \mathrm{mg} \mathrm{Sr}^{2+} \mathrm{L}^{1}$ & 0.2 & 4500 \\
\hline SrMST3 & $1 \mathrm{mg} \mathrm{Sr}^{2+} \mathrm{L}^{1}$ & 0.5 & 1800 \\
\hline SrMST4 & $1 \mathrm{mg} \mathrm{Sr}^{2+} \mathrm{L}^{1}$ & 1.0 & 900 \\
\hline
\end{tabular}

Figure 3-1 Photograph of the moist $\mathrm{Sr}^{2+}$-loaded MST samples analyzed using XAFS techniques. Sample 1a (left), which had the highest $\mathrm{Sr}^{2+}$ loading, is more yellow in color than that of the samples with lower levels of sorbed $\mathrm{Sr}^{2+}$. 
WSRC-TR-2001-00245, REVISION 0

Table 3-2 Reference $\mathrm{Sr}^{2+}$ materials used as standards for the XAFS analyses.

\begin{tabular}{|c|c|}
\hline Reference Material & Description \\
\hline $\mathrm{SrCl}_{2(\mathrm{aq})}$ & $10^{-6} \mathrm{M} \mathrm{Sr}^{2+}$ in de-ionized water (added as $\mathrm{SrCl}_{2}$ ) \\
\hline $\mathrm{SrHLW}_{(\mathrm{aq})}$ & $10^{-6} \mathrm{M} \mathrm{Sr}^{2+}$ in $\mathrm{MST}$-free $\mathrm{HLW}$ salt solution (added as $\mathrm{SrCl}_{2}$ ) \\
\hline $\mathrm{SrTiO}_{3(\mathrm{~s})}$ & Commercially available nanosized solid \\
\hline $\mathrm{SrCO}_{3(\mathrm{~s})}$ & Commercially available solid \\
\hline $\mathrm{Sr}\left(\mathrm{NO}_{3}\right)_{2(\mathrm{~s})}$ & Equilibrated for 45 C for 24 hours and filtered. \\
\hline
\end{tabular}

\subsubsection{XANES and EXAFS Data Collection and Analy ses.}

The Sr-XAFS data were collected at the Sr K-edge $(16.105 \mathrm{keV})$ on moist filtered MST solids and reference materials (Table 3-1; Table 3-2). The Sr-XAFS data were collected on beamline X23a2 (schematic shown in Figure 3-2) and beamline X26a (schematics shown in Figure 3-3; Error! Reference source not found.) at the National Synchrotron Light Source (NSLS, Brookhaven National Laboratory, Upton, NY). The XAFS data were collected in transmission and fluorescence mode using an unfocussed X-ray beam and a fixed-exit $\mathrm{Si}(311)$ monochromator (X23a2) or channel-cut $\mathrm{Si}(111)$ monochromator (X26a). Ion chambers were used to collect incident (Io) and transmission (It) signals at X23a2 whereas an ion chamber was used to collect $I o$ signals and a pin diode was used to measure It at X26a. Simultaneous data collection of a reference (Ir) signal was not feasible because the samples absorption of the X-ray beam was substantial. Gas ratios for the data collection in Io were $100 \%$ Ar. A Lytle detector was used to collect fluorescence $\mathrm{X}$-rays $(I f)$, using an $\mathrm{Al}$ metal foil to reduce the background fluorescence counts. The monochromator energy (X23a2) was maximized using a piezo stack feedback energy stabilization system, with a settling time of 0.3 seconds per change in monochromatic energy. Monochromator energy maximization was not required at beamline X26a. An X-ray beam size of 2 by $28 \mathrm{~mm}^{2}$ (X23a2) or $350 \mu \mathrm{m}^{2}$ (X26a) was used.

Background contribution to the EXAFS spectra was removed using an algorithm (AUTOBK) developed by Newville et al. (1993), which minimizes R-space values in low $k$ space. Each chi data set was read into the WINXAS analysis package. ${ }^{7,8}$ Replicate scans were co-added (that is the spectra were summed and divided by the number of scans) to improve $\mathrm{S} / \mathrm{N}$. After background subtraction and normalization, the XANES spectra were compared with spectra from the Sr standards and spectra from the literature. For the MST samples and most of the $\mathrm{Sr}$ reference materials, the Sr-EXAFS spectra were analyzed from 2 to $14 \AA^{-1}$. The $\mathrm{SrCO}_{3}$ and $\mathrm{Sr}\left(\mathrm{NO}_{3}\right)_{2}$ standards were analyzed from 2 to $11 \AA^{-1}$. Chi data were $k^{3}$-weighted. The chi data were Fourier-transformed (FT) to yield R-space or Radial Distribution Function (RDF) plots. ${ }^{9}$ The EXAFS spectra that were acquired for the $\mathrm{Sr}^{2+}$ references were used to estimate phase shifts, coordination environment and radial bond distances. Simulated EXAFS spectra were also generated based on the documented crystallographic properties for $\mathrm{Sr}^{2+}$ using ab initio based theory, which involved FEFF 7.2, a program created by researchers at the Univ. of Washington. 


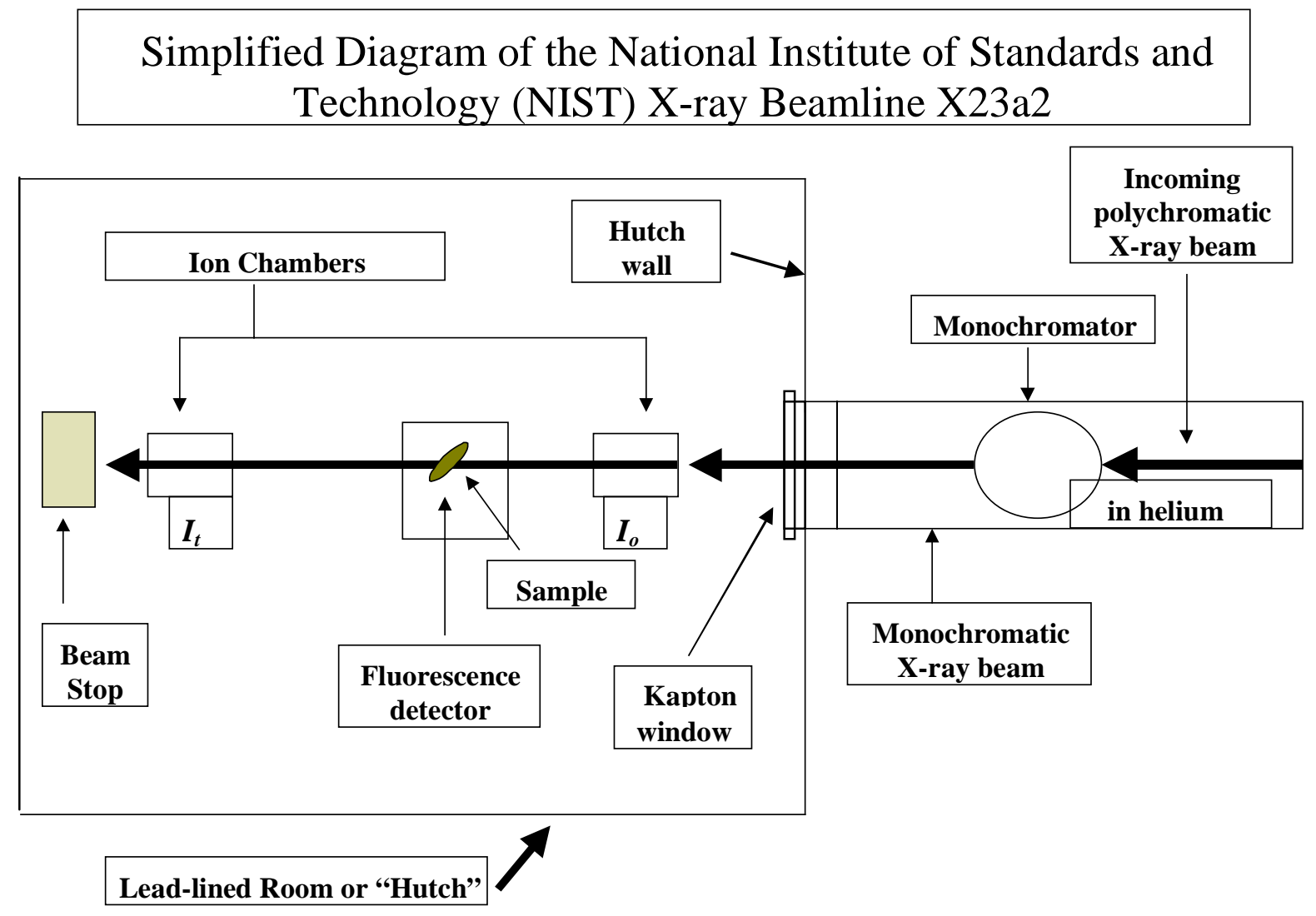

Figure 3-2 Diagram of the downstream portion of the hutch table at NIST beamline X23a2 (not drawn to scale). 


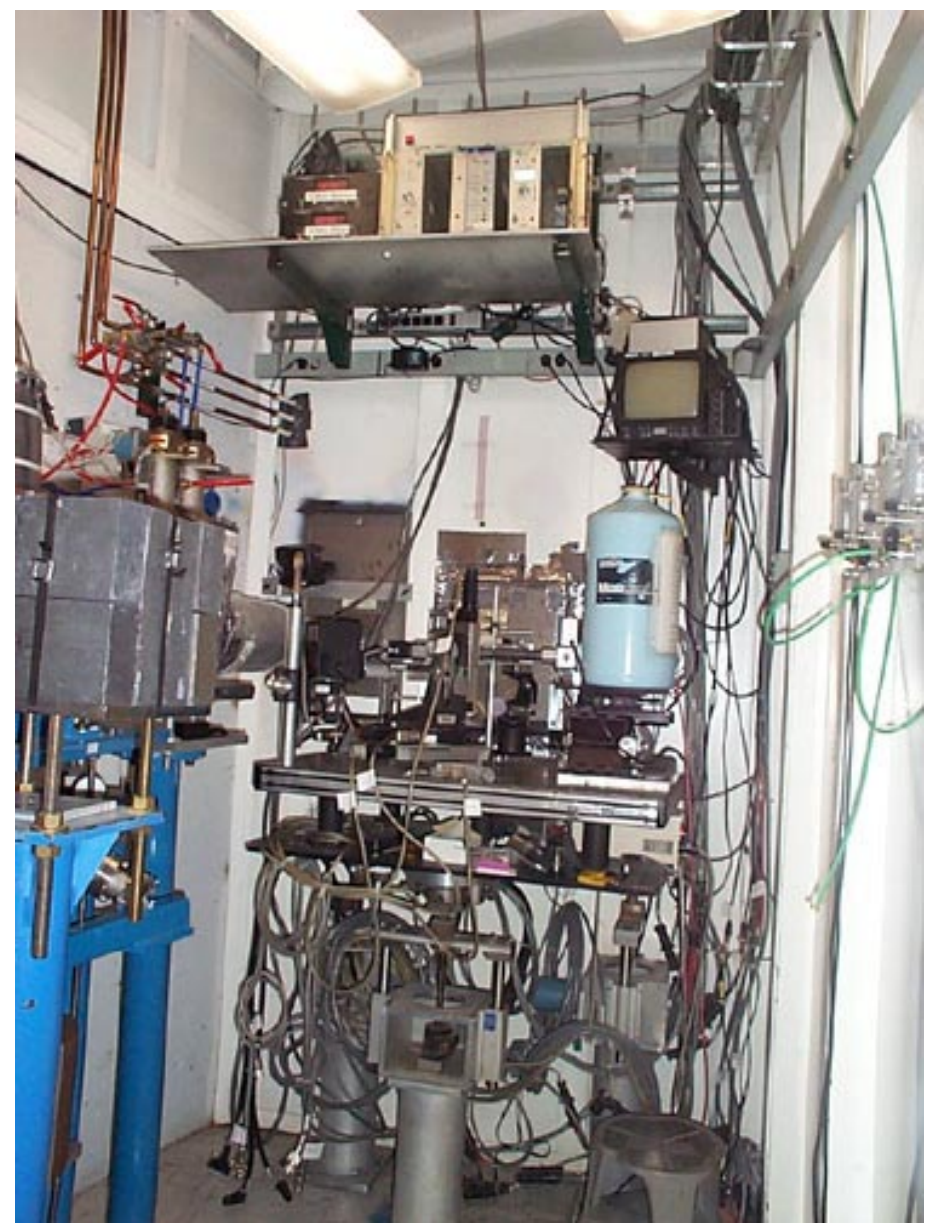

Figure 3-3 Side view of the downstream portion of the hutch table at beamline X26a. The SiLi detector (light blue item on right of table) was not used in this study (picture kindly provided by A. Lanzirotti, Univ. of Chicago). 


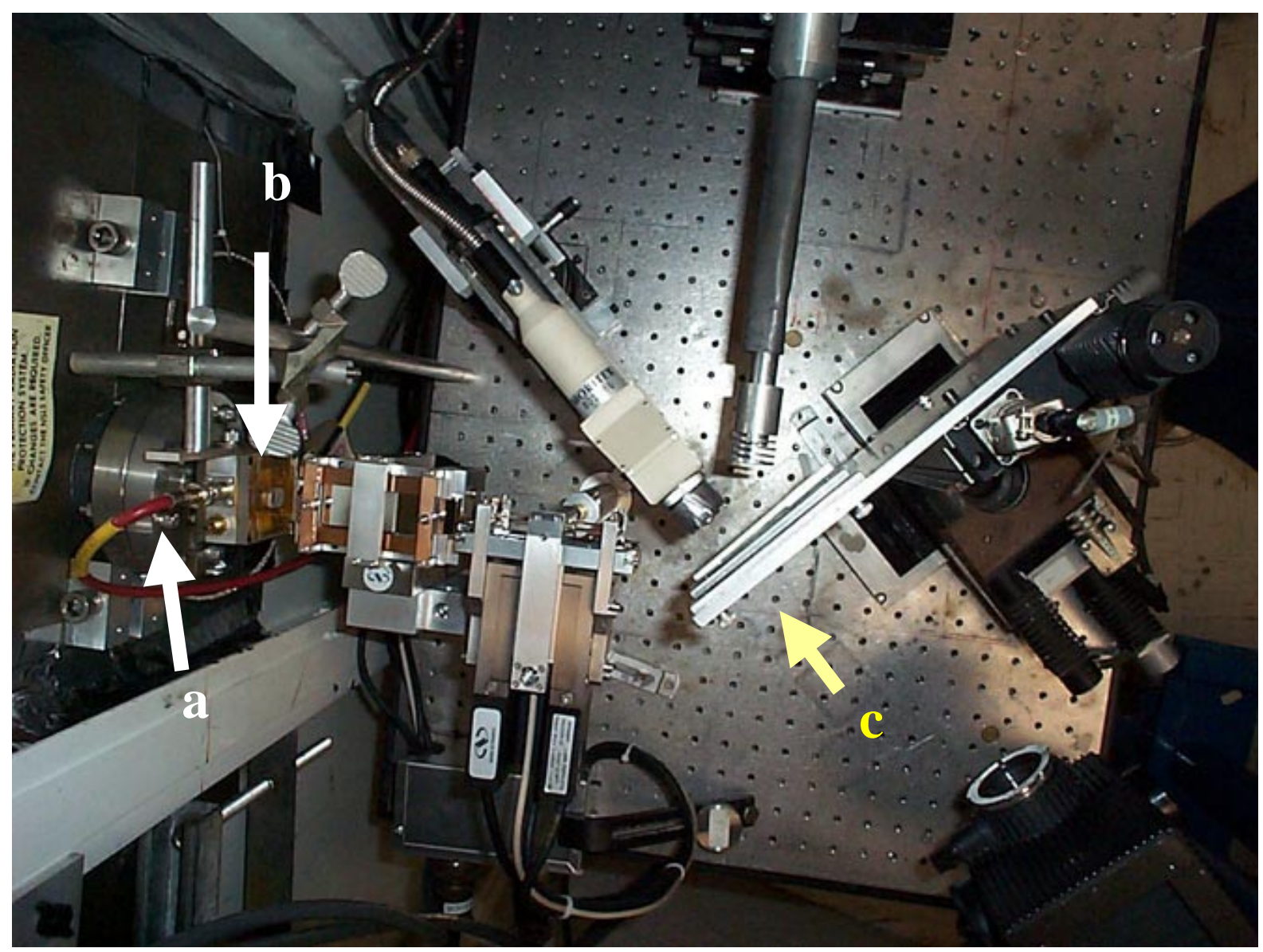

Figure 3-4 Overhead view of the downstream portion of the hutch table at beamline X26a showing a) the incoming beam with (closed) shutter, b) ion chamber, and c) the sample holder. The pin diode detector used in this study is not shown. (Photo provided by A. Lanzirotti, Univ. of Chicago.) 
WSRC-TR-2001-00245, REVISION 0

\subsection{RESULTS}

\subsubsection{Background on Sr-XAFS Studies with Sr-containing Materials.}

Strontium K-edge XANES and XAFS techniques have been applied to study the bonding environment of sorbed, solution and solid phase $\mathrm{Sr}^{2+}$ species. ${ }^{16,17,18,19,20}$ StrontiumXANES studies have been performed with $\mathrm{Sr}^{2+}$-rich carbonates and $\mathrm{Sr}^{2+}$-containing silicates and the interpretations of spectra from sample treatments are generally qualitative. ${ }^{20}$ This is because solution and solid phase $\mathrm{Sr}^{2+}$ species are typically present in the +II oxidation state and large energy shifts for the XANES edge of $\mathrm{Sr}^{2+}$ are usually not observed. However, ligand and coordination effects are observed and some comparisons can be made between the XANES spectra from the unknowns and that of the characterized reference materials of known coordination and bonding environment. ${ }^{20}$

Table 4-1 provides a summary of the Sr-XAFS data obtained from a review of these studies. Some of the EXAFS studies that have characterized the environment of sorbed $\mathrm{Sr}^{2+}$ on hydrous oxides of Fe and Mn observe a metal in the second coordination shell. ${ }^{16,17}$ Because a metal was found in the second coordination environment, these studies refer to the nature of the sorption as being due to the ion exchange of hydrated $\mathrm{Sr}^{2+}$ (Note: This conclusion is not consistent with the previous section that describes ion exchange in the strict sense. ${ }^{16,17}$ These studies also report that they could fit $\mathrm{Sr}$ or Fe in the second shell over a range of surface $\mathrm{Sr}^{2+}$ loadings and hence, these data present great confusion and about the quality of the XAFS data and the data analyses. ${ }^{21}$ In contrast, other sorption studies with $\mathrm{Sr}^{2+}$ sorbed on the FeOOH (goethite) do not observe a metal in the second coordination shell and conclude that outer sphere adsorption is operative. ${ }^{19}$ Extreme caution should be used when EXAFS studies are used to determine the nature of the sorption (such as ion exchange vs. specific adsorption, as described in O'Day et al. (2000).

O'Day et al. (2000) and Sahai et al. (2000) reviewed the use of Sr-EXAFS to characterize atomic structural properties of $\mathrm{Sr}^{2+}$ in solutions, in solids and on surfaces. They indicate the literature vary considerably due to the hydrated nature of the large divalent cation $\left(\mathrm{Sr}^{2+}\right){ }^{18,19}$ This behavior is mainly attributed to differences in experimental EXAFS fitting techniques associated with the determination of amplitude reduction factors, anharmonic disorder and the number of experimental shells included in the model fits. Additionally, some XAFS studies may not account for problems associated with light atom back-scattering. O'Day et al. (2000) and others have included a third cumulant term (C3) in their fits for first shell Sr-O interactions to account for anharmonicity among light backscattering atoms $\mathrm{Sr}$ and $\mathrm{O}$ in aqueous environments. ${ }^{16,17,18,19}$ For our studies, we will compare the results of our first shell Sr-O fits with and without the $\mathrm{C} 3 \mathrm{term}$. It is our opinion that the reports that have excluded the $\mathrm{C} 3$ term during the data analyses are in error. This term is important because of the hydrated nature of $\mathrm{Sr}^{2+}$ in solution. Exclusion of fitting with the $\mathrm{C} 3$ term is most common in the older literature. 
Table 4-1 Literature XAFS fit data for solid phase of $\mathrm{Sr}^{2+}$. The magnitude of the DebyeWaller Factor $\left[\sigma^{2}[\AA]^{2}\right]$ indicates the variation in the bond length determination.

\begin{tabular}{|c|c|c|c|c|}
\hline Sample & Interaction & $\mathbf{C N}$ & $\begin{array}{c}\text { Distance } \\
\mathbf{R}[\AA]\end{array}$ & $\sigma^{2}[\AA]^{2}$ \\
\hline $\mathrm{Sr}(\mathrm{II}) \mathrm{CO}_{3(\mathrm{~s})}{ }^{16}$ & Sr-O & 12.96 & 2.69 & 0.013 \\
\hline \multirow[t]{5}{*}{$\mathrm{Sr}(\mathrm{II}) \mathrm{CO}_{3(\mathrm{~s})}{ }^{18}$} & Sr-O & 9 & 2.61 & 0.0136 \\
\hline & $\mathrm{Sr}-\mathrm{C}$ & 3 & 3.05 & 0.0073 \\
\hline & $\mathrm{Sr}-\mathrm{Sr}$ & 4 & 4.14 & 0.0083 \\
\hline & $\mathrm{Sr}-\mathrm{Sr}$ & 2 & 4.29 & 0.0063 \\
\hline & $\mathrm{Sr}-\mathrm{Sr}$ & 4 & 4.92 & 0.0150 \\
\hline \multirow[t]{6}{*}{$\mathrm{Sr}(\mathrm{II}) \mathrm{CO}_{3(\mathrm{~s})}{ }^{20}$} & Sr-O & 9 & 2.59 & 0.016 \\
\hline & $\mathrm{Sr}-\mathrm{C}$ & 3 & 3.05 & 0.014 \\
\hline & Sr-C & 3 & 3.41 & 0.039 \\
\hline & $\mathrm{Sr}-\mathrm{Sr}$ & 2.6 & 4.01 & 0.002 \\
\hline & $\mathrm{Sr}-\mathrm{Sr}$ & 6 & 4.16 & 0.028 \\
\hline & $\mathrm{Sr}-\mathrm{Sr}$ & 6 & 4.91 & 0.029 \\
\hline $\mathrm{Sr}(\mathrm{II}) \mathrm{CO}_{3(\mathrm{~s})}$ at $\mathrm{RT}^{22}$ & $\mathrm{Sr}-\mathrm{O}$ & 9 & 2.61 & 0.0099 \\
\hline \multirow{7}{*}{$\mathrm{Sr}(\mathrm{II}) \mathrm{CO}_{3(\mathrm{~s})}{ }^{23}$} & $\mathrm{Sr}-\mathrm{O}$ & 9.2 & 2.63 & 0.016 \\
\hline & $\mathrm{Sr}-\mathrm{C}$ & 3.4 & 3.10 & 0.010 \\
\hline & Sr-C & 1.9 & 3.45 & 0.006 \\
\hline & $\mathrm{Sr}-\mathrm{Sr}$ & 2.6 & 4.01 & 0.002 \\
\hline & $\mathrm{Sr}-\mathrm{Sr}$ & 1.3 & 4.15 & 0.009 \\
\hline & $\mathrm{Sr}-\mathrm{Sr}$ & 2.6 & 4.17 & 0.004 \\
\hline & $\mathrm{Sr}-\mathrm{Sr}$ & 1.0 & 4.93 & 0.002 \\
\hline \multirow[t]{4}{*}{$\mathrm{Sr}(\mathrm{II}) \mathrm{TiO}_{3}$ (cubic) at $\mathrm{RT}^{18}$} & Sr-O & 12 & 2.72 & 0.0186 \\
\hline & Sr-Ti & 6 & 3.39 & 0.0080 \\
\hline & $\mathrm{Sr}-\mathrm{Sr}$ & 6 & 3.92 & 0.0121 \\
\hline & Sr-O & 24 & 4.78 & 0.0066 \\
\hline $\mathrm{Sr}^{2+}$ Sorbed on Kaolinite at $14 \mathrm{~K}^{19}$ & Sr-O & 9.9 & 2.62 & 0.0082 \\
\hline $\mathrm{Sr}^{2+}$ Sorbed on Kaolinite at $14 \mathrm{~K}^{20}$ & $\mathrm{Sr}-\mathrm{O}$ & 7.5 & 2.56 & 0.014 \\
\hline \multirow[t]{3}{*}{$\mathrm{Sr}^{2+}$-rich Zeolite (Heulandite) $\mathrm{RT}^{18}$} & $\mathrm{Sr}-\mathrm{O}$ & 8 & 2.60 & 0.0144 \\
\hline & $\mathrm{Sr}-\mathrm{Al} / \mathrm{Si}$ & 2 & 3.49 & 0.0139 \\
\hline & $\mathrm{Sr}-\mathrm{Al} / \mathrm{Si}$ & 2 & 4.14 & 0.0167 \\
\hline $\begin{array}{l}\mathrm{Sr}^{2+} \text { Sorbed on Goethite }(\mathrm{FeOOH}) \text { at } \\
\text { RT (low loading) }\end{array}$ & $\mathrm{Sr}-\mathrm{O}$ & 8.2 & 2.58 & 0.00116 \\
\hline \multirow{5}{*}{$\begin{array}{l}\mathrm{Sr}^{2+} \text { Sorbed on } \mathrm{FeOOH} \text { at RT (high } \\
\text { loading) }\end{array}$} & $\mathrm{Sr}-\mathrm{O}$ & 8.3 & 2.58 & 0.0140 \\
\hline & Sr-C & 0.4 & 3.03 & 0.0073 \\
\hline & $\mathrm{Sr}-\mathrm{Sr}$ & 3.1 & 4.13 & 0.0090 \\
\hline & $\mathrm{Sr}-\mathrm{Sr}$ & 1.5 & 4.30 & 0.0060 \\
\hline & $\mathrm{Sr}-\mathrm{Sr}$ & No data & No data & $>0.025$ \\
\hline
\end{tabular}


Table 4-1 Literature XAFS fit data for solid phase of $\mathrm{Sr}^{2+}$. The magnitude of the DebyeWaller Factor $\left[\sigma^{2}[\AA]^{2}\right]$ indicates the variation in the bond length determination.

\begin{tabular}{|c|c|c|c|c|}
\hline Sample Type & $\begin{array}{c}\text { Interacti } \\
\text { on }\end{array}$ & $\mathbf{C N}$ & $\begin{array}{c}\text { Distance } \\
\mathbf{r}[\AA]\end{array}$ & $\sigma^{2}[\AA]^{2}$ \\
\hline $\mathrm{Sr}^{2+}$ Sorbed on $\mathrm{FeOOH}$ at RT, $\mathrm{pH} 9.2^{23}$ & Sr-O & 8.0 & 2.61 & 0.012 \\
\hline \multirow[t]{2}{*}{$\mathrm{Sr}^{2+}$ Sorbed on $\mathrm{FeOOH}$ at RT, $\mathrm{pH} 10.2^{23}$} & Sr-O & 8.2 & 2.61 & 0.012 \\
\hline & $\mathrm{Sr}-\mathrm{Fe}$ & 1.8 & 4.29 & 0.011 \\
\hline \multirow[t]{2}{*}{$\mathrm{Sr}^{2+}$ Sorbed on HFO, $300^{\circ} \mathrm{K}$ (low loading) ${ }^{16,21}$} & Sr-O & 10.49 & 2.61 & 0.0098 \\
\hline & $\mathrm{Sr}-\mathrm{Fe}$ & 1.26 & 3.75 & 0.0061 \\
\hline \multirow[t]{2}{*}{$\mathrm{Sr}^{2+}$ Sorbed on HFO, $300^{\circ} \mathrm{K}$ (low loading) ${ }^{16,21}$} & $\mathrm{Sr}-\mathrm{O}$ & 12.62 & 2.64 & 0.015 \\
\hline & $\mathrm{Sr}-\mathrm{Sr}$ & 11.76 & 3.45 & 0.037 \\
\hline \multirow[t]{2}{*}{$\mathrm{Sr}^{2+}$ Sorbed on HFO, $300^{\circ} \mathrm{K}$ (high loading) ${ }^{16,21}$} & $\mathrm{Sr}-\mathrm{O}$ & 12.06 & 2.61 & 0.015 \\
\hline & $\mathrm{Sr}-\mathrm{Fe}$ & 2.52 & 3.40 & 0.034 \\
\hline \multirow[t]{2}{*}{$\mathrm{Sr}^{2+}$ Sorbed on HFO, $300^{\circ} \mathrm{K}$ (high loading) ${ }^{16,21}$} & $\mathrm{Sr}-\mathrm{O}$ & 12.06 & 2.61 & 0.010 \\
\hline & $\mathrm{Sr}-\mathrm{Sr}$ & 2.52 & 3.40 & 0.034 \\
\hline \multirow[t]{2}{*}{$\mathrm{Sr}^{2+}$ Sorbed on HMO, RT (low loading) ${ }^{17,21}$} & $\mathrm{Sr}-\mathrm{O}$ & 9.54 & 2.61 & 0.012 \\
\hline & Sr-Mn & 3.70 & 4.21 & 0.025 \\
\hline \multirow[t]{2}{*}{$\mathrm{Sr}^{2+}$ Sorbed on HMO, RT (low loading) ${ }^{17,21}$} & Sr-O & 9.97 & 2.61 & 0.013 \\
\hline & $\mathrm{Sr}-\mathrm{Sr}$ & 3.63 & 3.89 & 0.015 \\
\hline \multirow[t]{2}{*}{$\mathrm{Sr}^{2+}$ Sorbed on HMO, RT (moderate loading) ${ }^{17,21}$} & $\mathrm{Sr}-\mathrm{O}$ & 10.60 & 2.55 & 0.014 \\
\hline & Sr-Mn & 3.93 & 4.07 & 0.029 \\
\hline \multirow[t]{2}{*}{$\mathrm{Sr}^{2+}$ Sorbed on HMO, RT (moderate loading) ${ }^{17,21}$} & $\mathrm{Sr}-\mathrm{O}$ & 12.25 & 2.54 & 0.018 \\
\hline & $\mathrm{Sr}-\mathrm{Sr}$ & 10.12 & 3.81 & 0.036 \\
\hline \multirow[t]{2}{*}{$\mathrm{Sr}^{2+}$ Sorbed on HMO, RT (high loading) ${ }^{17,21}$} & $\mathrm{Sr}-\mathrm{O}$ & 11.26 & 2.56 & 0.017 \\
\hline & Sr-Mn & 5.46 & 4.14 & 0.034 \\
\hline \multirow[t]{2}{*}{$\mathrm{Sr}^{2+}$ Sorbed on HMO, RT (high loading) ${ }^{17,21}$} & $\mathrm{Sr}-\mathrm{O}$ & 12.18 & 2.57 & 0.019 \\
\hline & $\mathrm{Sr}-\mathrm{Sr}$ & 5.46 & 4.14 & 0.044 \\
\hline $\mathrm{Sr}^{2+}$ Sorbed on Silica at RT ${ }^{19}$ & $\mathrm{Sr}-\mathrm{O}$ & 9.7 & 2.57 & 0.013 \\
\hline
\end{tabular}

Table 4-2 First coordination shell $\mathrm{Sr}-\mathrm{O}$ fit literature data for dissolved $\mathrm{Sr}^{2+}$. The magnitude of the Debye-Waller Factor [represented in as $\left.\sigma^{2}[\AA]^{2}\right]$ indicates the variation of the bond length determination.

\begin{tabular}{|c|c|c|c|c|}
\hline Sample Type & Interaction & $\mathbf{C N}$ & Distance $\mathbf{r}[\AA]$ & $\sigma^{2}[\AA]^{2}$ \\
\hline $0.0001 \mathrm{M} \mathrm{SrCl}_{2(\mathrm{aq})}{ }^{20}$ & $\mathrm{Sr}-\mathrm{O}$ & 9 & 2.61 & 0.030 \\
\hline $0.0001 \mathrm{M} \mathrm{SrCl}_{2(\mathrm{aq})} 18$ & $\mathrm{Sr}-\mathrm{O}$ & $9-10$ & 2.65 & 0.011 \\
\hline $0.2 \mathrm{M} \mathrm{Sr}$ at $\mathrm{RT}^{24}$ & $\mathrm{Sr}-\mathrm{O}$ & 7.3 & 2.62 & 0.0009 \\
\hline $0.2 \mathrm{M} \mathrm{Sr}\left(\mathrm{NO}_{3}\right)_{2(\mathrm{aq})}{ }^{24}$ & $\mathrm{Sr}-\mathrm{O}$ & 7.3 & 2.62 & Not reported \\
\hline
\end{tabular}


O'Day et al. (2000) examined the environment of $\mathrm{Sr}^{2+}$ in zeolite (heulandite) cavities and observed $\mathrm{Sr}^{2+}$ existed as a hybrid-like species that maintains a partially-hydrated coordination sphere as well as has $\mathrm{Si} / \mathrm{Al}$ in the second coordination shell. ${ }^{18}$ These data indicate that $\mathrm{Sr}^{2+}$ is sorbs as a hydrated species and forms a bond with the zeolite surface in $\mathrm{Ca}^{2+}$ (B-channel) sites. There are two other types of cavities/channels in the heulandite, which contain $\mathrm{Na}^{+}$and $\mathrm{K}^{+}$sites but the Sr-EXAFS data indicate that the Sr-O bond distances are either too short or too long to accommodate the sorption of a hydrated $\mathrm{Sr}^{2+}$ species at these other sites.

\subsubsection{Sr-XANES Studies with Sr-loaded MST Samples.}

The XANES spectra are typically used to provide information on the average oxidation state of the element of interest. In HLW salt solutions, oxidation state information for $\mathrm{Sr}$ is not of concern because solution $\mathrm{Sr}$ is found as the $\mathrm{Sr}^{2+}$ species. No reductionoxidation reactions that could influence the valence of $\mathrm{Sr}$ are likely under the conditions of this study. However, Sr-XANES analyses will be conducted because these studies can provide useful information on the structural environment of the element of interest. Small shifts $(\mathrm{a}$ few $\mathrm{eV}$ ) in XANES absorption edge energies can occur when a metal undergoes a change in average oxidation state. As noted in the methods, the XAFS data were taken at beamlines X23a2 and X26a. The origin of the data is presented in the following figures or in figure captions.

The Sr-XANES data for the $\mathrm{Sr}^{2+}$-loaded MST solids studies are shown in Figure 4-1. These XANES data indicate that the samples are similar. They also resemble that of the solution $\mathrm{Sr}^{2+}$ (Figure 4-2). However, the XANES spectra for the samples do not resemble that of solid phase $\mathrm{Sr}^{2+}$ standards as shown in Figure 4-3. ${ }^{25}$ This is evidenced by the difference in such features as white-line maxima and the position of the post edge oscillations. 
WSRC-TR-2001-00245, REVISION 0

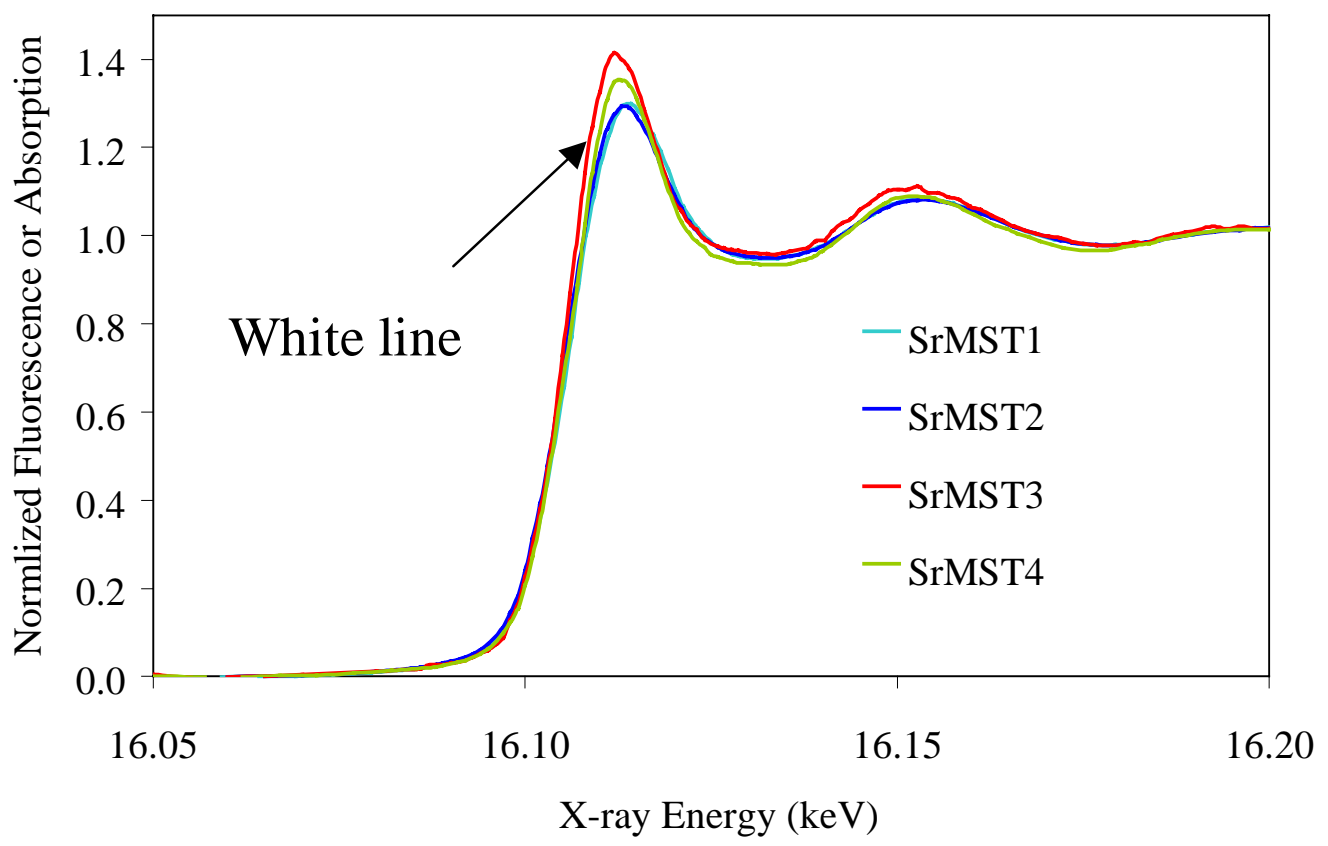

Figure 4-1 Plot of the Sr-XANES data for the $\mathrm{Sr}^{2+}$-loaded MST samples. We obtained the SrMST4 data at beamline X23a2; and acquired the remaining data at beamline X26a.

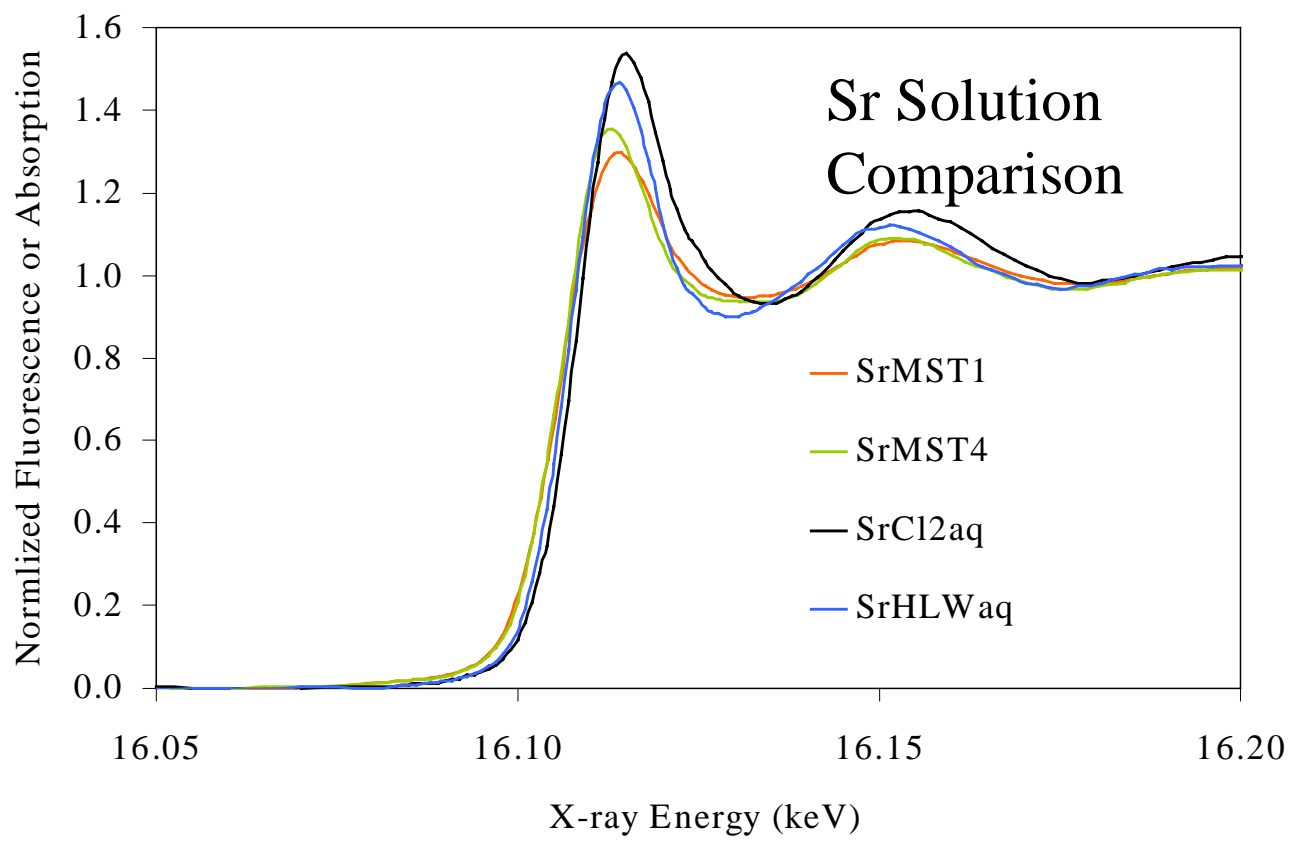

Page 14 of 43 
Figure 4-2 Plot of the Sr-XANES data for two of the $\mathrm{Sr}^{2+}$-loaded MST samples and the two $\mathrm{Sr}^{2+}$-containing solutions. We acquired the SrMST4 data at beamline X23a2 and acquired

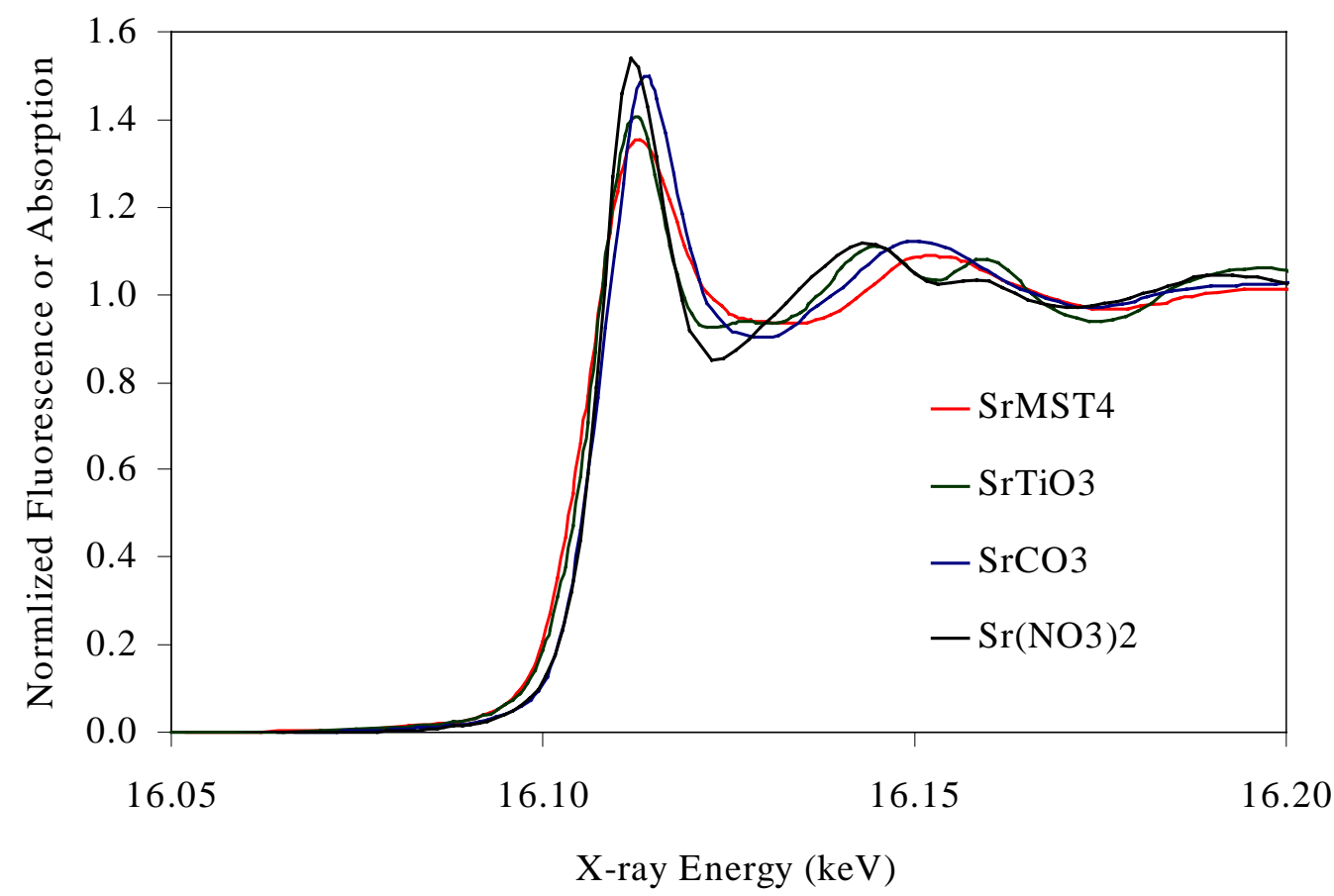

the remaining data at beamline $\mathrm{X} 26 \mathrm{a}$.

Figure 4-3 Plot of the Sr-XANES data for a $\mathrm{Sr}^{2+}$-loaded MST sample and the $\mathrm{Sr}^{2+}$ containing solids. We acquired the data for $\mathrm{Sr}$ standards at beamline X26a and acquired data for SrMST4 at beamline X23a2.

\subsection{EXAFS Analyses.}

In simple terms, chi data (the plot of the wavevector in reciprocal space) show the oscillation patterns (both constructive and destructive interference patterns) of the atoms in the neighbor environment of the element of interest. The chi data represent part of the photoelectron wave that can be defined by the EXAFS equation. ${ }^{5,6,26}$ The EXAFS equation is shown in a highly simplified form below (see list of definitions for explanation of equation terms).

$$
\operatorname{Chi}(\mathrm{k})=\frac{\mathrm{F}(\mathrm{k}) * \mathrm{~N} * \mathrm{~S}}{\mathrm{k} * \mathrm{R}^{2}} S_{0}^{2} e^{\left(-2 * \mathrm{k}^{3} \sigma^{2}\right)} \sin [2 * \mathrm{k} * \mathrm{R}+\delta(\mathrm{K})]
$$


As noted in the methods, the XAFS data were taken at beamlines X23a2 and X26a. The location of data acquisition is noted in the figure or figure caption.

\subsubsection{The $k^{3-}$ weighted Chi Data for the Sr Standards and Sr-Loaded MST.}

The $k^{3}$-weighted chi data (the EXAFS wavevector component) for the four $\mathrm{Sr}^{2+}-$ loaded MST treatments and the dilute $\mathrm{Sr}^{2+}$ in aqueous solution are shown in Figure 4-4. The EXAFS data for the four $\mathrm{Sr}^{2+}$-loaded MST samples were very similar. The chi data indicate the environment around the $\mathrm{Sr}^{2+}$ sorbed on MST is unlike that of $\mathrm{Sr}^{2+}$ in an aqueous solution - as evidenced by the substantial difference in the amplitudes of the sample and solution data at low chi. This difference in amplitude could be indicative of unlike first-shell coordination numbers. The sample spectra also indicate that the first shell bond distance is slightly shorter than that of the $\mathrm{Sr}^{2+}$ in an aqueous solution. The shift in the phase indicates a shorter bond length exists for the sample spectra relative to that of the $\mathrm{Sr}^{2+}$ in aqueous solution. This shift is most visible in the low energy portion of the chi data (Figure 4-4).

The chi data for the $\mathrm{Sr}^{2+}$-loaded MST samples were also unlike that of $\mathrm{Sr}^{2+}$ in HLW salt simulant and in $\mathrm{SrCO}_{3(\mathrm{~s})}$ (Figure 4-5). One of the differences is there are beat nodes in the spectra for the $\mathrm{Sr}^{2+}$ in the HLW salt solution and in $\mathrm{SrCO}_{3(\mathrm{~s})}$ and but they are absent in the spectra for the of $\mathrm{Sr}^{2+}$-loaded MST samples (Figure 4-4 and Figure 4-5). Figure 4-6 shows the chi data for the $\mathrm{SrTiO}_{3(\mathrm{~s})}$ that was acquired at beamlines X23a2 and X26a. The data compare well and they indicate that the $\mathrm{Sr}^{2+}$ in the $\mathrm{Sr}^{2+}$-loaded MST samples is not similar to that of the $\mathrm{Sr}^{2+}$ in the $\mathrm{SrTiO}_{3(\mathrm{~s})}$. This solid has a cubic structure and although the chi spectra appear to have light atoms (such as $\mathrm{O}$ ) (as evidenced by the envelope at low chi which starts at $3 \AA^{-1}$ and disappears at around $8 \AA^{-1}$ ), the spectra for $\mathrm{SrTiO}_{3(\mathrm{~s})}$ do not resemble that of the MST samples (compare Figure 4-4 with Figure 4-6). There are obvious differences in the phase and amplitude of the spectra for the MST and the $\mathrm{SrTiO}_{3(\mathrm{~s}) \text {. }}$. Data for $\mathrm{Sr}\left(\mathrm{NO}_{3}\right)_{2(\mathrm{~s})}$ (in search of structural data) were also very different than that the $\mathrm{Sr}^{2+}$-loaded MST (compare Figure 4-4 with Figure 4-7). 


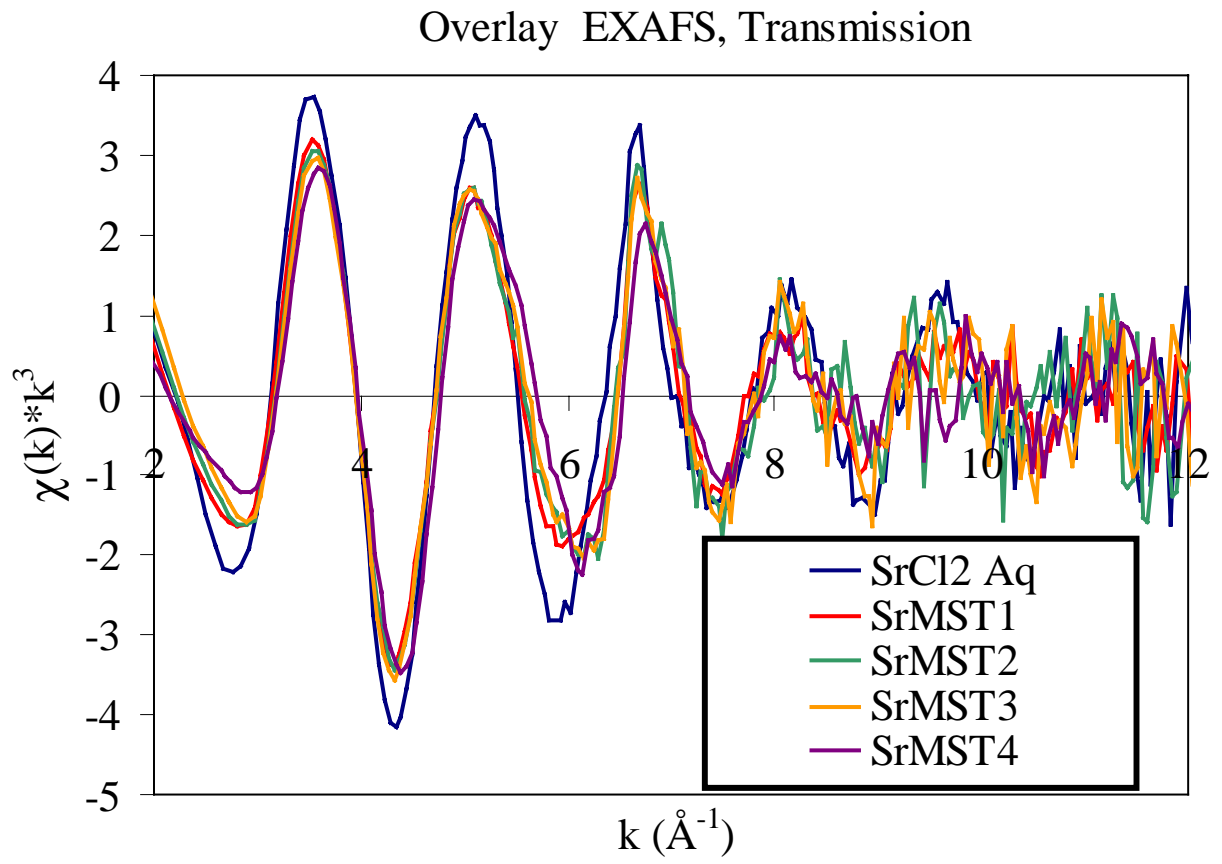

Figure 4-4 The $k^{3}$-weighted chi data (the plot of the wavevector in reciprocal space) for the $\mathrm{Sr}^{2+}$-loaded MST samples. We collected the data at beamline X26A-with the exception of that for SrMST4, which we collected at X23a2.

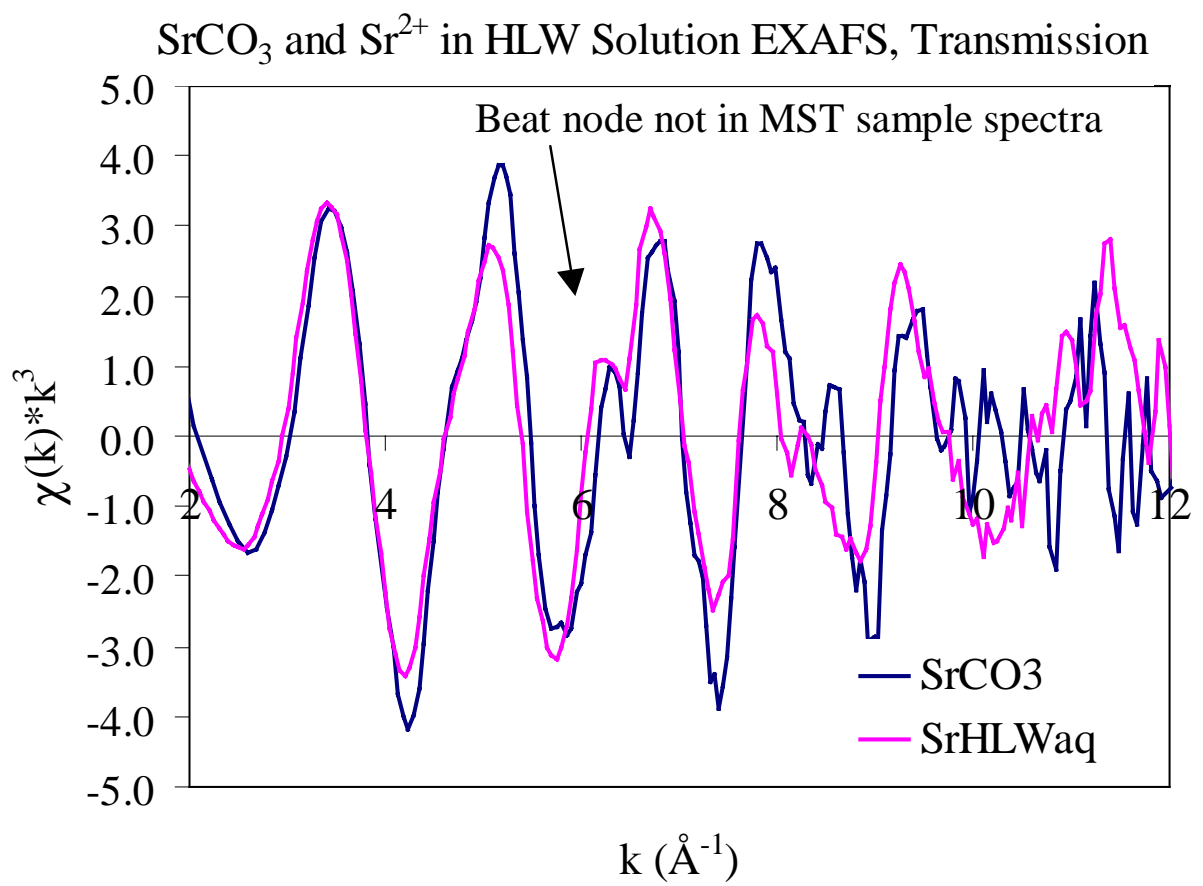

Figure 4-5 The $k^{3}$-weighted chi data for $\mathrm{Sr}^{2+}$ in $\mathrm{SrCO}_{3(\mathrm{~s})}$ and $\mathrm{SrHLW}_{(\mathrm{aq})}$. We collected the data at beamline X26A. 


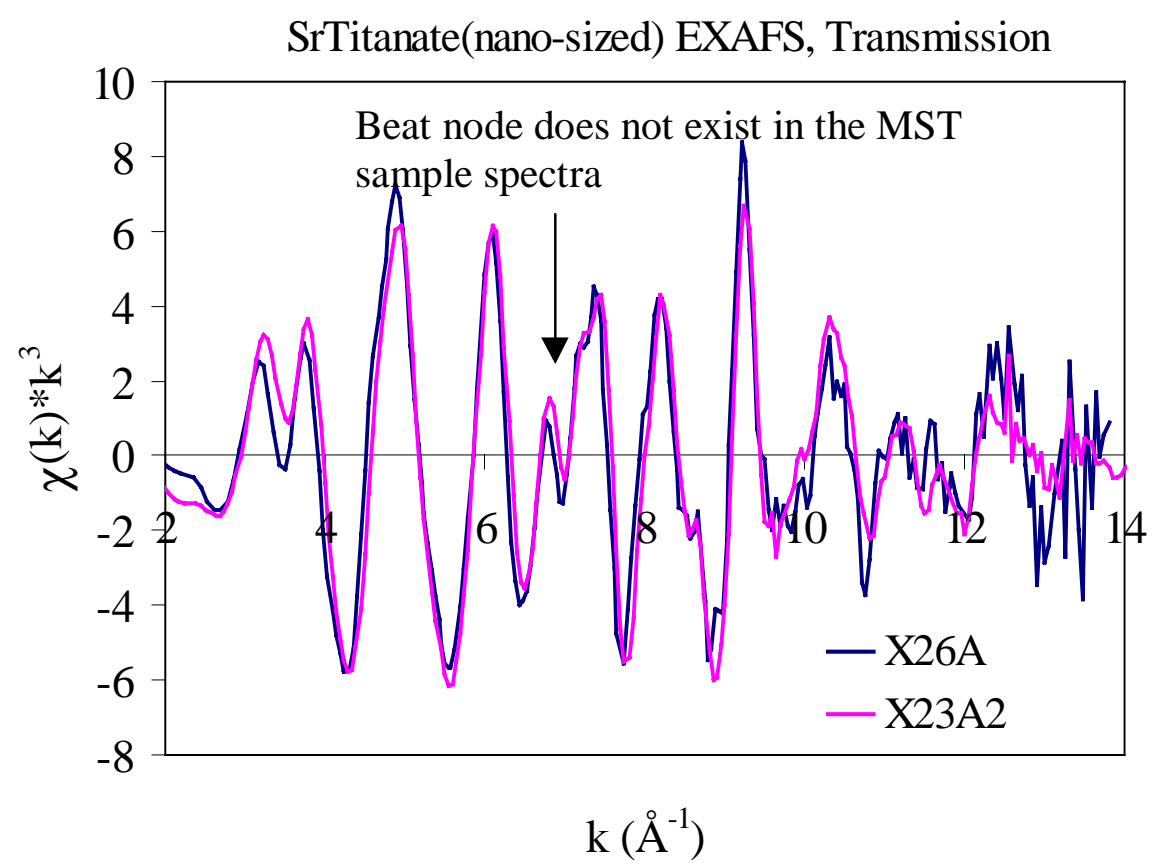

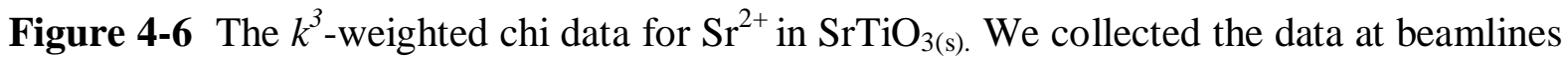
$\mathrm{X} 26 \mathrm{a}$ and X23a2.

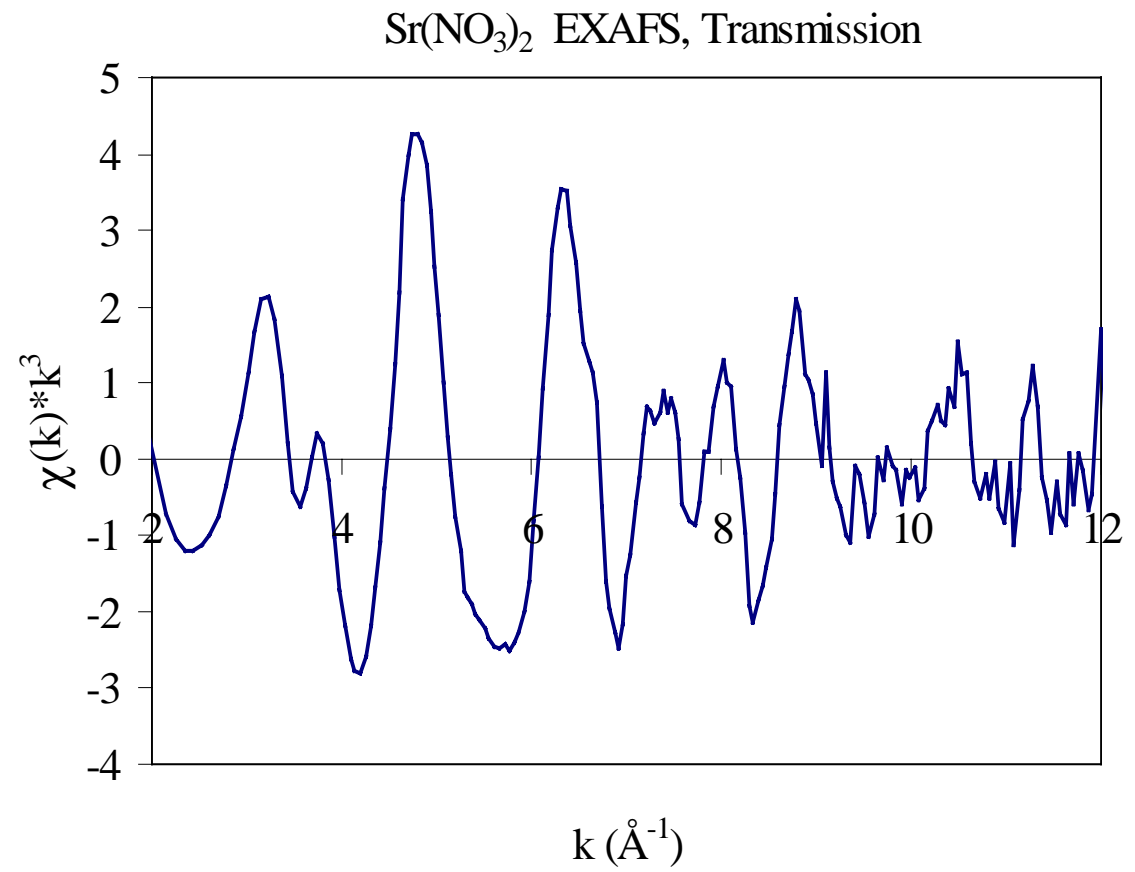

Figure 4-7 The $k^{3}$-weighted chi data $\mathrm{Sr}^{2+}$ in $\mathrm{Sr}\left(\mathrm{NO}_{3}\right)_{2(\mathrm{~s})}$ We collected the data at beamline X26a. 
WSRC-TR-2001-00245, REVISION 0

\subsubsection{Fourier-Transformed Data for the Dilute $\mathrm{SrCl}_{2} \mathrm{Solution}_{\text {and }} \mathrm{Sr}^{2+}$-loaded MST.}

An overlay of the Fourier-transformed (FT) radial distribution function (RDF) plots for the $\mathrm{Sr}^{2+}$ in dilute solution and the four $\mathrm{Sr}^{2+}$-containing MST samples is shown in Figure 4-8. In simpler terms, these plots give radial information about the radial atom "density" around the $\mathrm{Sr}^{2+}$ in the sample. Figure 4-9 shows the similarities between each of the $\mathrm{Sr}^{2+}$ containing MST samples and the dilute $\mathrm{Sr}^{2+}$ solution. The shoulder feature on the low $\mathrm{R}$ side of the primary peak in the FT data could not be included in our fits of the first shell interactions in any of our data. Comparing our FT data with that of the literature, we find that this lack of fit is common to most all of the FT Sr-EXAFS data and no explanation of this shoulder feature has been provided by these references.

As discussed in Section 4.2.1, there were substantial differences observed between the chi spectra for $\mathrm{Sr}^{2+}$-sorbed on MST and that of the $\mathrm{Sr}^{2+}$ in $\mathrm{HLW}$ solution and $\mathrm{Sr}^{2+}$ in the solid phase standards. Therefore, $\mathrm{Sr}^{2+}$ in dilute solution was deemed the best standard from which to fit the spectra of the MST samples. Model fits and transforms were only performed on the spectra for three of the four MST samples. Fits for the SrMST2 treatment were not performed due to insufficient data. The RDF distribution plots for the $\mathrm{Sr}^{2+}$ in dilute solution standard and three of the four $\mathrm{Sr}^{2+}$-containing MST samples are shown in Figure 4-10 through Figure 4-15. Two FT RDF plots are shown per $\mathrm{Sr}^{2+}$-loaded MST treatment. These plots represent two mathematical approaches to the model fits. One method uses the standard EXAFS equation. The second method uses the EXAFS equation and a third cumulant (C3) term. As previously discussed the rationale for including the $\mathrm{C} 3$ term is discussed in the works of O'Day et al. (2000) and others. ${ }^{17,18}$ This additional term is used to account for the anharmonicity of low atomic weight back-scatterers. ${ }^{17,18}$

Our analyses used the value obtained for the $\mathrm{CN}$ of solution $\mathrm{Sr}^{2+}(\sim 9.5)$ by O'Day et al. (2000) and those values were used to obtain an amplitude reduction factor. The obtained amplitude reduction factors for both $\mathrm{Sr}^{2+}$ sorbed on MST and $\mathrm{Sr}^{2+}$ (aq) were fixed. This gave a $\mathrm{CN}$ for $\mathrm{Sr}^{2+}$ to $\mathrm{O}$ of 7 for $\mathrm{Sr}^{2+}$-sorbed on MST that was considerably lower than that which we determined for $\mathrm{Sr}^{2+}{ }_{\text {(aq) }}(\mathrm{CN}=9)$ (shown in Figure 4-15 and Table 4-3). This decrease in the $\mathrm{CN}$ is significant-indicating that $\mathrm{Sr}^{2+}$ undergoes dehydration upon sorption to MST.

However, when the third cumulant term (C3) is included in our data analyses, the first shell $\mathrm{CN}$ for $\mathrm{Sr}^{2+}$ decreased from about 7 to 10 to about 5 to 7 . Without the use of the third cumulant term, the fitting analyses of the Sr-EXAFS data for $\mathrm{Sr}^{2+}$ in solution indicate the first shell environment for $\mathrm{Sr}^{2+}$ contains roughly 9.5 first shell O atoms at $2.57 \AA$ (Table 4-2). Similar results were obtained when we used the third cumulant in our analyses. Our findings contrast with that in other studies. ${ }^{18}$ O'Day et al. (2000) found that adding the C3 term produced a better fit for solution $\mathrm{Sr}^{2+}$ whereas we did not observed a better fit with the $\mathrm{C} 3$ term for aqueous $\mathrm{Sr}^{2+}$. In conclusion, fits with the $\mathrm{C} 3$ term were substantially better than that without the term. When the $\mathrm{C} 3$ term was included, the magnitude of the Debye-Waller Factor values were lower and the fits were visually better as seen by comparing Fig, 4-10 with Fig, 4-11, Fig. 4-12 with Fig. 4-13 and Fig. 4-14 with Fig. 4-15. 


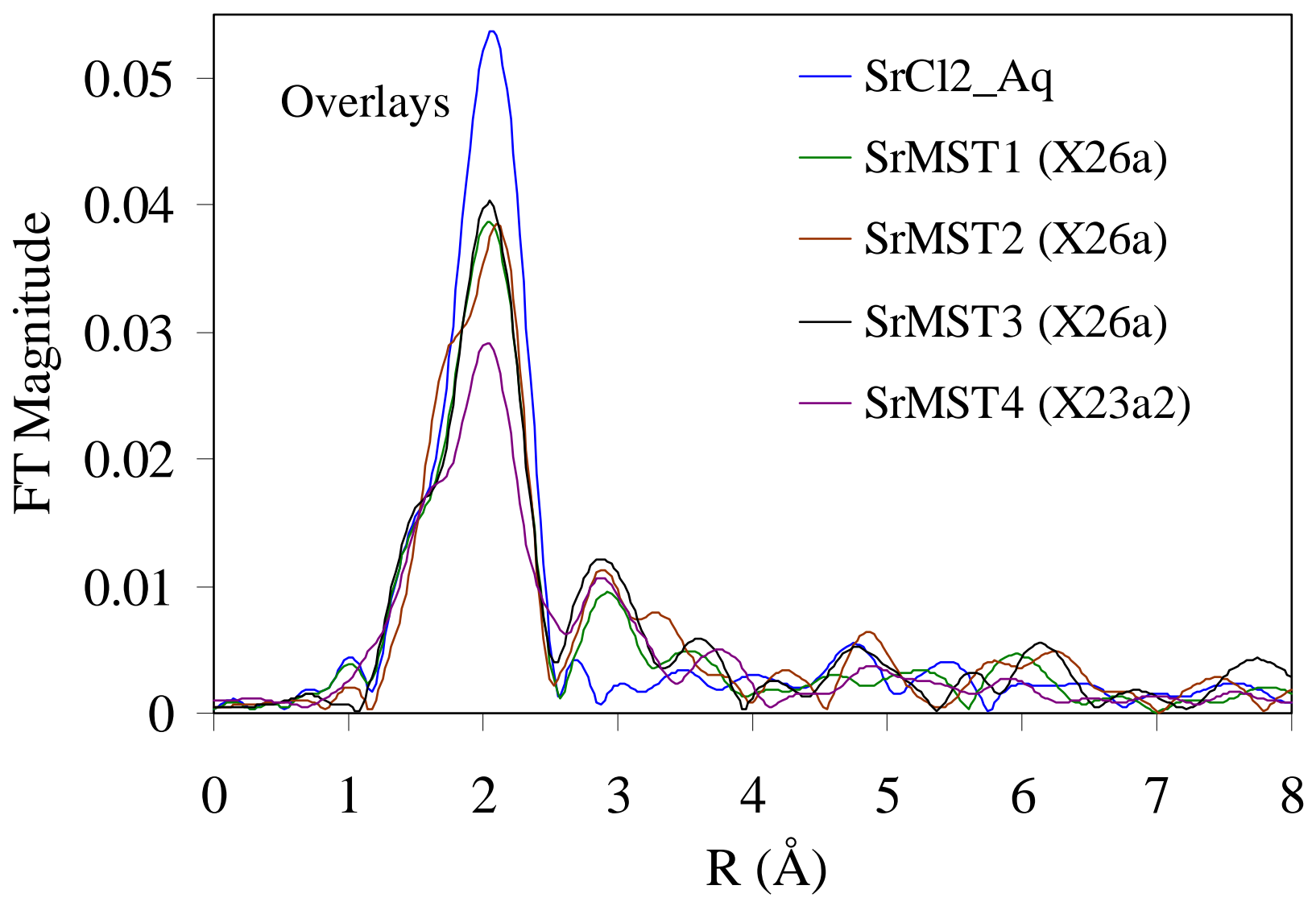

Figure 4-8 FT RDF data for $\mathrm{Sr}^{2+}$-loaded MST samples and the $\mathrm{SrCl}_{2(\text { aq) }}$ standard. 


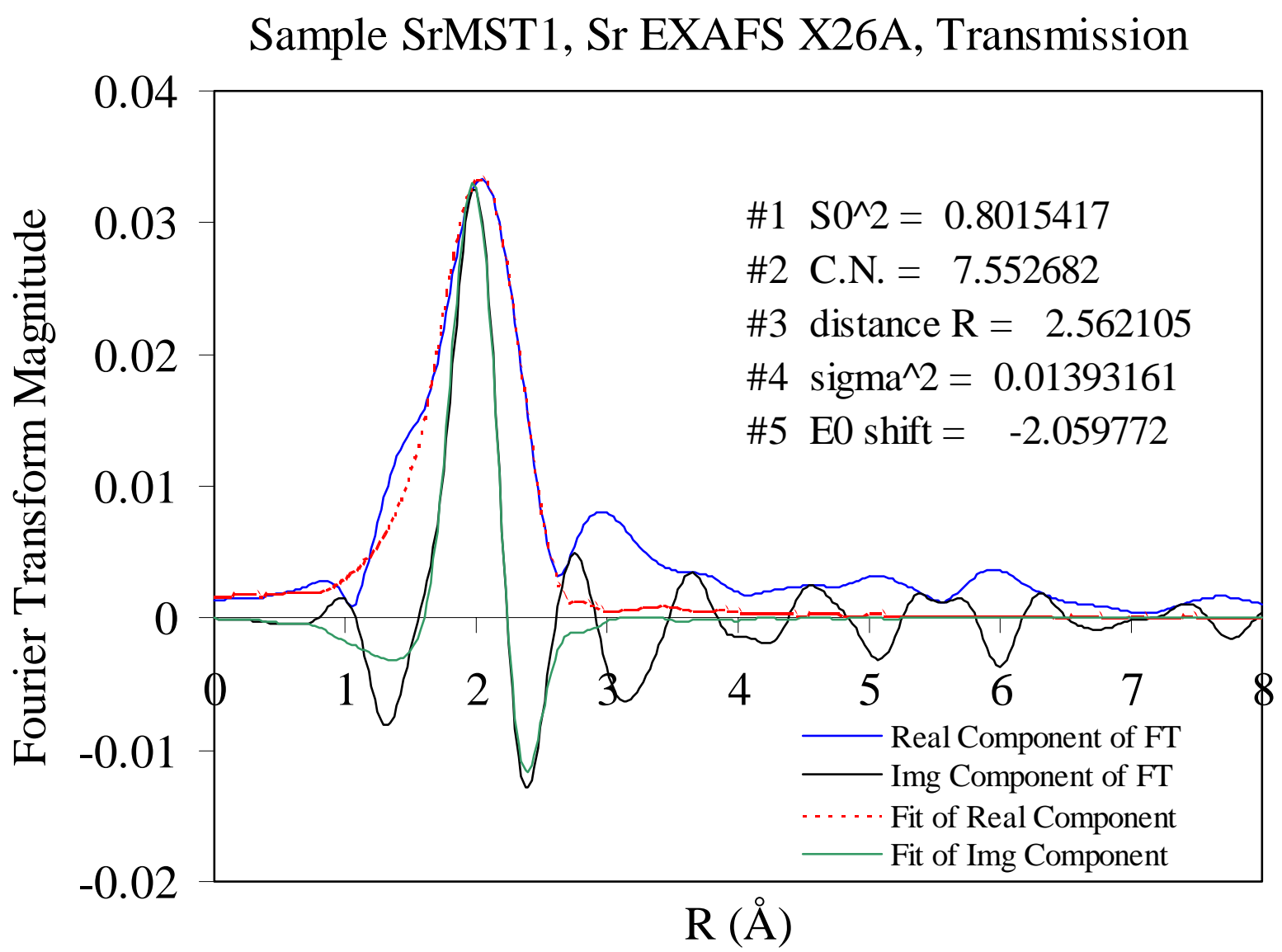

Figure 4-9 FT RDF data and first shell Sr-O model fit data for SrMST1 without the third cumulant term-uncorrected for phase shift. 
Sample SrMST1, Sr EXAFS X26A, Trans. Fit w/3rd Cumulant (C3)

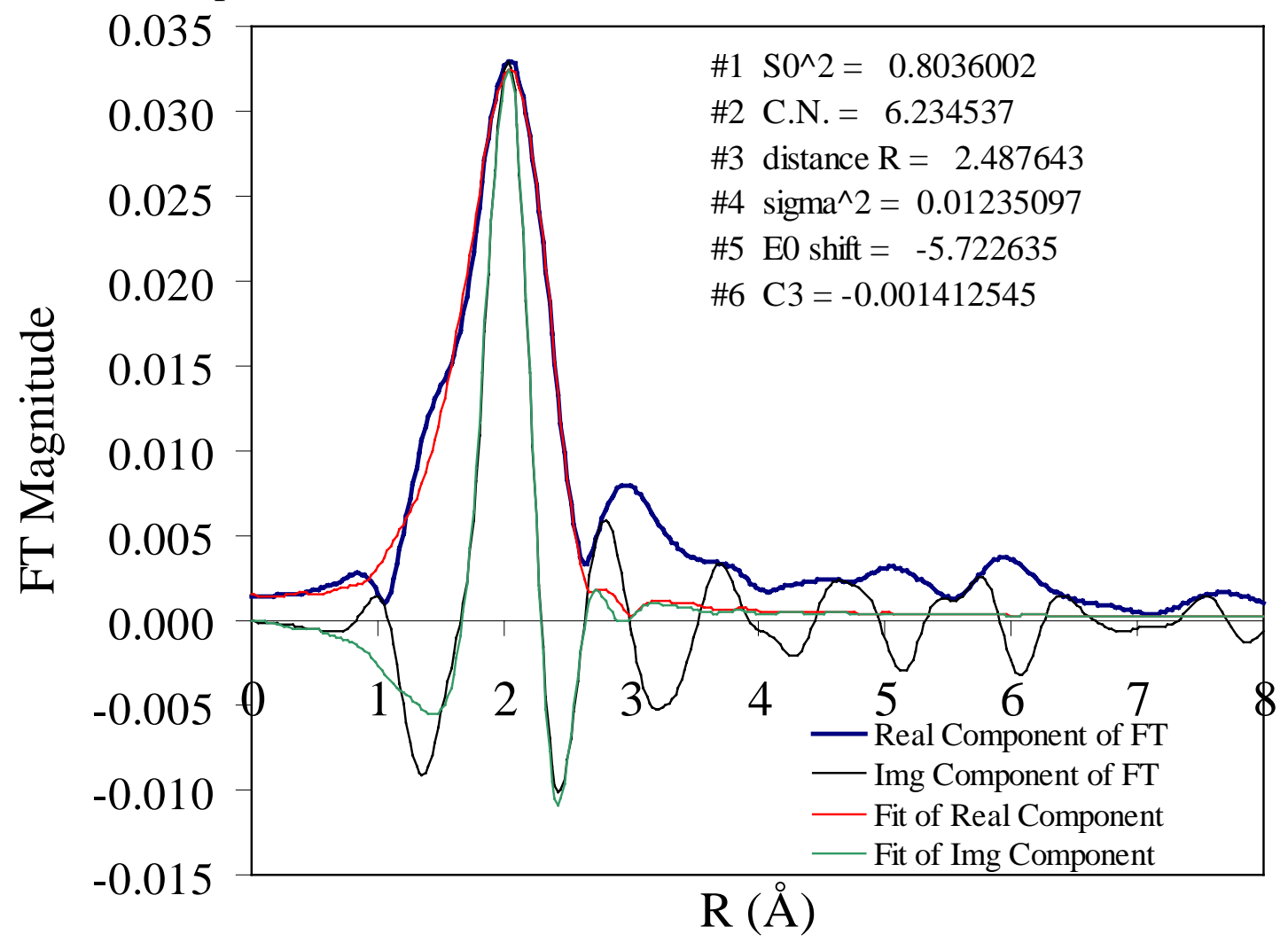

Figure 4-10 FT RDF data and first shell Sr-O model fit data for SrMST1. The third cumulant term was included in the fit-uncorrected for phase shift. 


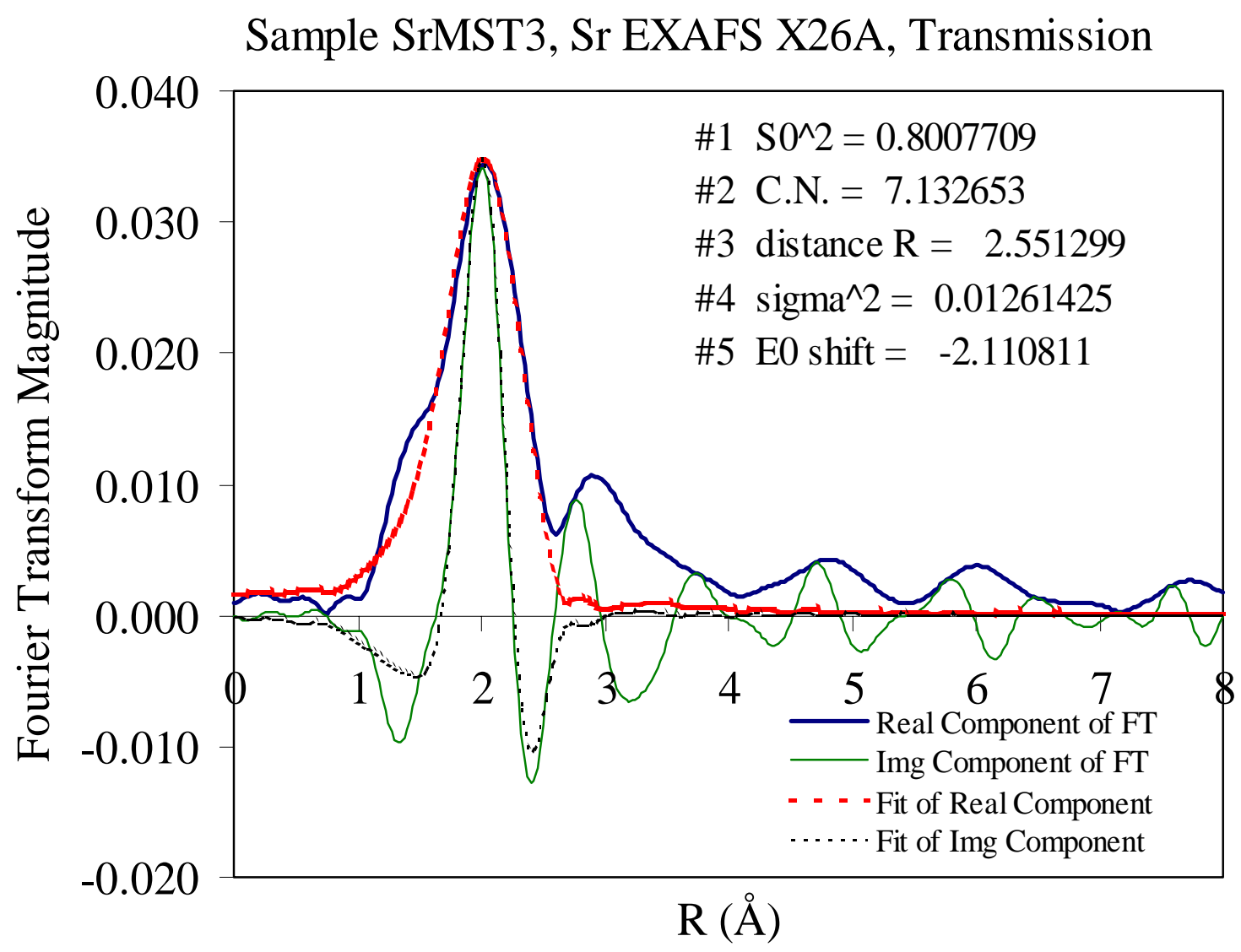

Figure 4-11 FT RDF data and first shell Sr-O model fit data for SrMST3 without the third cumulant term-uncorrected for phase shift. 
Sample SrMST3, Sr EXAFS X26A, Trans. Fit with 3rd Cumulant (C3)

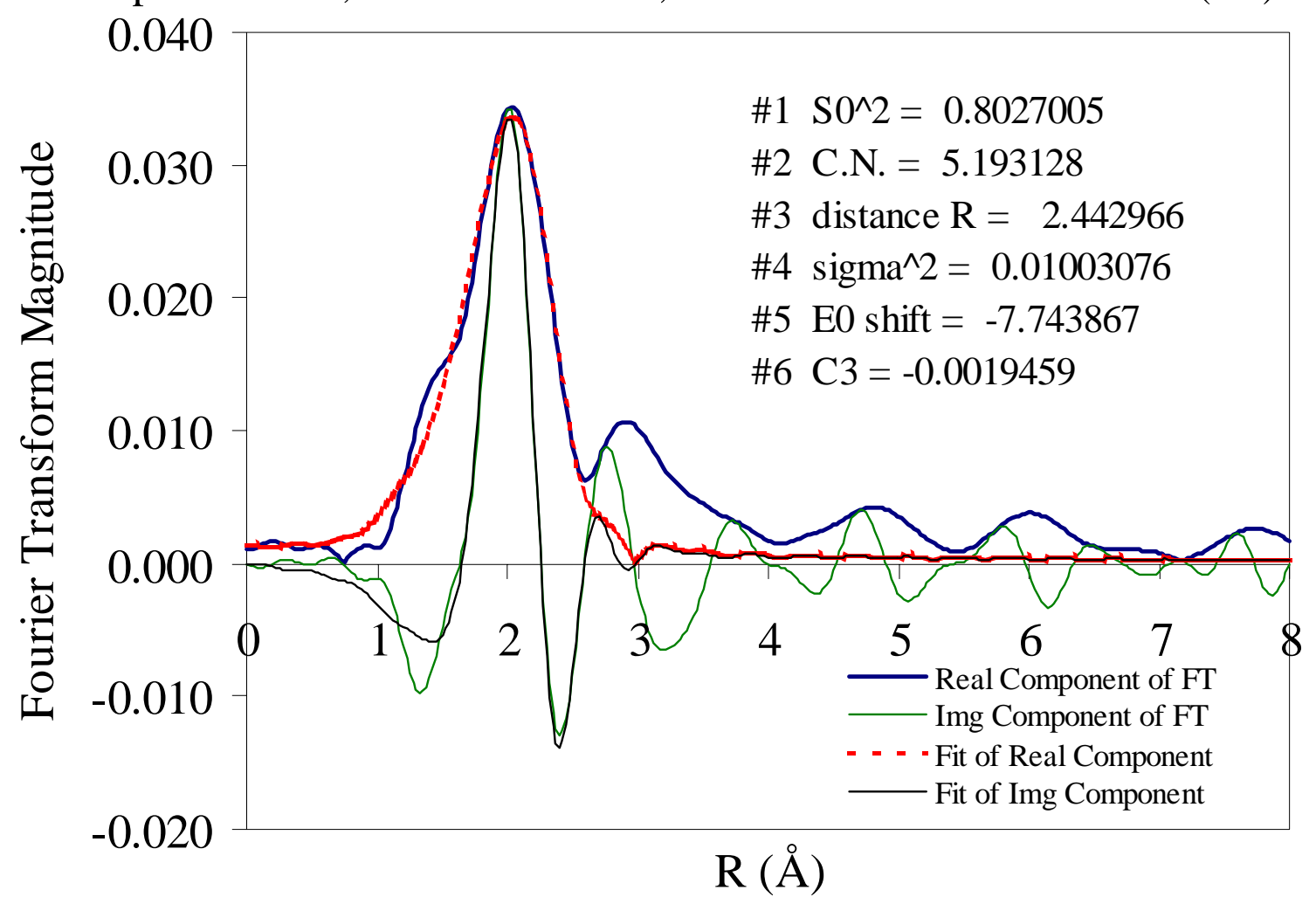

Figure 4-12 FT RDF data and first shell Sr-O model fit data for SrMST3. The third cumulant term was included in the fit—uncorrected for phase shift. 


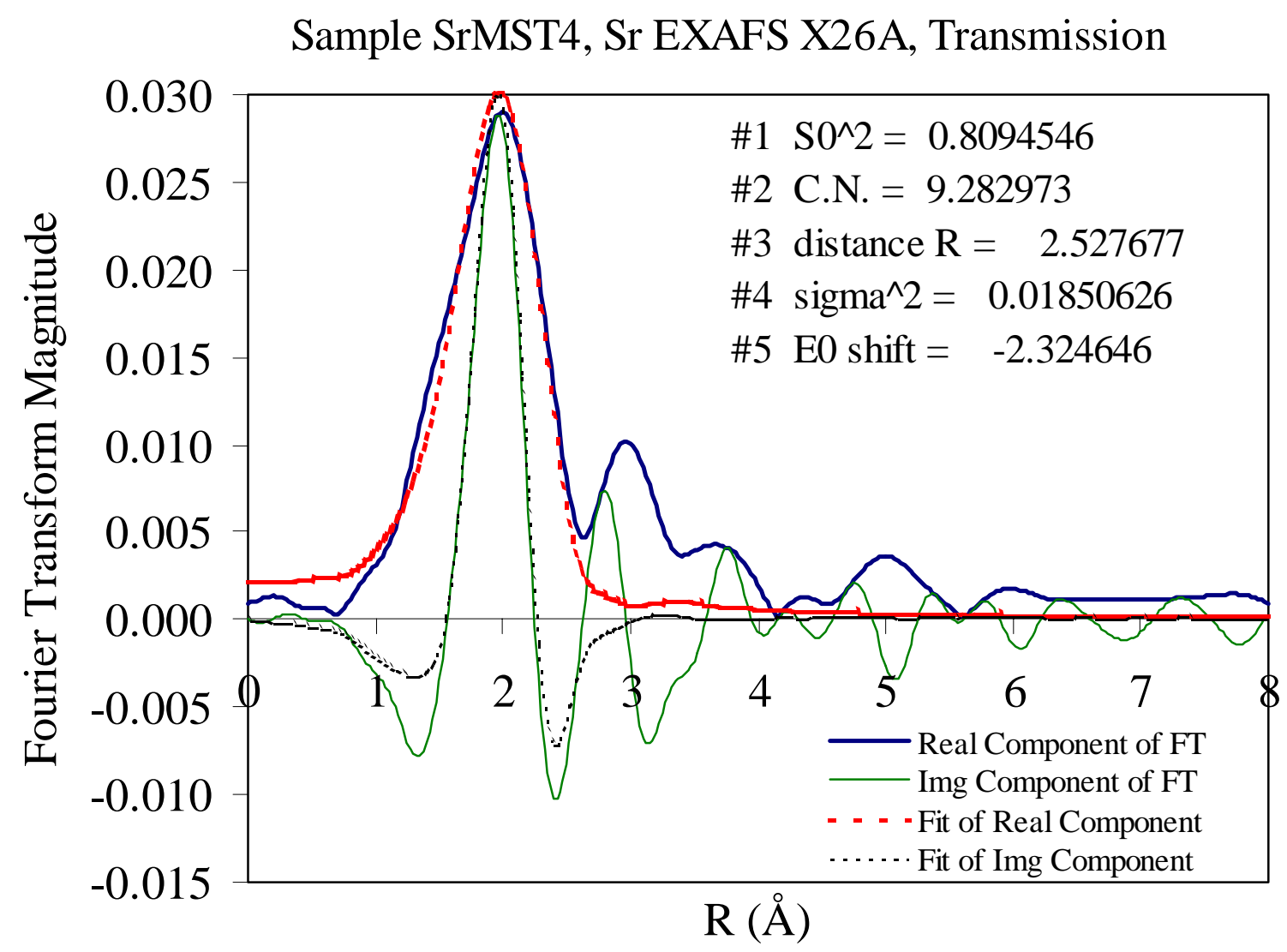

Figure 4-13 FT RDF data and first shell Sr-O model fit data for SrMST4 without the third cumulant term—uncorrected for phase shift. 
Sample SrMST4, Sr EXAFS X23A2, Fluor. Fit with 3rd Cumulant (C3)

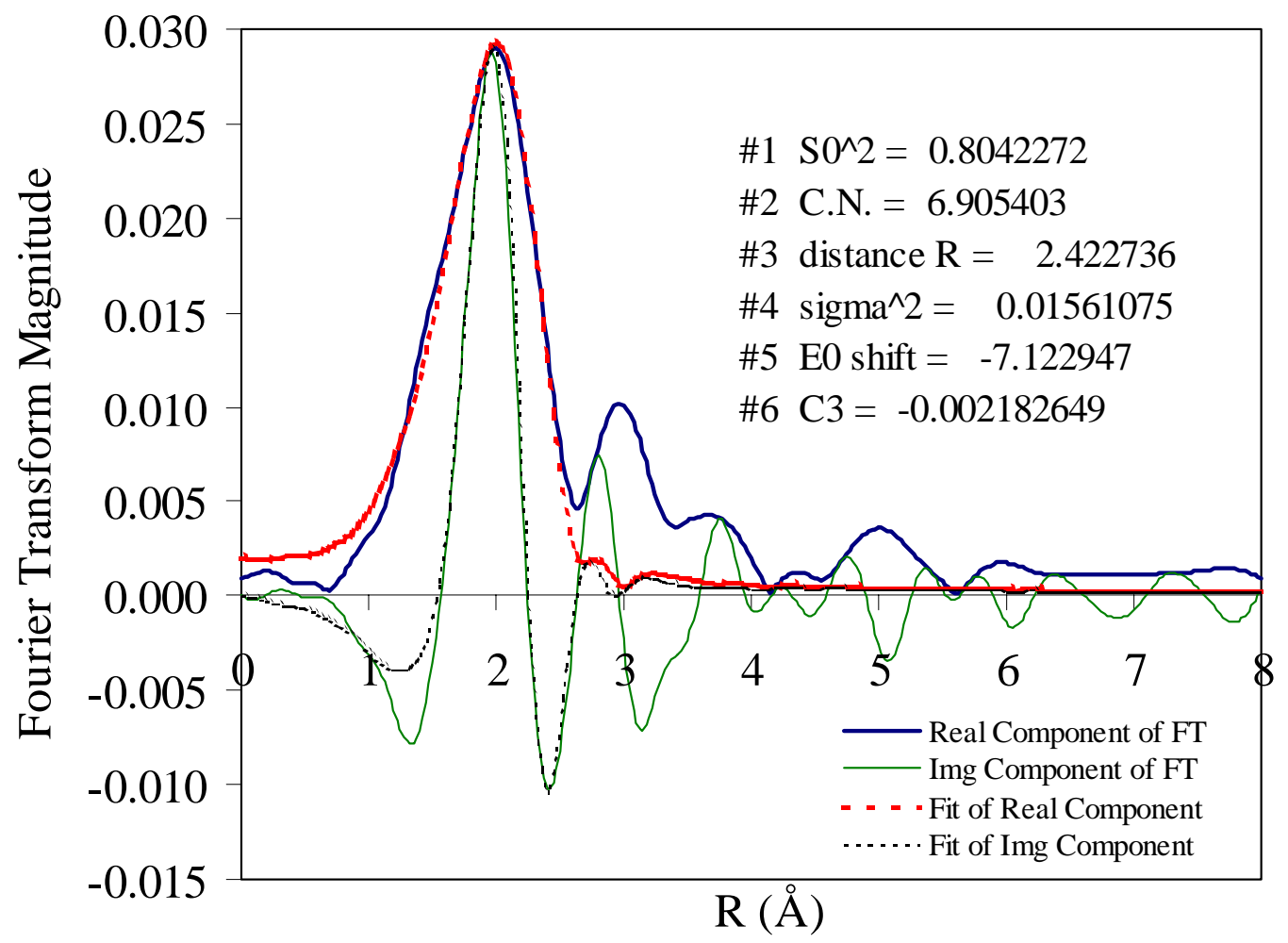

Figure 4-14 FT RDF data and first shell Sr-O model fit data for SrMST4. The third cumulant term was included in the fit—uncorrected for phase shift. 


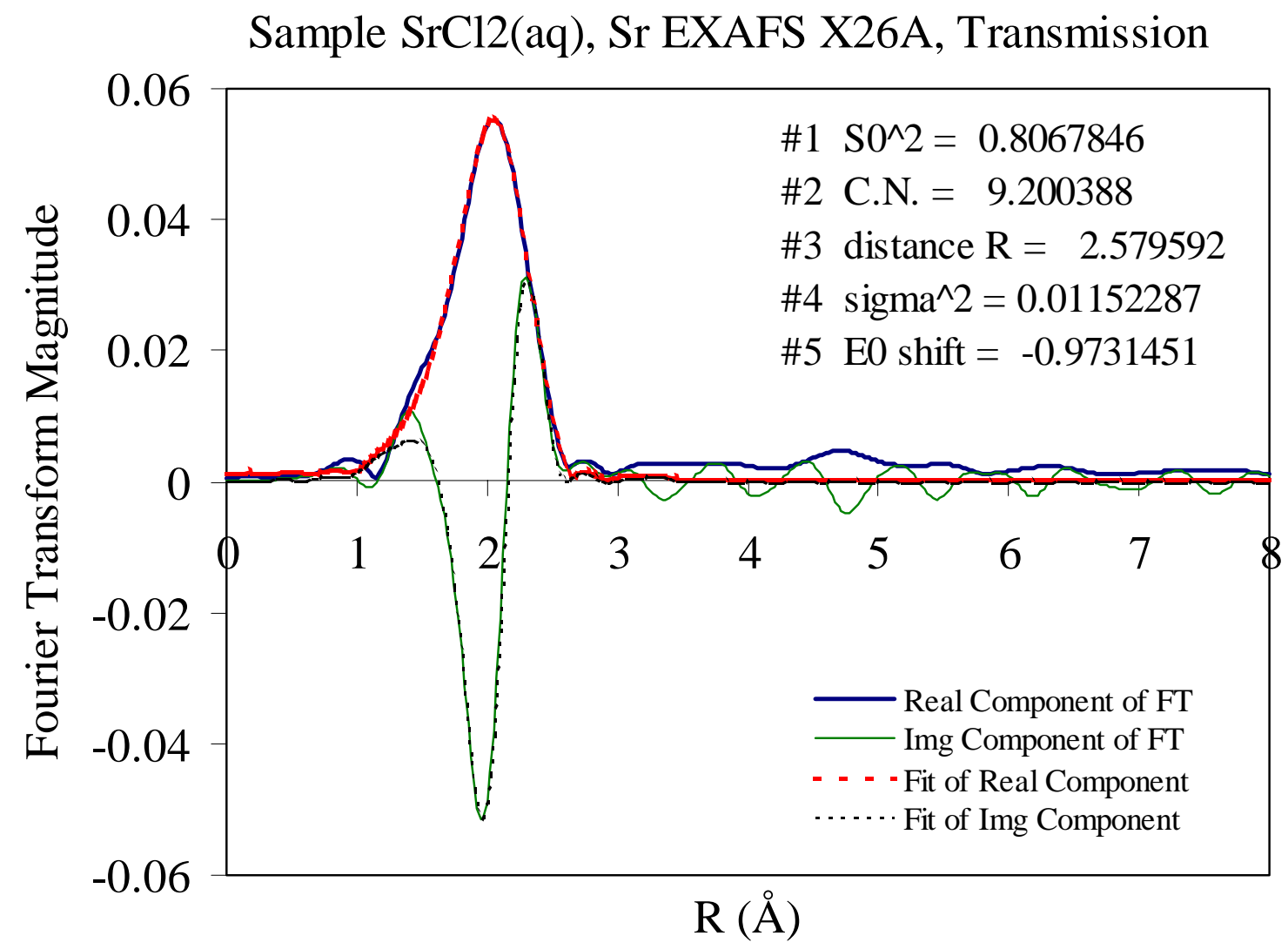

Figure 4-15 FT RDF data and first shell $\mathrm{Sr}-\mathrm{O}$ model fit data for the dilute $\mathrm{SrCl}_{2}$ solution without the third cumulant term-uncorrected for phase shift. 
Table 4-3 Fit results for a first shell Sr-O interaction with and without the third cumulant (C3) term for the $\mathrm{Sr}^{2+}$ sorbed MST samples. Use of the third cumulant term in the fits for $\mathrm{Sr}$ in the dilute $\mathrm{SrCl}_{2 \text { (aq) }}$ solution yielded no differences (in CN or R). Fits for SrMST2 were not performed due to insufficient data quality. DeltaR and deltaCN represent the change in $\mathrm{R}$ and $\mathrm{CN}$ values (respectively) with the inclusion of the $\mathrm{C} 3$ term. The magnitude of the DebyeWaller Factor [represented in as $\left.\sigma^{2}[\AA]^{2}\right]$ indicates the variation of the bond length determination (or spread but not error). It also provides information on goodness of fit-for example, a negative value would indicate a poor fit. A decrease in the $\mathrm{D}-\mathrm{W}$ factor with inclusion of the $\mathrm{C} 3$ term signifies that there is less variance and hence better fit. Addition of the third cumulant (C3) term in the fit accounts for the anharmonicity arising from weak back-scatterers. The addition of this $\mathrm{C} 3$ variable in the fitting process should result in a smaller $\mathrm{D}-\mathrm{W}$ factor. Without the $\mathrm{C} 3$ term, the $\mathrm{D}-\mathrm{W}$ factor is overestimated.

\begin{tabular}{|c|c|c|c|c|c|c|}
\hline & Interaction & $\mathbf{C N}$ & $\mathbf{R}(\AA)$ & $\sigma^{2}[\AA]^{2}$ & deltaR & deltaCN \\
\hline SrCl $_{2(a q)}$ & Sr-O & 9.5 & 2.57 & 0.0115 & NA & NA \\
\hline SrMST1 & Sr-O & 7.6 & 2.55 & 0.0139 & 0.6 & 1.4 \\
\hline SrMST1 + C3 & Sr-O & 6.2 & 2.49 & 0.0123 & & \\
\hline SrMST2 & Sr-O & No Fits & No Fits & No Fits & No Fits & No Fits \\
\hline SrMST2 + C3 & Sr-O & No Fits & No Fits & No Fits & No Fits & No Fits \\
\hline SrMST3 & Sr-O & 7.1 & 2.55 & 0.0126 & 0.11 & 1.9 \\
\hline SrMST3 + C3 & Sr-O & 5.2 & 2.44 & 0.010 & & \\
\hline SrMST4 & Sr-O & 9.3 & 2.53 & 0.0185 & 0.11 & 2.4 \\
\hline SrMST4 + C3 & Sr-O & 6.9 & 2.42 & 0.0156 & & \\
\hline
\end{tabular}

The magnitude of the Debye-Waller Factor [represented in as $\left.\sigma^{2}[\AA]^{2}\right]$ indicates the variation of the bond length determination (or spread but not error). It also provides information on goodness of fit-for example, a negative value would indicate a poor fit. A decrease in the $\mathrm{D}-\mathrm{W}$ factor with inclusion of the $\mathrm{C} 3$ term signifies that there is less variance and hence better fit.

\subsubsection{Higher Shell Fits for Sr-Ti and Sr-O Interactions.}

The fits were performed in chi space because this provided better separation of the atoms in the higher shells. The higher shell fitting process began with sample SrMST1 by fitting for a second shell $\mathrm{Sr}-\mathrm{O}$ interaction with and without the third cumulant term (fit results shown in Table 4.4) but these fits were not adequate. Most of the attempted fits (shown in the APPENDIX) for SrMST1 were unsatisfactory—as shown in Figures 8-1 through 8-7 and discussed below. [Note: the figures show back-transformed (Fourier-filtered) higher shell data that do not contain the first shell Sr-O interactions.] 
Fits that included a second shell Sr-Ti interaction with and without the C3 term and these fits were not satisfactory. Third shell fits for a Sr-O interaction were attempted with and without the $\mathrm{C} 3$ term and these fits were not satisfactory. Third shell fits with a Sr-Ti interaction did not converge. A combination of a single second shell Sr-Ti interaction and a third shell Sr-O interaction were better at describing the data but the most successful fits were obtained by fitting two second shell Sr-Ti interactions and a third shell Sr-O interaction-as shown in Figure 4-16. For the SrMST1 sample, our attempts to fit first shell $\mathrm{Sr}-\mathrm{Sr}$ interactions were not successful (i.e., they did not converge).

The EXAFS data for the MST samples were so similar, fits were only performed for the SrMST3 and SrMST4 data using two second shell Sr-Ti interactions and a single third shell Sr-O interaction (fits shown in Figures 4-17 and 4-18). Model fits for Ti in the second shell of the $\mathrm{Sr}^{2+}$ for the remaining SrMST samples produced similar results (SrMST1, SrMST3 and SrMST4 as shown in Table 4-4). Fits for Ti in the second coordination shell for $\mathrm{Sr}^{2+}$ (Table 4-4) typically indicate the presence of two or more Ti atoms between $3.42 \AA$ and $3.63 \AA$-suggesting more than one $\mathrm{TiO}_{6}$ octahedron (Figure 4-17) is present in the local environment. The radial distances of higher shell $\mathrm{O}$ atoms ranged from 3.9 to $4.01 \AA$.

There is considerable spread in the third shell $\mathrm{CN}$ values for the Sr-O interactions in the three SrMST samples (Table 4-4). Although we obtained $\mathrm{CN}$ values from our third shell fits, they are in general, not as reliable as first shell and second shell $\mathrm{CN}$ values. This is because information obtained at higher radial distances from the absorbing atom is more subject to noise and the signal is weak-particularly for a light atom such as $\mathrm{O}$. The $\mathrm{CN}$ values are related to the amplitude of the EXAFS oscillations. In contrast, the atomic distances in EXAFS spectra are related to the frequency of the oscillations, which is less subject to noise and atom weight than that of $\mathrm{CN}$ values. Another factor that could introduce some error in our $\mathrm{CN}$ value determinations is that we did not account for multiple scattering paths. Accounting for multiple scattering paths (in addition to single scattering paths) is not straightforward when the structural arrangement of the atoms is not known. We did not know the structure of local environment of these atoms so multiple scattering paths were not included. Hence, third shell fit data for sorbed $\mathrm{Sr}^{2+}$ species are typically, absent in the literature.

\subsection{Modeling of $\mathrm{Sr}^{2+}$ Sorption on MST}

Based on model fits of the EXAFS data, molecular models were generated using the program Chem3D. ${ }^{27}$ The modeling assums the Ti are octrahedrally coordinate to $\mathrm{O}$ as would be consistent for an amorphous form of $\mathrm{Sr}^{2+}$ nonatitanate. ${ }^{28}$ Arrangement of a $\mathrm{Sr}^{2+}$ atom bound to a single $\mathrm{TiO}_{6}$ octahedron is shown in Figure 4-21 and an arrangement of a $\mathrm{Sr}^{2+}$ bound to a four $\mathrm{TiO}_{6}$ octahedron is shown in Figure 4-23. Although the structure of MST is not known, these models suggest that $\mathrm{Sr}^{2+}$ is associated with the MST via a specific adsorption mechanism because the distance between the $\mathrm{Sr}^{2+}$ and the $\mathrm{Ti}$ is short enough and the models support this conclusion. Some structural incorporation cannot be excluded but the low amount of $\mathrm{Ti}$ (two atoms on average) in the second coordination shell of the $\mathrm{Sr}^{2+}$ suggests that specific adsorption to the MST surface is the dominant mechanism of metal uptake of $\mathrm{Sr}^{2+}$.

Page 29 of 43 
Table 4-4 Fit results for a second and third shell Sr interactions with and without the third cumulant (C3) term for the $\mathrm{Sr}^{2+}$ sorbed MST samples. Use of the third cumulant term in the fits for $\mathrm{Sr}$ in the dilute $\mathrm{SrCl}_{2(\mathrm{aq})}$ solution yielded no differences (in $\mathrm{CN}$ or $\mathrm{R}$ ). The third cumulant term was not included in fits for second and third shell interactions due to a limited number of degree of freedom, which did not allow addition of another floating variable. Fits for SrMST2 were not performed due to insufficient data quality.

\begin{tabular}{|c|c|c|c|c|c|}
\hline Sample & Shell & Interaction & CN & $\mathbf{R}(\AA)$ & $\sigma^{2}[\AA]^{2}$ \\
\hline \multirow[t]{12}{*}{ SrMST1 } & \multirow[t]{4}{*}{ Second } & Sr-O & 6.22 & 3.87 & 0.02 \\
\hline & & $\mathrm{Sr}-\mathrm{O}$ with $\mathrm{C} 3$ & 5.70 & 4.02 & 0.01 \\
\hline & & $\mathrm{Sr}-\mathrm{Ti}$ & 3.64 & 3.52 & 0.025 \\
\hline & & Sr-Ti with C3 & 2.77 & 3.59 & 0.02 \\
\hline & \multirow[t]{3}{*}{ Third } & $\mathrm{Sr}-\mathrm{O}$ & 1.20 & 3.98 & 0.0029 \\
\hline & & Sr-O with C3 & 1.29 & 4.03 & 0.0029 \\
\hline & & $\mathrm{Sr}-\mathrm{Ti}$ or $\mathrm{Sr}-\mathrm{Sr}$ & ND & fit did not converge & ND \\
\hline & \multirow{5}{*}{$\begin{array}{c}\text { Second } \\
\text { and Third }\end{array}$} & Sr-Ti & 0.70 & 3.46 & 0.008 \\
\hline & & $\mathrm{Sr}-\mathrm{O}$ & 2.15 & 3.92 & 0.006 \\
\hline & & $\mathrm{Sr}_{\mathrm{T}} \mathrm{Ti}_{1}$ & 1.10 & 3.42 & 0.002 \\
\hline & & $\mathrm{Sr}-\mathrm{Ti}_{2}$ & 0.65 & 3.51 & 0.001 \\
\hline & & $\mathrm{Sr}-\mathrm{O}_{1}$ & 2.20 & 3.91 & 0.005 \\
\hline \multirow[t]{3}{*}{ SrMST2 } & \multirow{3}{*}{$\begin{array}{c}\text { Second } \\
\text { and Third }\end{array}$} & $\mathrm{Sr}^{-\mathrm{Ti}_{1}}$ & No Fits & No Fits & No Fits \\
\hline & & $\mathrm{Sr}^{-\mathrm{Ti}_{2}}$ & No Fits & No Fits & No Fits \\
\hline & & $\mathrm{Sr}-\mathrm{O}_{1}$ & No Fits & No Fits & No Fits \\
\hline \multirow[t]{3}{*}{ SrMST3 } & \multirow{3}{*}{$\begin{array}{c}\text { Second } \\
\text { and Third }\end{array}$} & Sr-Ti $i_{1}$ & 2.40 & 3.43 & 0.0014 \\
\hline & & $\mathrm{Sr}-\mathrm{Ti}_{2}$ & 2.80 & 3.52 & 0.0003 \\
\hline & & $\mathrm{Sr}-\mathrm{O}_{1}$ & 7.05 & 3.90 & 0.0079 \\
\hline \multirow[t]{3}{*}{ SrMST4 } & \multirow{3}{*}{$\begin{array}{c}\text { Second } \\
\text { and Third }\end{array}$} & Sr-Ti $i_{1}$ & 1.39 & 3.53 & 0.0015 \\
\hline & & $\mathrm{Sr}-\mathrm{Ti}_{2}$ & 1.15 & 3.63 & 0.0003 \\
\hline & & $\mathrm{Sr}-\mathrm{O}_{1}$ & 1.75 & 4.01 & 0.0048 \\
\hline
\end{tabular}

\subsection{Comparison of First Shell Coordination Data with Literature Findings}

Our findings for the first shell interactions of $\mathrm{Sr}^{2+}$ and $\mathrm{O}$ are most similar to that of $\mathrm{Sr}^{2+}$ in heulandite, and of $\mathrm{Sr}^{2+}$-sorbed on kaolinite, silica and $\mathrm{FeOOH}$ (goethite). ${ }^{18,19,23}$ O'Day et al. (2000) did not use the C3 term in their fits for $\mathrm{Sr}^{2+}$ in the zeolite (P. O'Day, Univ. of Arizona, personal communication, 2001). Sahai et al (2000) and Parkman et al. (1998) did not use the C3 term in their fits. ${ }^{18,19}$ However, our data without the C3 term are similar (compare Table 4-1 and Table 4-3). The Sr-EXAFS data for heulandite have a Sr-O interaction with a $\mathrm{CN}$ value of 8 and a $\mathrm{Sr}-\mathrm{O}$ distance of $2.60 \AA$, which compares well with our data analyses that did not used the $\mathrm{C} 3$ term (Tables 4-1 and 4-3). ${ }^{18}$ Collins et al. (1998) did not use the $\mathrm{C} 3$ term in their fits however, their work with $\mathrm{Sr}^{2+}$-sorbed $\mathrm{FeOOH}$ in $\mathrm{pH} 10.2$ solutions show 8 first shell $\mathrm{O}$ atoms at $2.6 \AA$ and these results compare well with ours. ${ }^{23}$ Our Sr-EXAFS data do not compare as well with the other first shell data in the literature for sorbed $\mathrm{Sr}^{2+}$ species listed in Table 4-1. 


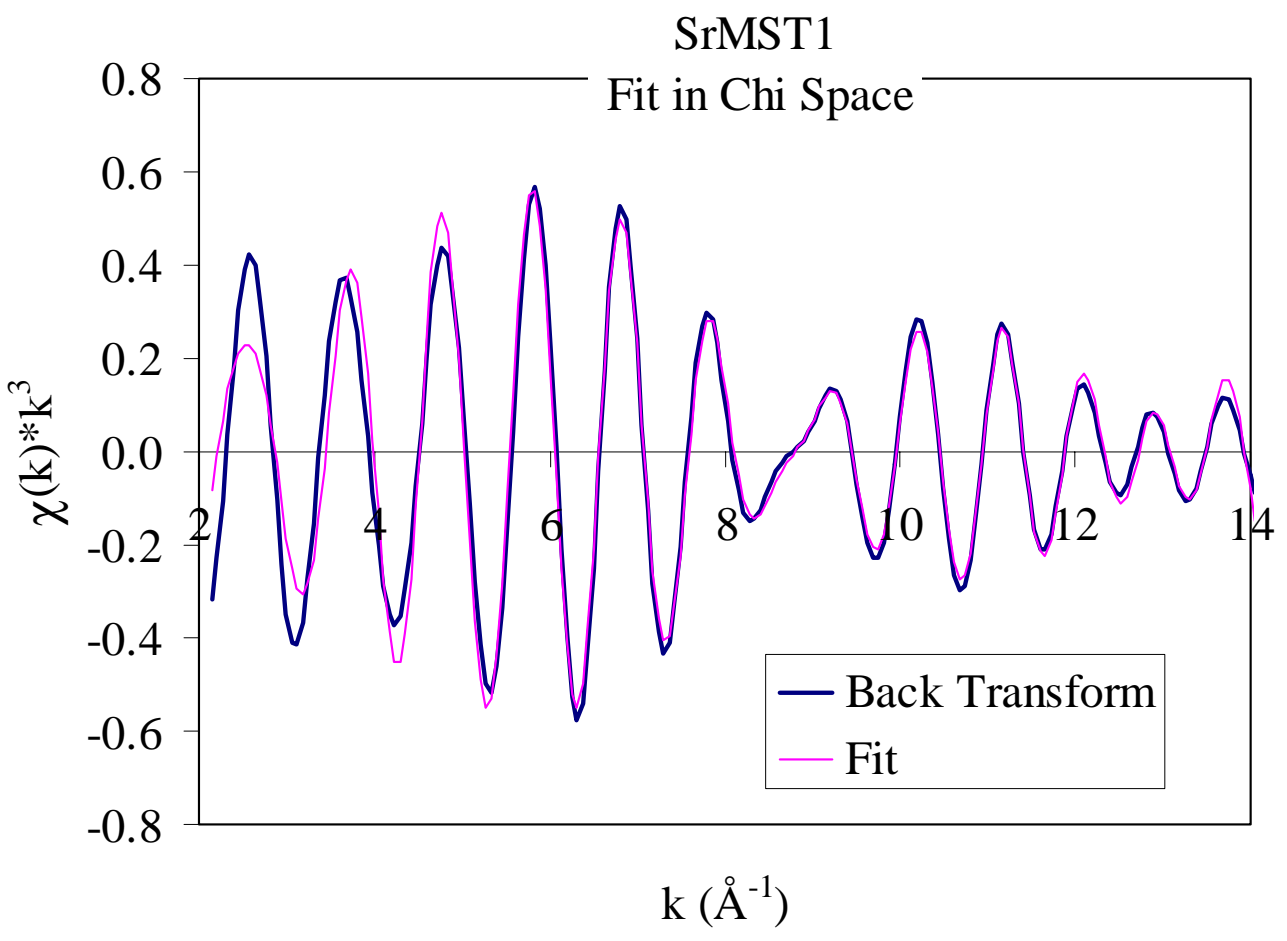

Figure 4-16 Back-transformed chi data and model second and third shell fit data for interactions of $\mathrm{Sr}_{-}-\mathrm{Ti}_{1}, \mathrm{Sr}-\mathrm{O}_{1}$ and $\mathrm{Sr}_{-} \mathrm{Ti}_{2}$ for $\mathrm{Sr}^{2+}$-loaded $\mathrm{SrMST} 1$.

SrMST3

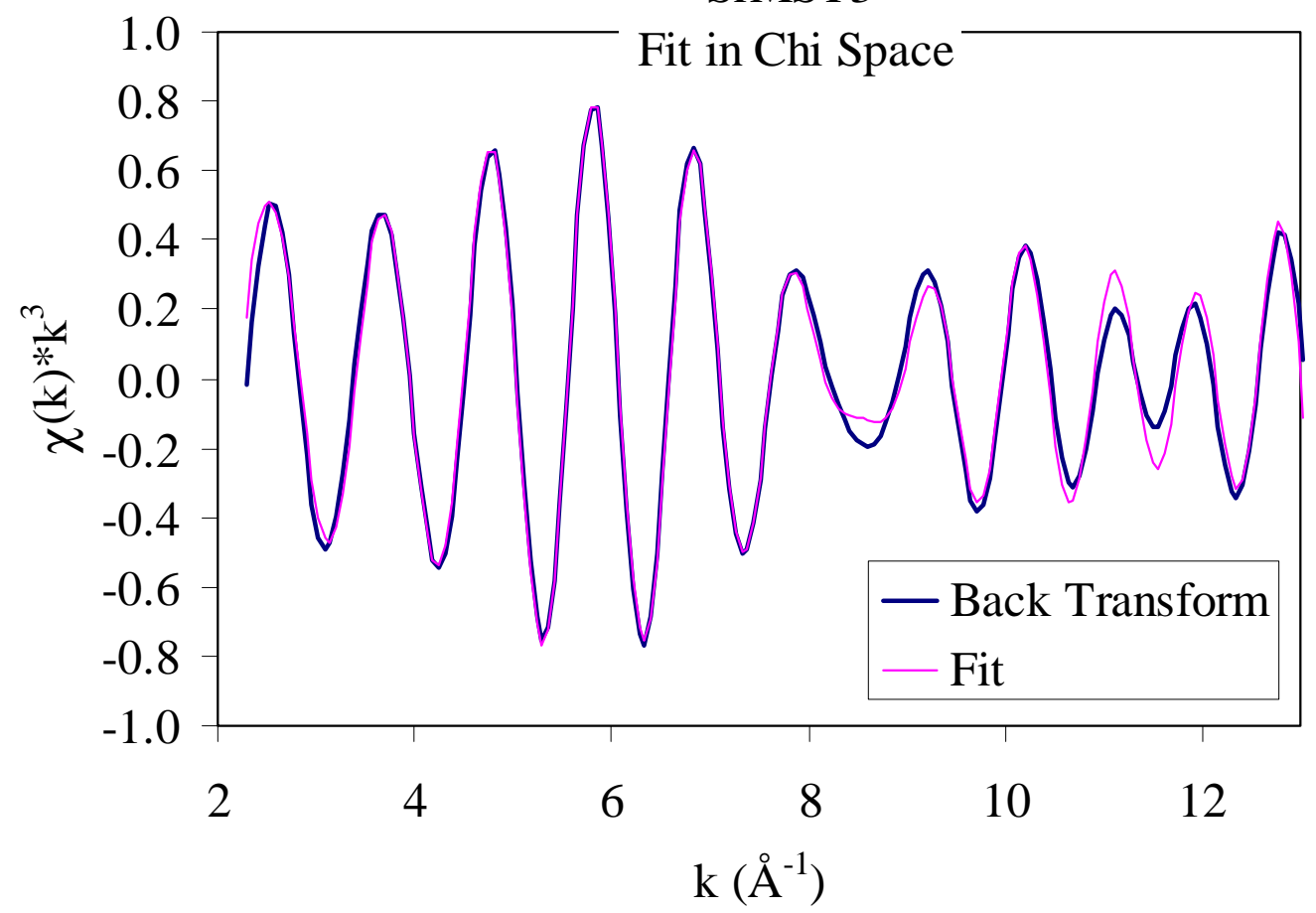

Figure 4-17 Back-transformed chi data and model second and third shell fit data for interactions of $\mathrm{Sr}-\mathrm{Ti}_{1}, \mathrm{Sr}-\mathrm{O}_{1}$ and $\mathrm{Sr}-\mathrm{Ti}_{2}$ for $\mathrm{Sr}^{2+}$-loaded $\mathrm{SrMST} 3$. 


\section{SrMST4}

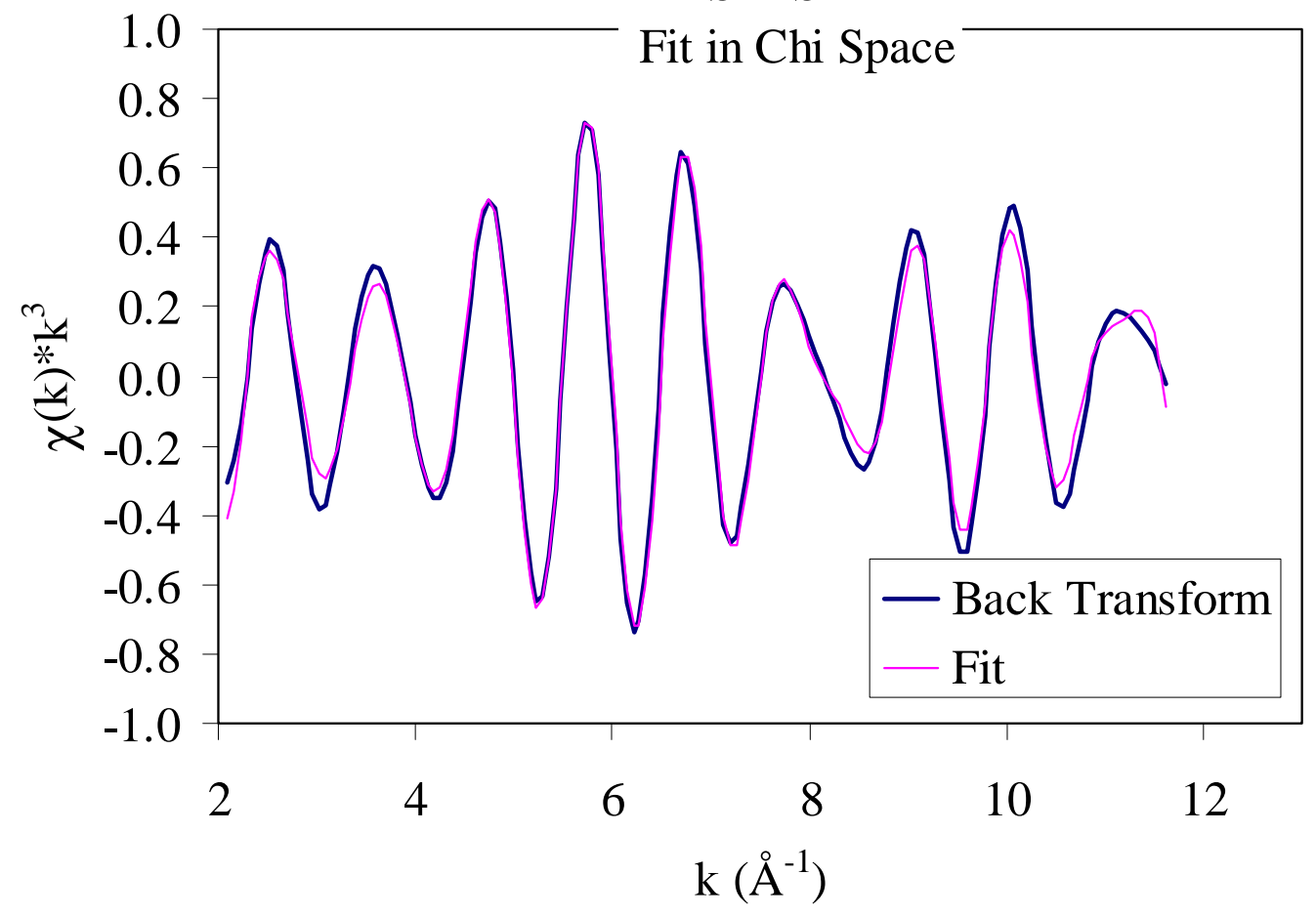

Figure 4-18 Back-transformed chi data and model second and third shell fit data for interactions of $\mathrm{Sr}-\mathrm{Ti}_{1}, \mathrm{Sr}_{-} \mathrm{O}_{1}$ and $\mathrm{Sr}-\mathrm{Ti}_{2}$ for $\mathrm{Sr}^{2+}$-loaded SrMST4.

\subsection{Comparison of Second and Third Shell Coordi nation Data with Literature Findings}

Our findings for the second shell interactions of $\mathrm{Sr}^{2+}$ and $\mathrm{Ti}$ are most similar to that of $\mathrm{Sr}^{2+}$ in heulandite, which had two second shell $\mathrm{Si} / \mathrm{Al}$ radial distances with $\mathrm{CN}$ values of 2 at 3.49 and $4.14 \AA^{.18}$ No other Sr-EXAFS studies have reported the existence two second shell atoms at two different distances around the $\mathrm{Sr}^{2+}$ (Table 4-1). However, such fits require high quality data acquisition, which is difficult when light atom back scatterers are present in the spectra. 


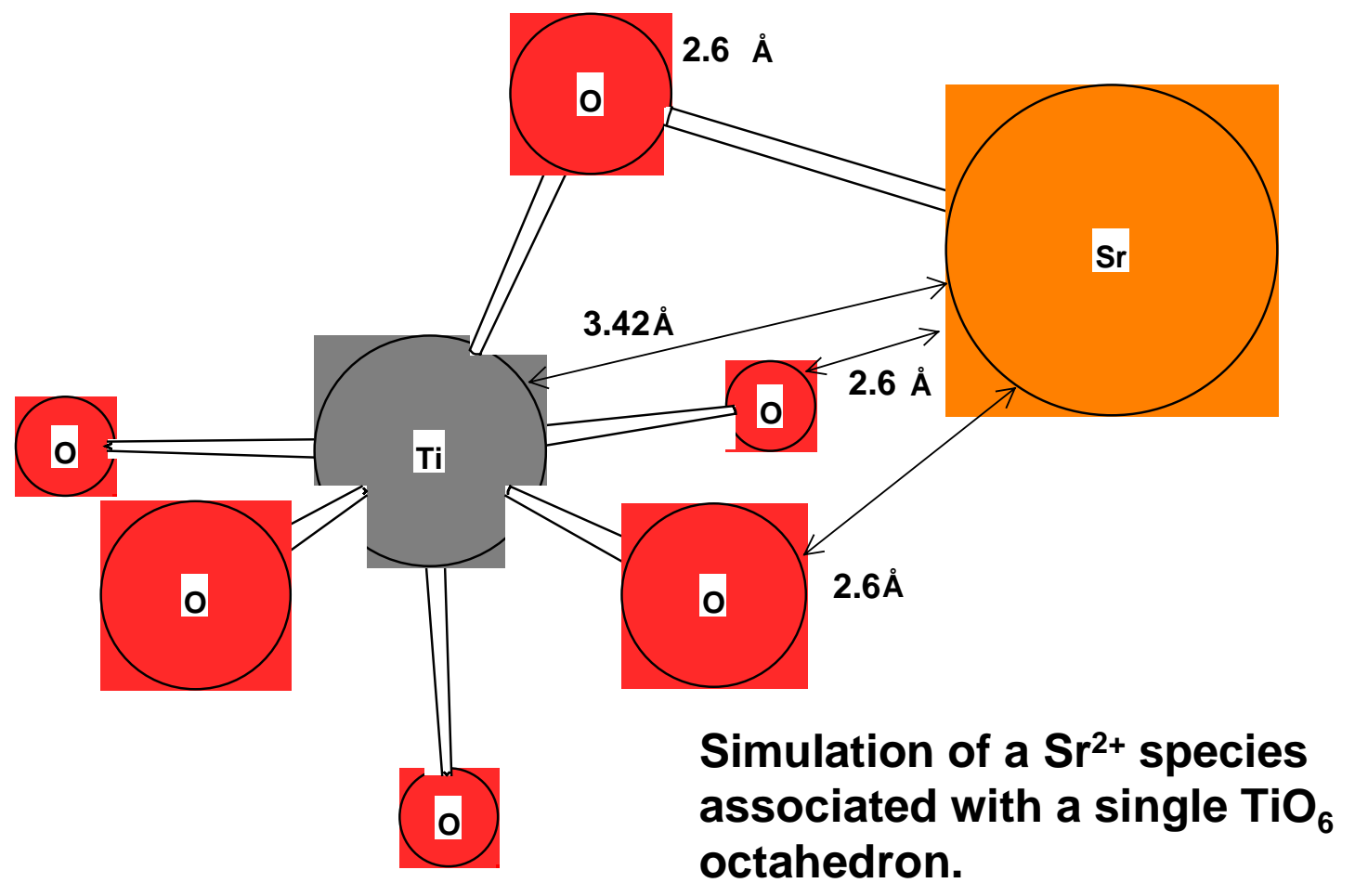

Figure 4-19 EXAFS-based molecular model of association of $\mathrm{Sr}^{2+}$ with $\mathrm{TiO}_{6}$ groups.

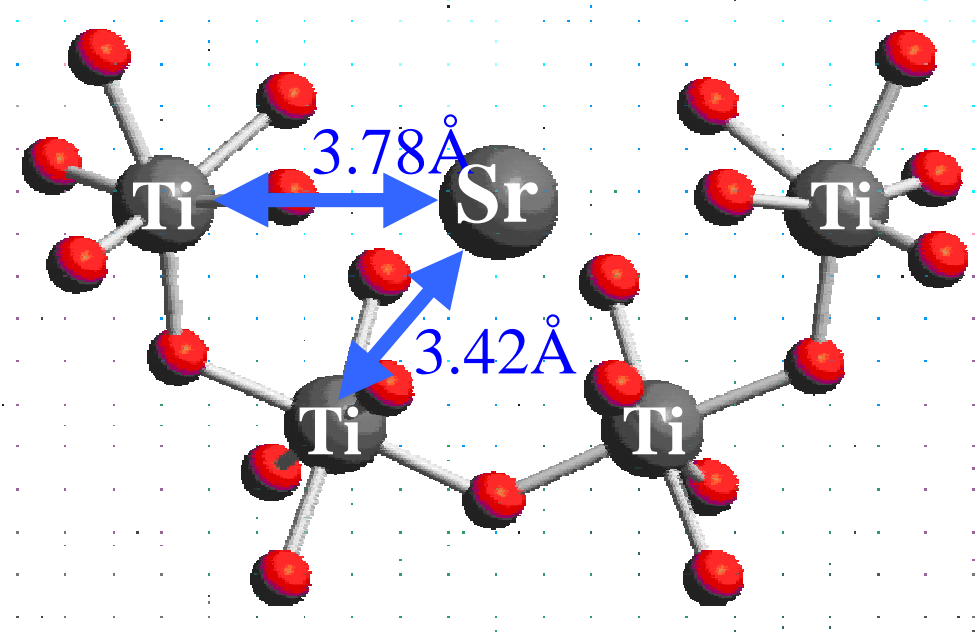

Figure 4-20 EXAFS-based molecular model of association of $\mathrm{Sr}^{2+}$ with corner-shared $\mathrm{TiO}_{6}$ groups. 
WSRC-TR-2001-00245, REVISION 0

\subsection{DISCUSSION AND CONCLUSIONS}

\subsection{Determination of the Uptake Mechanism.}

Strontium sorption studies were conducted using MST and XAFS data collection was conducted on these materials and reference solid and aqueous materials. The literature on $\mathrm{Sr}^{2+}$ sorption was reviewed and compared with the results of our studies. Data analyses were performed on the Sr-XAFS data for the MST samples and on one of the $\mathrm{Sr}^{2+}$ references. The XANES and EXAFS data indicate that (on average) the environments of the $\mathrm{Sr}^{2+}$ in the MST samples were similar and that they resembled that of solution $\mathrm{Sr}^{2+}$. First and second shell fits of the Sr-EXAFS data indicate that $\mathrm{O}$ is in the first and third coordination shell and more than one $\mathrm{Ti}$ (on average) is in the second shell. The EXAFS data and the molecular modeling suggest the $\mathrm{Sr}^{2+}$ is closely associated with MST.

We compared our findings with Sr-XAFS studies in the literature that examined the $\mathrm{Sr}^{2+}$ sorption on a variety of materials. We found some similarities with the findings from the literature. However, most of these studies were conducted under environmentally relevant conditions (such as the groundwater environments under leaky HLW tanks at Hanford, WA or potentially contaminated environments at proposed nuclear waste geologic repositories). These conditions are not equivalent to that of highly alkaline HLW salt solutions. Because little is known about the local environment of sorbed $\mathrm{Sr}^{2+}$ species in HLW salt solutions, the literature provides a useful foundation on $\mathrm{Sr}^{2+}$ sorption behavior to metal oxides and methods of Sr-XAFS data analyses.

We conclude that the nature of the $\mathrm{Sr}^{2+}$ sorption does not involve ion exchange of fully hydrated $\mathrm{Sr}^{2+}$ species because there was a pronounced loss in waters of hydration upon sorption-regardless of whether the $\mathrm{C} 3$ term was used in the fits or not. Removal of $\mathrm{Sr}^{2+}$ is via specific adsorption of a partially hydrated $\mathrm{Sr}^{2+}$ species, which signifies that the removal mechanism is not surface precipitation-even at high Sr-loadings. The primary uptake mechanism of the $\mathrm{Sr}^{2+}$ is not structural incorporation. If the $\mathrm{Sr}^{2+}$ were present within the MST structure, it would have multiple second shell Ti atoms. For example, this is the case for $\mathrm{Sr}^{2+}$ in $\mathrm{SrTiO}_{3}$ solid shown in Table 4-1, which has $6 \mathrm{Ti}$ atoms in the second shell environment. The fact that only one $\mathrm{Ti}$ atom is present in the first shell suggests that structural incorporation is not likely and that the $\mathrm{Sr}^{2+}$ is bound via specific adsorption to the MST surface.

\subsection{Influence of Sorption Mechanism on Process}

Specific adsorption implies some good process attributes. If irreversible, this mechanism has the benefit that the $\mathrm{Sr}^{2+}$ will remain bound at higher temperatures and will not leach into solution and potentially transfer with the supernatant to the undesired process stream. If removal of solution $\mathrm{Sr}^{2+}$ occurred via surface precipitation on MST, washing of the $\mathrm{Sr}^{2+}$-loaded MST would dissolve the $\mathrm{Sr}^{2+}$ solid phases that formed and complicate the decontamination process by partitioning the $\mathrm{Sr}^{2+}$ into a wash process stream. Similarly, we do not observe $\mathrm{Sr}^{2+}$ uptake via an outer-sphere (ion exchange), which means that the washing of the MST post decontamination would not effect the ability of the MST to retain the $\mathrm{Sr}^{2+}$. 
WSRC-TR-2001-00245, REVISION 0

\subsection{The Structure of MST is Unknown}

The structure of MST is not known. High-resolution TEM and Ti-XAFS studies are likely to provide structural information that conventional X-ray diffraction techniques cannot (the MST is does not have long range order and is amorphous). It has been suggested by A. Clearfield (Texas A and M University, College Station, TX, 2001) that MST may exist as long sheet-like layers of edge-linked Ti octahedra such as in the simplified diagram below:

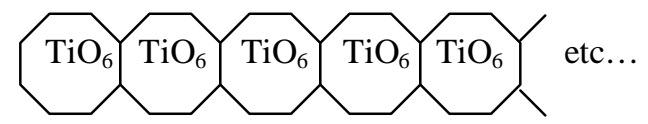

If the structure of MST contained sheets of Ti octahedra, the Sr-EXAFS information that would be obtained for the local environment of structural $\mathrm{Sr}^{2+}$ would be nearly equivalent to that of Sr-EXAFS information obtained for specifically adsorbed $\mathrm{Sr}^{2+}$. The uptake mechanism would involve direct bonds and no outer sphere sorption or surface precipitation.

\subsection{Suggestions for Further Study}

Our findings are consistent with that of specific or inner sphere adsorption and they involve a partially hydrated $\mathrm{Sr}^{2+}$ species that binds to the MST surface. Even though specific adsorption is operative, some items in need further study. The effect of temperature on the environment of (partially-hydrated) $\mathrm{Sr}^{2+}$ species on surfaces has been investigated. ${ }^{29} \mathrm{In}$ kinetic studies, Hobbs and co-researchers observe decreased uptake of $\mathrm{Sr}^{2+}$ (at equilibrium) at $45{ }^{\circ} \mathrm{C}$ (relative to studies at $25{ }^{\circ} \mathrm{C}$ ). ${ }^{29}$ However, these studies were conducted with solutions of $\mathrm{Sr}^{2+}$ and multiple actinides. Competitive effects among the dissolved species may have been operative. At higher temperatures $\left(65^{\circ} \mathrm{C}\right)$ the effect of temperature on $\mathrm{Sr}^{2+}$ sorption is not clearly evident from the data. An increase in temperature could cause the release of waters of hydration from the sorbed $\mathrm{Sr}^{2+}$ species and possibly change the mechanism or amount of $\mathrm{Sr}^{2+}$ uptake. ${ }^{29}$

Another condition that could influence the sorption of dissolved species is that of competition and competition for surface sites by the $\mathrm{Sr}^{2+}$ and the actinides on the MST may be a function of temperature. Studies should be conducted to examine whether there is competition between $\mathrm{Sr}^{2+}$ with $\mathrm{Na}^{+}$for sorption sites on the MST. Work has shown that decreased $\mathrm{Sr}^{2+}$ sorption is observed at higher $\mathrm{Na}^{+}$solution concentrations $(4.5 \mathrm{M}$ versus 7.5 $\left.\mathrm{M} \mathrm{Na}^{+}\right){ }^{30}$ Competitive sorption studies could also be done with $\mathrm{Sr}^{2+}$ and actinides. There could be more than one type of binding site for $\mathrm{Sr}^{2+}$ on the MST. Our Sr-XAFS data gives average information and we must be aware that multiple binding sites could exist on the MST. The availability of strong binding sites may decrease as they are removed from the general pool upon $\mathrm{Sr}^{2+}$ adsorption. This may leave weaker binding sites for other species such as the actinides.

The authors also propose a series of studies with $\mathrm{Sr}^{2+}$ and two other materials: SrTreat and sodium nonatitanate $\left(\mathrm{Na}_{4} \mathrm{Ti}_{9} \mathrm{O}_{24}\right)$ for the later portion of FY-01. Such a study will Page 35 of 43 
provide fundamental insights on how sorption efficiency varies with structural features of the titanates thus guiding changes in synthesis methods to improve process performance.

On going work in this project concerns the XAFS data analyses of the U(VI) studies, and planned XAFS analyses for a suite of $\mathrm{Np}$ and Pu loaded MST samples. A report will be put forth on each of the actinides.

\subsection{ACKNOWLEDGMENTS}

The authors thank J. Woicik (NIST), A. Ackerman (BNL), W. Rao (University of Georgia), W. Tamosaitis (SRTC) and J.U. Coughlin (WSRC), for their assistance, support and bright ideas. N. Gregory, M. Bloom, and H. L. Thacker (all of SRTC) are acknowledged for their assistance in the preparation of the MST samples. 


\subsection{APPENDIX}

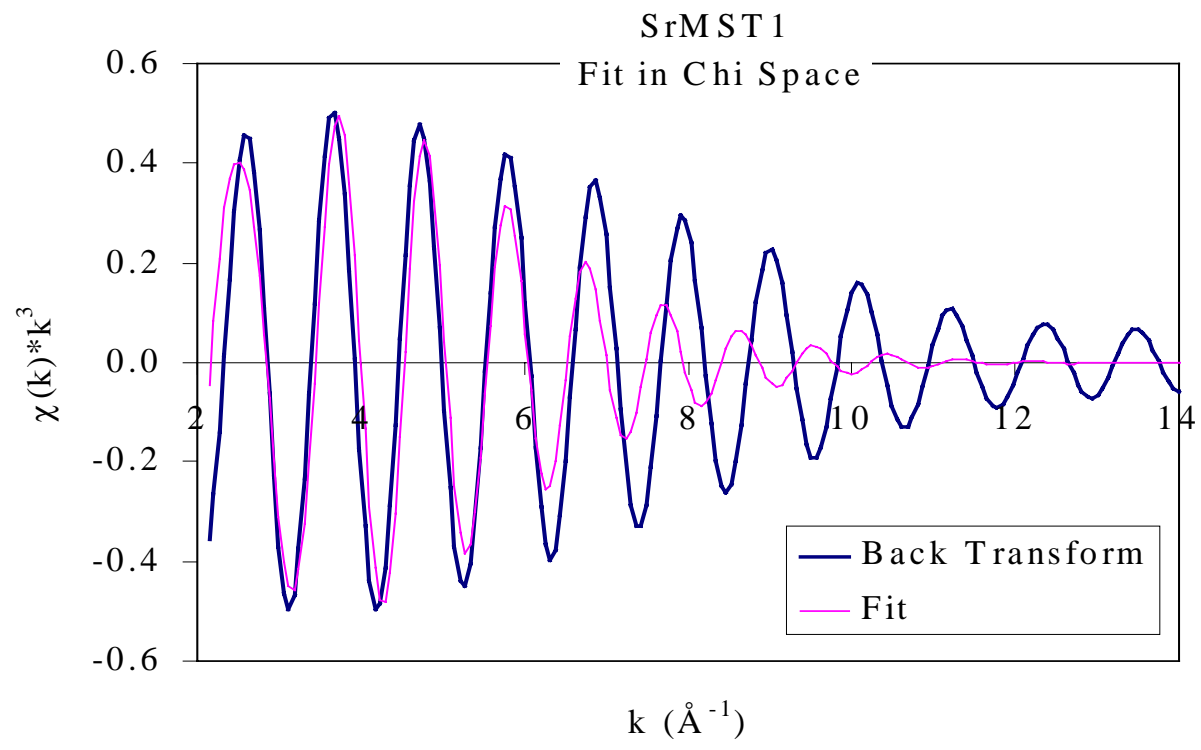

Figure 7-1 Back-transformed chi data and model fit second shell data for interactions of Sr$\mathrm{O}$ without the C3 term for $\mathrm{Sr}^{2+}$-loaded SrMST1.

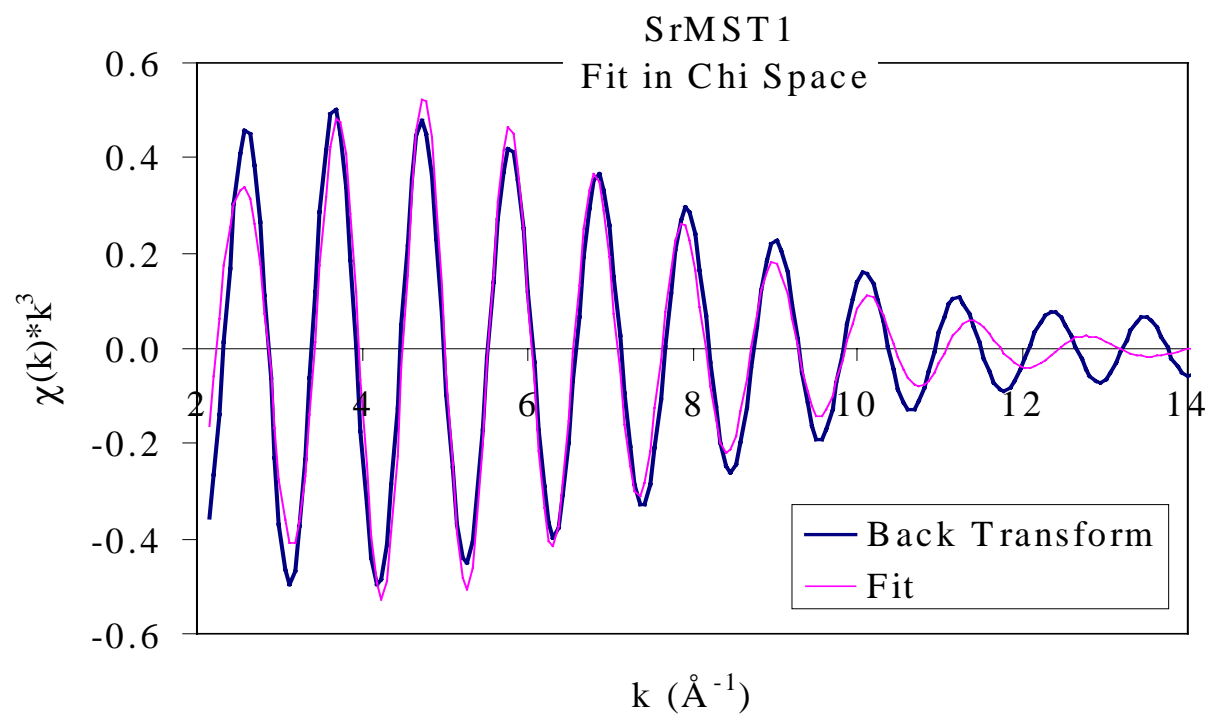

Figure 7-2 Back-transformed chi data and model fit second shell data for interactions of $\mathrm{Sr}$ $\mathrm{O}$ with the $\mathrm{C} 3$ term for $\mathrm{Sr}^{2+}$-loaded SrMST1. 


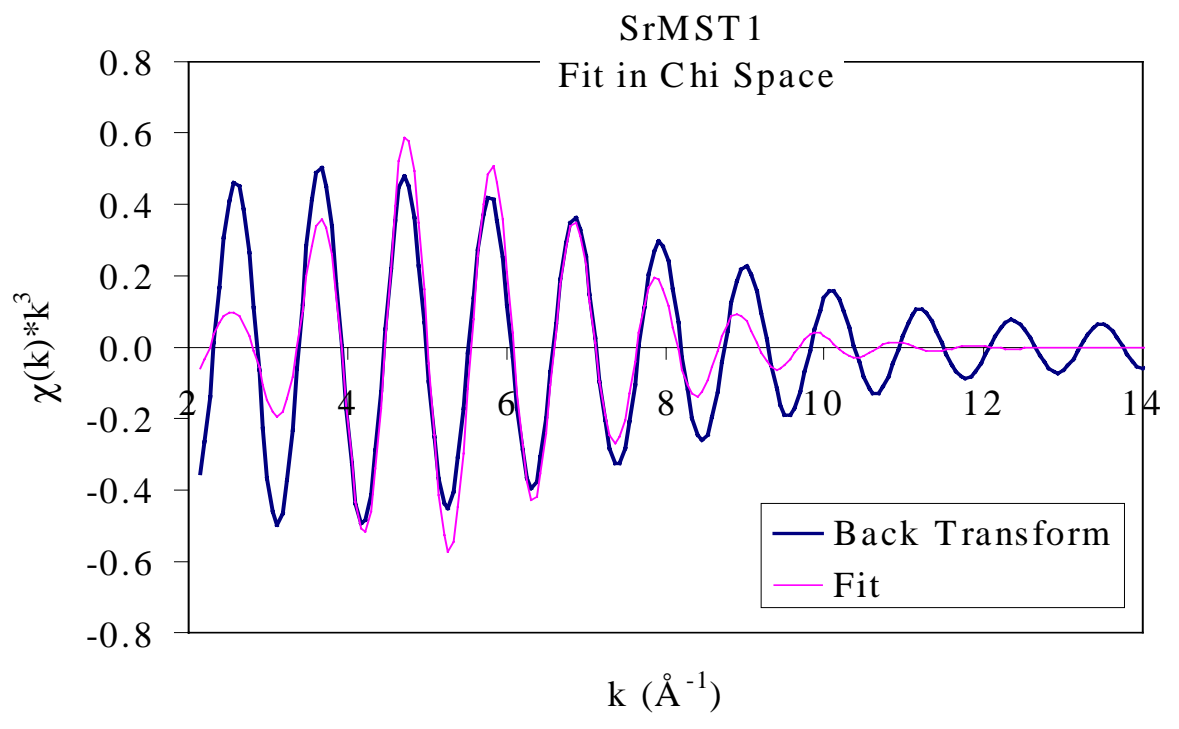

Figure 7-3 Back-transformed chi data chi data and model fit data for second shell interaction of Sr-Ti without the C3 term for $\mathrm{Sr}^{2+}$-loaded SrMST1.

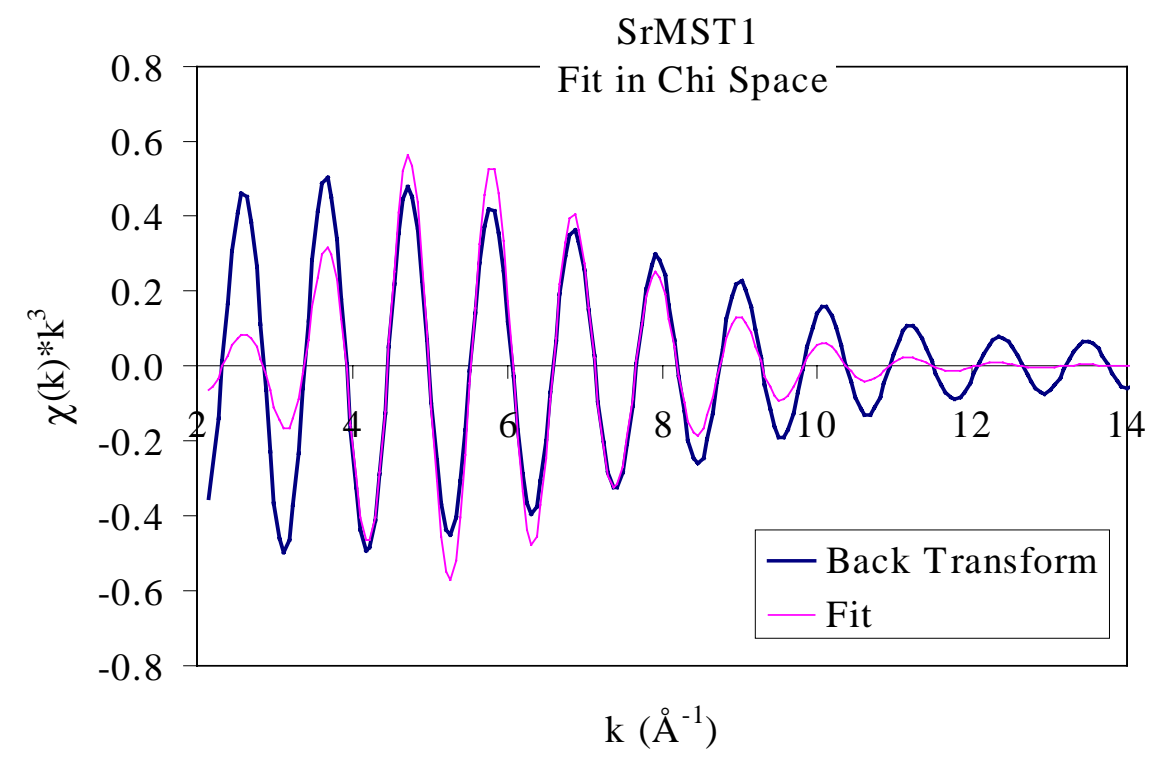

Figure 7-4 Back-transformed chi data and model fit data for second shell interactions of SrTi with the C3 term for $\mathrm{Sr}^{2+}$-loaded SrMST1. 


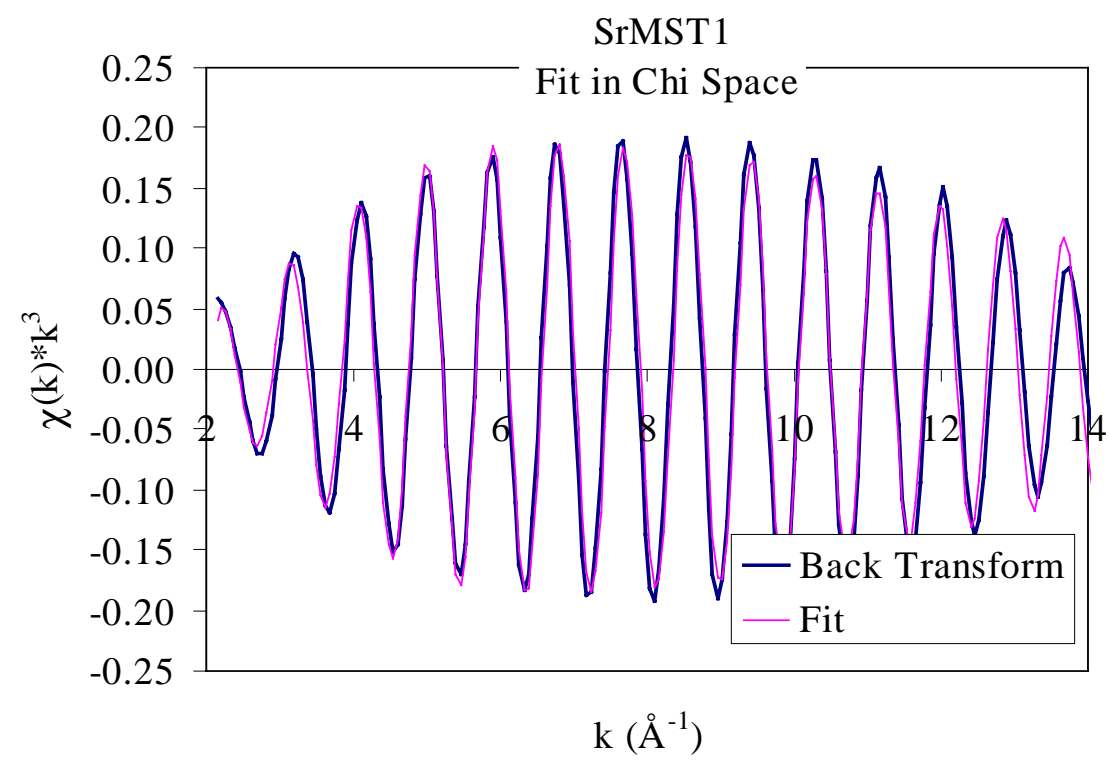

Figure 7-5 Back-transformed chi data and model fit data for third shell Sr-O interactions without the C3 term for $\mathrm{Sr}^{2+}$-loaded SrMST1.

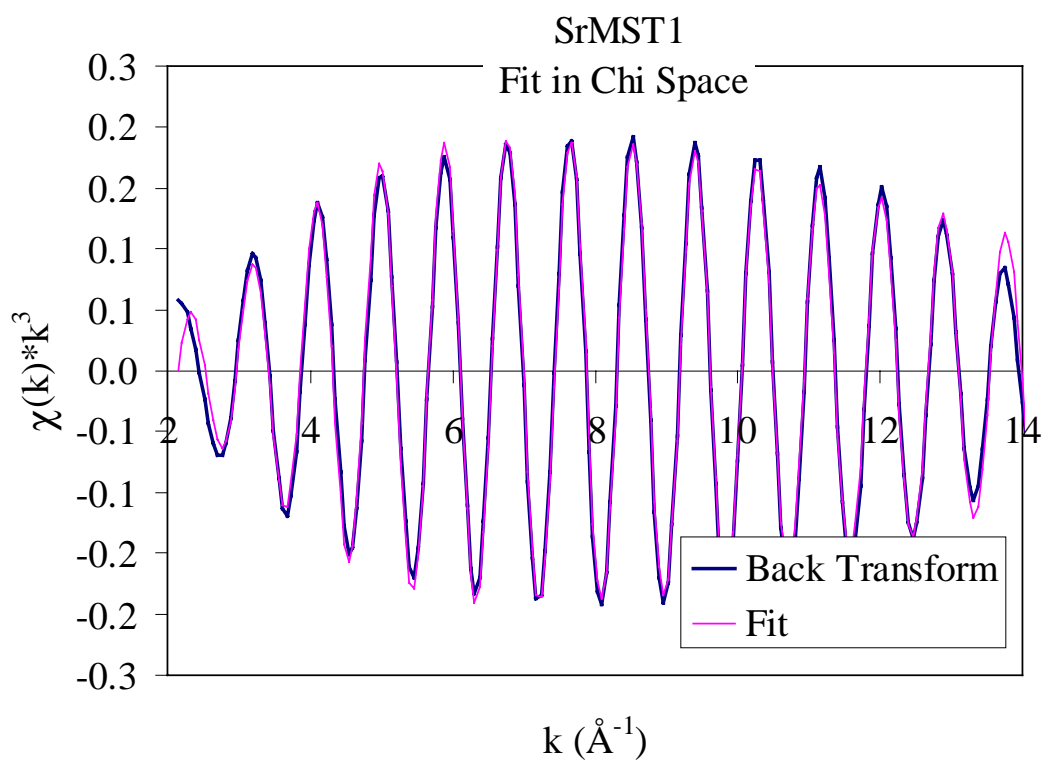

Figure 7-6 Back-transformed chi data and model fit data for third shell $\mathrm{Sr}-\mathrm{O}$ interactions with the $\mathrm{C} 3$ term for $\mathrm{Sr}^{2+}$-loaded SrMST1. 
WSRC-TR-2001-00245, REVISION 0

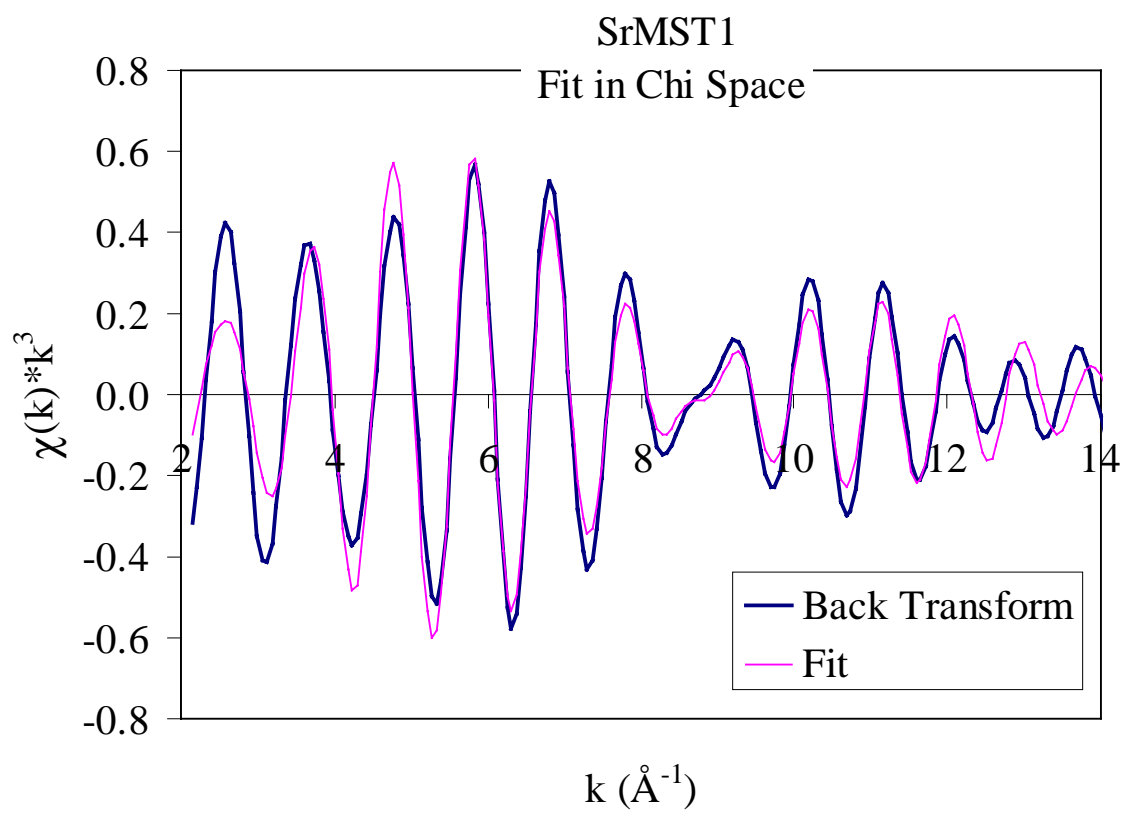

Figure 7-7 Back-transformed chi data and model fit data for interactions of second shell Sr$\mathrm{Ti}$ and third shell Sr-O interactions for $\mathrm{Sr}^{2+}$-loaded SrMST1-without the C3 term. 
WSRC-TR-2001-00245, REVISION 0

\title{
8.0 REFERENCES
}

\begin{abstract}
${ }^{1}$ Stumm, W. 1992. Chemistry of the Solid-Water Interface: Processes at the Mineral-Water and Particle-Water Interface in Natural Systems. Wiley-Interscience, NY.

${ }^{2}$ McBride, M.B. 1994. Environmental Chemistry of Soils. Oxford Press, NY.

${ }^{3}$ Sorption reversibility of sorption is tested by leaching the metal loaded solid with a target metal-free solution that has the same properties (i.e. ionic strength, background electrolytes, $\mathrm{pH}$ etc...) and measuring the leachate solution to determine whether any target metal is released. Specificallyadsorbed species are typically not leached with lower ionic strength solutions and specific adsorption processes are not a function ionic strength (assuming the electrolytes do not interact with the sorbed species via complexation etc.). Outer-sphere species can be readily removed with solutions of low ionic strength or solutions that contain high concentrations of a cation that has a higher affinity for the surface than the outer-sphere species. Therefore, outer-sphere sorption is viewed as reversible and a function of ionic strength whereas specific adsorption is not.
\end{abstract}

${ }^{4}$ Specific adsorption is typically a function of surface charge properties. When a participating surface has a charge that varies with solution $\mathrm{pH}$, specific adsorption exhibits $\mathrm{pH}$-dependent behavior. For example, a surface that is highly protonated (at low $\mathrm{pH}$ ) will have more affinity for negativelycharged species (such as than negatively-charged species. As the $\mathrm{pH}$ decreases, the surface charge of $\mathrm{pH}$-dependent charged surfaces becomes more negative and the uptake of positively-charged species is favored. Therefore, surface of metal oxides (for example) specifically adsorb more positivelycharged species as the solution $\mathrm{pH}$ increases. However, this behavior is generalized. As the solution $\mathrm{pH}$ increases sorbing species undergoes a change in speciation-such as hydrolysis. In this case, the amount of specific adsorption becomes a function of solution speciation. Ion exchange resins that sorb free ions of actinides (e.g., the non-hydrolyzed $\mathrm{Pu}^{4+}$ species) at high $\mathrm{H}^{+}$concentrations (i.e., low $\mathrm{pH}$ ) will release sorbed $\mathrm{Pu}^{4+}$ species when the solution $\mathrm{pH}$ is raised-due to the hydrolysis of the sorbed $\mathrm{Pu}^{4+}$ (e.g., $\left.\mathrm{Pu}(\mathrm{OH})_{3}{ }^{+}, \mathrm{Pu}(\mathrm{OH})_{2}{ }^{2+}\right)$. The hydrolysis species have a lower overall charge and their size (as an ion group) is larger than the free ion-making them have a lower affinity for the surface. Other processes that can influence sorption are metal complexation with ligands (i.e., with carbonate ion) or in the case of anions, protonation (e.g., $\mathrm{PO}_{4}{ }^{3-}+\mathrm{H}^{+} \rightarrow \mathrm{HPO}_{4}{ }^{2-}$ ). Specific adsorption processes are a function of many variables.

${ }^{5}$ Koningsberger, D. C. and Prins, R. 1988. X-ray Absorption: Techniques of EXAFS, SEXAFS and $X A N E S$, Wiley, New York.

${ }^{6}$ Stern, E. A. 1974. Theory of extended X-ray absorption fine structure. Phys. Rev. B10, 3027-3037.

${ }^{7}$ Ressler, T. (1999). WinXAS. A Program for X-ray Absorption Spectroscopy Data Analysis under MS Windows.

${ }^{8}$ Newville, M., Livins, P., Yacoby, Y., Rehr, J. J. and Stern, E. A. (1993). Near-edge X-rayabsorption fine-structure of $\mathrm{Pb}-\mathrm{A}$ comparison of theory and experiment. Phys. Rev. B-Cond. Matter, 47, 14126-14131.

${ }^{9}$ Sayers, D. E. and Bunker, B. A. (1988). In X-ray Absorption: Techniques of EXAFS, SEXAFS and XANES. Koningsberger, D. C. and Prins, R. (eds). Wiley, New York, Chap. 6.

Page 41 of 43 
${ }^{10}$ FEFF is a software package that was generated by researchers at the Univ. of Washington with DOE funding support. Access and use of this software is free within the DOE complex.

${ }^{11}$ Mustre de Leon, J., Rehr, J. J., Zabinsky, S. I. and Albers, R. C. (1991). Ab initio curved-wave xray-absorption fine structure, Phys. Rev. B44, 4146.

${ }^{12}$ Rehr, J. J. and Albers, R. C. (1990). Scattering-matrix formulation of curved-wave multiplescattering theory: Application to x-ray-absorption fine structure. Phys. Rev. B41, 8139.

${ }^{13}$ Rehr, J. J., Mustre de Leon, J., Zabinsky, S. I. and Albers, R. C. (1991). Theoretical X-ray absorption fine structure standards. J. Am. Chem. Soc. 113, 5135.

${ }^{14}$ Rehr, J. J., Zabinsky, S. I. and Albers, R. C. (1992). High-order multiple scattering calculations of x-ray-absorption fine structure. Phys. Rev. Let. 69, 3397.

${ }^{15}$ Stern, E. A., Newville, M., Ravel, B., Yacoby, Y. and Haskel, D. (1995). The UWAFS analysis package - Philosophy and details. Physica B. 208-209, 117-120.

${ }^{16}$ Axe, L., Bunker, G. B., Anderson, P. R. and Tyson, T. A. (1998). An XAFS analysis of strontium at the hydrous ferric oxide surface. J. Coll. Interf. Sci. 199, 44-52.

${ }^{17}$ Axe, L., Tyson, T. A., Trivedi, P. and Morrison, T. (2000). Local structure analyses of strontium sorption to hydrous manganese oxide. J. Coll. Interf. Sci. 224, 408-416.

${ }^{18}$ O’Day, P. A., Newville, M., Nuehoff, P. S., Sahai, N. and Carroll, S. A. (2000). X-ray absorption spectroscopy of strontium(II) coordination. 1. Static and thermal disorder in crystalline, hydrated and precipitated solids and in aqueous solution. J. Coll. Interf. Sci. 222, 184-197.

${ }^{19}$ Sahai, N., Carroll, S. A., Roberts, S. and O’Day, P. A. (2000). X-ray absorption spectroscopy of strontium(II) coordination. 2. Sorption and precipitation at kaolinite, amorphous silica and goethite surfaces. J. Coll. Interf. Sci. 222, 198-212.

${ }^{20}$ Parkman, R. H., Charnock, J. M., Livens, F. R. and Vaughn, D. J. (1998). A study of the interaction of strontium ions in aqueous solution with the surfaces of calcite and kaolinite. Geochim. Cosmochim. Acta. 62, 1481-1492.

${ }^{21}$ In these studies, the data showing $\mathrm{Sr}$ and $\mathrm{Fe}$ (or Mn) in the second shell presents considerable confusion. Isolation of the second shell atom should provide information on whether Fe (or $\mathrm{Mn}$ ) or $\mathrm{Sr}$ are present-due to the substantial difference in atomic weight. These researchers claim that they were not able distinguish $\mathrm{Sr}$ from a much lighter atom (Fe or $\mathrm{Mn}$ ). Examination of the reported data indicates there may have been considerable noise, which would make distinguishing one atom from another heavier atom difficult. It is the author's opinion that this study should be redone.

${ }^{22}$ Pingatore, N. E., Jr., Lytle, F. W., Davies, B. M. Eastman, M. P., Eller, P. G. and Larson, E. M. (1992). Mode of incorporation of $\mathrm{Sr}^{2+}$ in calcite: Determination by X-ray absorption spectroscopy. Geochim. Cosmochim. Acta. 56, 1531-1538.

${ }^{23}$ Collins, C. R., Sherman, D. M. and Ragnarsdottir, K. V. (1998). The adsorption mechanism of $\mathrm{Sr}^{2+}$ on the surface of goethite. Radiochim. Acta 77, 201-206. 
${ }^{24}$ Pfund, D. M., Darab, J. G., Fulton, J. L., and Ma, Y. (1994). An XAFS study of strontium ions and krypton in supercritical water. 98, 13102-13107.

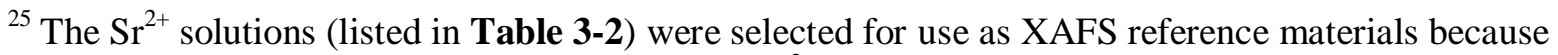
previous XAFS studies indicated that the sorbed $\mathrm{Sr}^{2+}$ species remain partially hydrated upon

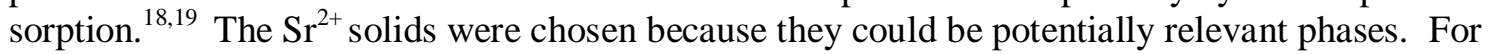
example, $\mathrm{Sr}\left(\mathrm{NO}_{3}\right)_{2(\mathrm{~s})}$ is a phase that could potentially form in $\mathrm{NO}_{3}$-rich HLW solutions and nucleate on the MST. The $\mathrm{Sr}^{2+}$ in $\mathrm{SrTiO}_{3(\mathrm{~s})}$ may have a similar environment to that of $\mathrm{Sr}^{2+}$-loaded MST solids.

${ }^{26}$ Teo, B. K. (1986). EXAFS: Basic Principles and Data Analysis. Inorganic Chemistry Concepts, Vol. 9, Springer-Verlag. Berlin.

${ }^{27}$ Cambridge Soft Corporation, 100 Cambridge Dr, Cambridge, MA.02140-2317.

${ }^{28}$ Behrens, E. A., Sylvester, P. and Clearfield, A. (1998). Assessment of a sodium nonatitanate and pharmacosiderite-type ion exchangers for strontium and cesium removal from doe waste simulants. Environ. Sci. Technol. 32, 101-107.

${ }^{29}$ Hobbs, D. T., Bronikowski, M. G., Edwards, T. B. and Pulmano, R. L. (1999). Final Report on Phase III Testing of Monosodium Titanate Adsorption. WSRC-TR-99-00134, May 28, 1999.

${ }^{30}$ Hobbs, D. T., Blume, M. S. and Thacker, H. L. (2000). Phase V Simulant Testing of Monosodium Titanate Asdorption Kinetics, Report WSRC-TR-2000-00142. 